

\section{Editorial Board}

\section{Editor in Chief}

Mark Zilberman, MSc, Shiny World Corporation, Toronto, Canada

\section{Scientific Editorial Board}

Viktor Andrushhenko, PhD, Professor, Academician of the Academy of Pedagogical Sciences of Ukraine, President of the Association of Rectors of pedagogical universities in Europe

John Hodge, MSc, retired, USA

Petr Makuhin, PhD, Associate Professor, Philosophy and Social Communications faculty of Omsk State Technical University, Russia

Miroslav Pardy, PhD, Associate Professor, Department of Physical Electronics, Masaryk University, Brno, Czech Republic

Lyudmila Pet'ko, Executive Editor, PhD, Associate Professor, National Pedagogical Dragomanov University, Kiev, Ukraine

\section{IntellectualArchive, Volume 9, Number 4}

\begin{tabular}{|c|c|}
\hline $\begin{array}{l}\text { Publisher } \\
\text { Address }\end{array}$ & $\begin{array}{l}\text { : Shiny World Corp. } \\
\text { : } 9200 \text { Dufferin Street } \\
\text { P.O. Box } 20097 \\
\text { Concord, Ontario } \\
\text { L4K 0C0 } \\
\text { Canada }\end{array}$ \\
\hline $\begin{array}{l}\text { E-mail } \\
\text { Web Site } \\
\text { Series } \\
\text { Frequency } \\
\text { Month } \\
\text { ISSN } \\
\text { DOI } \\
\text { Trademark }\end{array}$ & $\begin{array}{l}\text { : support@IntellectualArchive.com } \\
: \text { www.IntellectualArchive.com } \\
: \text { Journal } \\
: \text { Every } 3 \text { months } \\
: \text { October - December } 2020 \\
: 1929-4700 \\
: 10.32370 / I A \text { 2020_12 } \\
: \text { IntEllectualArchiveTM }\end{array}$ \\
\hline
\end{tabular}

(C) 2020 Shiny World Corp. All Rights Reserved. No reproduction allowed without permission. Copyright and moral rights of all articles belong to the individual authors. 


\section{Intellectual Archive}

Volume 9

Number 4

October/December 2020

\section{Table of Contents}

\section{Physics}
M. Pardy
M. Pardy
J.C. Hodge

K. Lysenko, V. Vereshchaga

\section{Shekhovtsov}

D. Shekhovtsov

D. Shekhovtsov
Photons Generated by Plasma Fluctuations

The Lorentz Transformations by Way of the Wave Equations

Scalar Theory of Everything (STOE) Unites the Big, the Small, and the Four Forces (GUT) by Extending Newton's Model

\section{Mathematics}

Properties of Composition Geometric Modelling

\section{Engineering}

Innovative Design of Equipment and Tools. Innovative Systems with Elements of Artificial Intelligence and Neural Networks

Application of Systems for Complex Integrative Automatic Assembly of Electronic Components Super Systems and Subsystems with Pre-Stamping of Incoming Parts and Elements

\section{Law}

\section{N. Pavlovska,}

M. Kulyk,

Y. Tereshchenko,

H. Strilets,

N. Filipova

E. Svoboda,

N. Pavlovska,

L. Herasymenko,

N. Morhun,

R. Kutsyi
Humans as Genetic Information Carriers in the Pandemic Conditions (Criminal,

Criminal Legal, and Civil Legal Aspects) 


\section{Table of Contents (continued)}

\section{Social Work}

I. Rizak

Characteristics of Social Work with Children with Disabilities in Great Britain

O. Karpenko, V. Ostapchuk

Theoretical Aspects of Future Social Workers' Professional Self-Development ......

\section{Education}

G. Turchynova,

L. Pet'ko,

Studying Gardens of the World with Students of Higher Education Establishments

T. Holovko

L. Petrukhan-

Scherbakova,

N. Chernukha

The Main Aspects of the Activities of Charitable Organizations in the Legacy of

Mary Ellen Richmond

N. Sabat

System of Exercises for Anglophone Strategic Competence Formation in Future Interpreters

V. Vyshkivska,

O. Shykyrynska,

O. Malinka,

I. Lobachuk

Theoretical and Methodological Aspects of Using Dialogue for the Purpose of

Organizing Productive Interaction of Subjects of the Educational Process

Art

E. Lukyanenko Plotless Ballets on the Stage of Ukrainian Theaters

132

\section{Toronto, October / December 2020}




\title{
PHOTONS GENERATED BY PLASMA FLUCTUATIONS
}

\author{
Miroslav Pardy \\ Department of Physical Electronics \\ and \\ Laboratory of Plasma physics \\ Masaryk University \\ Kotlářská 2, 61137 Brno, Czech Republic \\ e-mail:pamir@physics.muni.cz
}

August 15, 2020

\begin{abstract}
The totally ionized charged collisionless plasma at finite temperature is considered. Using the statistical and Schwinger field methods we derive the production of photons from the plasma by the Cerenkov mechanism. We derive the spectral formula of emitted photons by the plasma fluctuations. The calculation can be extended to the photon propagator involving radiative corrections.
\end{abstract}

PACS: 52.55, 52.20, 41.60B

\section{Introduction}

The production of photons by the plasma fluctuations is one of the problems which form the basic ingredients of the quantum field theory (QFT) at finite temperature. This theory has been formulated some years ago by Dolan and Jackiw (1974), Weinberg (1974) and Bernard (1974) and some of the first applications of this theory were the calculations of the temperature behaviour of the effective potential in the Higgs sector of the standard model.

Information on the systematic examination of the finite temperature effects in quantum electrodynamics (QED) at one loop order was given by Donoghue, Holstein and Robinett (1985). They treated about calculation of mass, charge, wave function renormalization and so on; they demonstrated the running of the coupling constant at finite temperature and discussed the normalized vertex function and the energy momentum tensor.

The similar discussion of QED was published by Johansson, Peressutti and Skagerstam (1986).

The finite-temperature QED, QFT and also quantum chromodynamics usually deal with the specific processses of these theories in the heat bath of photons or other particles. 
On the other hand Ford (1982) and del Campo (1988), have considered production of gravitons by the fluctuations of the electromagnetic field of plasma.

Fluctuations are the integral part of the thermodynamical system. The physical quantities which characterize the macroscopic system in the equilibrium state are with great accuracy equal to their average values. Neverthless, they sometime deflect stochastically from their average values. In other words they fluctuate. The existence of fluctuations can be considered in certain sense as the fundamental feature of the thermal system. In such a way we can decide if the system is thermal or nonthermal. Such a criterium is important in particle physics where, for instance, the collisions of nucleons at low energies is nonthermal; however, in the high energy regime the plasma of particles is formed with the physical characteristics of the thermal system, where also thermodynamical fluctuations play important role.

In this article we slightly modify the approach of Ford and del Campo and compute the power spectral formula $P(\omega, t)$ of produced photons by the plasma fluctuations in the framework of the Schwinger field theory. We use here the statistical methods and Schwinger source theory for the determination of the plasma fluctuations. Because the thermal plasma has the electrodynamical index of refraction $n$, the resulting effect is the Čerenkov production of photons by plasma fluctuation. Such effect is considered in physics, to our knowledge, for the first time and in the source theory it was never solved. The relation to the experiments with the ionized plasma is evident and it is not excluded it will be sooner or later experimentally investigated.

The generalization of our mathematical procedure to the situation with the photon propagator with radiative corrections is possible (Schwinger, 1973; Pardy, 1994b; 1994c; 1994d). Then, we work with the high-temperature plasma, where the creation of pairs occurs. The relation of our theory to the experiments with the ionized plasma and with the plasma formed during the heavy-ion collisions is evident and can help to understand other processes inside the plasma.

\section{Formulation of the problem in source theory}

The basic formula of the Schwinger source theory is the vacuum-vacuum amplitude (Schwinger, 1970):

$$
<0_{+} \mid 0_{-}>=e^{\frac{i}{\hbar} W}
$$

where in case of the electromagnetic field the action $W$ is defined as (Schwinger et al., 1976)

$$
W=\frac{1}{2 c^{2}} \int(d x)\left(d x^{\prime}\right) J_{\mu}(x) D_{+}^{\mu \nu}\left(x-x^{\prime}\right) J_{\nu}\left(x^{\prime}\right),
$$

where $J^{\mu} \equiv(c \varrho, \mathbf{J})$ being the conserved current and $D_{+}^{\mu \nu}\left(x-x^{\prime}\right)$ is the photon propagator in a medium with the index of refraction $n$, the magnetic permeability $\mu$ and the dielectric 
constant $\varepsilon$.

The explicit form of $D_{+}^{\mu \nu}\left(x-x^{\prime}\right)$ has been obtained as (Schwinger et al., 1976)

$$
D_{+}^{\mu \nu}=\frac{\mu}{c}\left[g^{\mu \nu}+\left(1-n^{-2}\right) \beta^{\mu} \beta^{\nu}\right] D_{+}\left(x-x^{\prime}\right),
$$

where $\beta^{\mu}=(1,0)$ and

$$
D_{+}\left(x-x^{\prime}\right)=\int \frac{(d k)}{(2 \pi)^{4}} e^{i k\left(x-x^{\prime}\right)} \frac{1}{\left|\mathbf{k}^{2}\right|-n^{2}\left(k^{0}\right)^{2}-i \epsilon}
$$

with $k^{\mu}=\left(k^{0}, \mathbf{k}\right)$. The Green function $D_{+}\left(x-x^{\prime}\right)$ can be further specified as

$$
D_{+}\left(x-x^{\prime}\right)=\frac{i}{c} \frac{1}{4 \pi^{2}} \int_{0}^{\infty} d \omega \frac{\sin \frac{n \omega}{c}\left|\mathbf{x}-\mathbf{x}^{\prime}\right|}{\left|\mathbf{x}-\mathbf{x}^{\prime}\right|} e^{-i \omega\left|t-t^{\prime}\right|}
$$

by the standard contour integral method (Schwinger et al., 1976).

The vacuum persistence probability follows from eq. (1) in the form (Schwinger et al., 1976):

$$
\left|<0_{+}\right| 0_{-}>\left.\right|^{2}=e^{-\frac{2}{\hbar} \operatorname{Im} W}
$$

Using the definition of the spectral function $P(\omega, t)$

$$
\frac{2}{\hbar} \operatorname{Im} W \stackrel{d}{=} \int \frac{d \omega d t}{\hbar \omega} P(\omega, t)
$$

we get after some calculation (Schwinger et al., 1976):

$$
\begin{aligned}
P(\omega, t)= & -\frac{\omega}{4 \pi^{2}} \frac{\mu}{n^{2}} \int d \mathbf{x} d \mathbf{x}^{\prime} d t^{\prime} \frac{\sin \frac{n \omega}{c}\left|\mathbf{x}-\mathbf{x}^{\prime}\right|}{\left|\mathbf{x}-\mathbf{x}^{\prime}\right|} \cos \omega\left(t-t^{\prime}\right) \times \\
& \times\left[\varrho(\mathbf{x}, t) \varrho\left(\mathbf{x}^{\prime}, t^{\prime}\right)-\frac{n^{2}}{c^{2}} \mathbf{J}(\mathbf{x}, t) \cdot \mathbf{J}\left(\mathbf{x}^{\prime}, t^{\prime}\right)\right],
\end{aligned}
$$

where $\varrho$ and $\mathbf{J}$ are connected with the four potential $A_{\mu}=(\varphi, \mathbf{A})$ according to the equation (Schwinger et al., 1976):

$$
\begin{gathered}
\Delta \varphi-\frac{\mu \varepsilon}{c^{2}} \frac{\partial^{2} \varphi}{\partial t^{2}}=-\frac{1}{\varepsilon} \varrho \\
\Delta \mathbf{A}-\frac{\mu \varepsilon}{c^{2}} \frac{\partial^{2} \mathbf{A}}{\partial t^{2}}=-\frac{\mu}{c} \mathbf{J} .
\end{gathered}
$$

As a consequence of the definition $(7), P(\omega, t)$ has the physical content of the power spectrum of emitted photons. Formula (8) was applied to many interseting cases, such as the linear motion of charge in a medium, the circular motion of a charge in this medium, and so on. Obviously it can be applied to other complicated motion of charges in the medium.

Formula (8) enables a determination of the spectrum of emitted photons in the case of the finite temperature regime. When the situation is such that a charge moves linearly in 
the finite temperature medium, we get so called the finite-temperature Cerenkov radiation which was discussed by Pardy (1989).

On the other hand it is possible to consider a case when the system is formed by charges with density $\varrho$ and current density $\mathbf{J}$ and has the temperature $T$. Such system corresponds physically to the totally ionized plasma.

To our knowledge, such problem has been not so far solved in the framework of the source theory and it is our goal to determine the spectrum of photons emitted by the fluctuations of such system. Our article is based on the article by author (Pardy, 1991; 1994a; 1994b).

It is obvious that system in thermal equilibrium cannot produce photons by the average charge and current densities, however, it can do it by the thermal fluctuations which are involved in the correlation functions $<\varrho(\mathbf{x}, t) \varrho\left(\mathbf{x}^{\prime}, t^{\prime}\right)>$ and $<\mathbf{J}(\mathbf{x}, t) \cdot \mathbf{J}\left(\mathbf{x}^{\prime}, t^{\prime}\right)>$. A similar problem was solved by Ford (1982) and by del Campo (1988) who have been considered the emission of gravitons by the thermal fluctuations of the electromagnetic field of plasma where the electromagnetic fields fluctuations has been expressed by the correlation function of the tensor of energy and momentum $T_{\mu \nu}$ of the electromagnetic field.

Here we determine the correlation functions of the charge and current densities of totaly ionized hot plasma by the statistical methods.

\section{The correlation functions}

First, let us calculate the correlation function $<\varrho(\mathbf{x}, t) \varrho\left(\mathbf{x}^{\prime}, t^{\prime}\right)>$ at the temperature $T$. To achieve this goal let us consider the specific model of plasma, namely the plasma nonlimited in space, homogenous and totaly ionized in the state of the thermal equilibrium. Since the ions are assumed to have large masses, their motion can be neglected. The presence of ions forms only the necessary compensation of charge. A plasma, where the motion of ions is absolutely neglected is called the electron plasma. We suppose that such a plasma has an electromagnetic index of refraction and we will see later that it is the existence of this index of refraction, which is formed by the thermal motion of plasma particles that enables the production of Čerenkovian photons by plasma fluctuations.

The density of electrons in a plasma is given by the relation

$$
N(\mathbf{x}, t)=\sum_{\alpha}^{\infty} \delta\left(\mathbf{x}-\mathbf{x}_{\alpha}(t)\right)
$$

where $\mathbf{x}_{\alpha}(t)$ is the coordinate of the electron with number $\alpha$. The summation concerns electrons within the unit volume. We will supoose there is no scattering between electrons.

Then we can write

$$
\mathbf{x}_{\alpha}(t)=\mathbf{x}_{\alpha}+\mathbf{v}_{\alpha} t
$$


where $\mathbf{x}_{\alpha}$ and $\mathbf{v}_{\alpha}$ are the vector coordinate and velocity of the electron with number $\alpha$ at the initial time moment $t=0$. The generalization to the case with the arbitrary initial conditions is obvious.

The statistical average value of the particle density can be introduced by the following definition:

$$
N_{0}=<N(\mathbf{x}, t)>
$$

Then, obviously:

$$
N(\mathbf{x}, t)=N_{0}+\delta N(\mathbf{x}, t)
$$

or,

$$
\delta N(\mathbf{x}, t)=N(\mathbf{x}, t)-N_{0} .
$$

For the correlation function $<N(\mathbf{x}, t) N\left(\mathbf{x}^{\prime}, t^{\prime}\right)>$ we have:

$$
<N(\mathbf{x}, t) N\left(\mathbf{x}^{\prime}, t^{\prime}\right)>=N_{0} N_{0}+<\delta N(\mathbf{x}, t) \delta N\left(\mathbf{x}^{\prime}, t^{\prime}\right)>.
$$

As a consequence of the homogenity of the ion background, the correlation function of a charge density is related to the correlation function of particles in the following way:

$$
<\varrho^{2}>=e^{2}<\delta N^{2}>=e^{2}<\delta N(\mathbf{x}, t) \delta N\left(\mathbf{x}^{\prime}, t^{\prime}>\right.
$$

and the correlation function depends only on the space and time differences. Only correlation function of the charge density and the current density can contribute to the formula (8), determining the spectral density of photons emitted by the fluctuations of the charged plasma.

Obviously, for our plasma model we have (Sitenko, 1965)

$$
<\delta N^{2}>=<\sum_{\alpha} \delta\left(\mathbf{x}-\mathbf{x}_{\alpha}-\mathbf{v}_{\alpha} t\right) \delta\left(\mathbf{x}^{\prime}-\mathbf{x}_{\alpha}^{\prime}-\mathbf{v}_{\alpha} t^{\prime}\right)>,
$$

which is a consequence of eq. (11) and eq. (15).

Now, let us introduce the one-particle distribution function $f(\mathbf{v})$ normalized by condition

$$
\int d \mathbf{v} f(v)=1
$$

where $v=|\mathbf{v}|$.

Then obviously (Sitenko, 1965)

$$
<\delta N^{2}>=N_{0} \int d \mathbf{v} f(v) \delta\left(\mathbf{x}-\mathbf{x}^{\prime}-\mathbf{v}\left(t-t^{\prime}\right),\right.
$$

where $N_{0}$ is the density of thermal electrons. 
The non-relativistic Maxwell distribution is of the form

$$
f(v)=(m / 2 \pi k T)^{3 / 2} e^{-\frac{m v^{2}}{2 k T}},
$$

where temparature $T$ is measured in the Kelvin scale, and $k$ is the Planck constant. The generalization of eq. (21) for the relativistic situation gives the Maxwell distribution in the following form (Sitenko, 1965):

$$
\begin{gathered}
f(v)=\frac{1}{\left(4 \pi \frac{k T}{m c^{2}} K_{2}\left(\frac{m c^{2}}{k T}\right)\right)} \times \\
\frac{c^{2}}{\left(c^{2}-v^{2}\right)^{5 / 2}} \exp \left\{-\frac{m c^{2}}{k T} \frac{1}{\sqrt{1-(v / c)^{2}}}\right\},
\end{gathered}
$$

where $K_{2}(x)$ is so called MacDonald function with index 2 and it is defined by the equation (Tikhonov et al., 1977):

$$
K_{2}(x)=\frac{1}{2}\left[\left(\frac{\partial I_{-\nu}}{\partial \nu}\right)_{\nu=2}-\left(\frac{\partial I_{\nu}}{\partial \nu}\right)_{\nu=2}\right]
$$

with

$$
I_{\nu}(x)=\sum_{k=0}^{\infty} \frac{1}{\Gamma(k+1) \Gamma(k+\nu+1)}\left(\frac{x}{2}\right)^{2 k+\nu} .
$$

Now, let us determine the current density correlation function if we know that the current density is given by the formula

$$
\mathbf{J}(\mathbf{x}, t)=\sum_{\alpha} e \mathbf{v}_{\alpha} \delta\left(\mathbf{x}-\mathbf{x}_{\alpha}(t)\right)
$$

It may be easy to show that using eq. (25) we get

$$
<J_{i} J_{j}>=e^{2} N_{0} \int d \mathbf{v} v_{i} v_{j} f(v) \delta\left(\mathbf{x}-\mathbf{x}^{\prime}-\mathbf{v}\left(t-t^{\prime}\right)\right) .
$$

\section{The power spectral formula}

At this moment we are prepared to write the power spectral formula $P(\omega, t)$ which expresses the distribution of emitted photons by the fluctuations of the totally ionized plasma. Using equations for density correlation function (20), and the current correlation function (26), and inserting them eq. (8), we obtain the general form for the spectrum of photons emitted by the plasma fluctuations:

$$
\begin{gathered}
P(\omega, t)=-e^{2} N_{0} \frac{\omega}{4 \pi^{2}} \frac{\mu}{n^{2}} \int d \mathbf{x} d \mathbf{x}^{\prime} d \mathbf{v} d t^{\prime} \times \\
f(v) \delta\left(\mathbf{x}-\mathbf{x}^{\prime}-\mathbf{v}\left(t-t^{\prime}\right)\right)\left(1-\frac{n^{2}}{c^{2}} v^{2}\right) \frac{\sin \frac{n \omega}{c}\left|\mathbf{x}-\mathbf{x}^{\prime}\right|}{\left|\mathbf{x}-\mathbf{x}^{\prime}\right|} \cos \omega\left(t-t^{\prime}\right),
\end{gathered}
$$


where $f(v)$ is given by eq. (21) in the non-relativistic limit, or by eq. (22) in the relativistic case. It is obvious that the spectral formula does not depend on time as a consequence of combination $t-t^{\prime}$ in this formula.

So, in the nonrelativistic situation we get after insertion of eq. (21) in the formula (27) and after the $\mathbf{x}^{\prime}$-integration the power spectral formula of produced photons by the plasma fluctuations in the following form:

$$
\begin{gathered}
P(\omega, t)=\frac{-\omega}{4 \pi^{2}} \frac{\mu}{n^{2}} e^{2} N_{o} \times \\
\int d \mathbf{v} d \mathbf{x} d \tau f(v)\left(1-\frac{n^{2} v^{2}}{c^{2}}\right) \frac{\sin \frac{n \omega v}{c} \tau}{v \tau} \cos \omega \tau,
\end{gathered}
$$

where we have put $\tau=t-t^{\prime}$.

As the quantity $N_{o}$ is the number of particles in the unit volume, the $\mathbf{x}$-integration gives volume $V$ of the plasma system; together with $N_{o}$, we get the total number $N_{V}$ of particles in the volume $V$.

The second mathematical operation is the $\tau$-integration. It is well known that

$$
\int_{-\infty}^{\infty} d \tau \frac{\sin n \omega \beta \tau}{\tau} \cos \omega \tau=\pi ; n \beta>1 ;(\beta=v / c)
$$

and the same integral is equal to zero for $n \beta<1$.

In such a way it is necessary to evaluate integral

$$
\int_{n \beta>1} d v_{x} d v_{y} d v_{z} \frac{1}{v}\left(1-\frac{n^{2} v^{2}}{c^{2}}\right) e^{-\frac{m v^{2}}{2 k T}}
$$

The last formula contains two integrals which can be evaluated in the spherical coordinates. For the first integral we have:

$$
J_{1}=\int_{c / n}^{\infty} d v v e^{-\frac{m v^{2}}{2 k T}}=\frac{k T}{m} e^{-\frac{m c^{2}}{2 k T n^{2}}} .
$$

For the second integral we have:

$$
J_{2}=\int_{c / n}^{\infty} d v v^{3} e^{-\frac{m v^{2}}{2 k T}}=\frac{k T c^{2}}{m n^{2}} e^{-\frac{m c^{2}}{2 k T n^{2}}}+\frac{2 k T}{m} J_{1}
$$

as a result of the elementary integration.

Now, if we combine eqs.(28 )-(32), we get the power spectral formula for the production of the photons by the plasma fluctuations in the following form:

$$
P(\omega)=N_{V} \omega \mu \frac{e^{2}}{c^{2}}\left(\frac{k T}{2 \pi^{3} m}\right)^{1 / 2} e^{-\frac{m c^{2}}{2 k T n^{2}}} .
$$

In case of the relativistic Maxwell distribution involving the MacDonald functions, the evaluations of the integrals requires more complex technique of integration than in the nonrelativistic case. Nevertheless, the problem is solvable. 


\section{Discussion}

The power spectral formula for the photons produced synergically by the thermal plasma fluctuations and by the Cerenkovian mechanism is here derived, to our knowledge, from the source theory and the plasma physics for the first time. It depends on the index of refraction of the plasma. The $\omega$-dependence is the same as in case of the original Cerenkov radiation (Schwinger et al., 1976) and it proves that the photons are produced just by the Čerenkovian mechanism in plasma with the index of refraction $n>1$.

Although the considered effect is only the ideal version of the physical reality, it can be related to the problems dealing with the heavy-ion colliosions in the high energy laboratories. During such processes the quark-gluon plasma is formed with the corresponding index of refraction. In such a way, during the thermal evolution of this plasma the Čerenkovian photons are produced by the plasma fluctuations during the late stage of the plasma evolution. While usually the proof of the plasma formation is the phase transformation of nuclear matter, we have determined the Čerenkovian photons as the possible signature of the late phase of the quark-gluon plasma formation.

The production of photons by the plasma fluctuations does not correspond to the production of photons from the energy loss $d E / d x$ of a heavy leptons propagating through a high-temperature QED plasma (Braaten et al., 1991) because our process is soft process, while the high temperature plasma is formed during the first stages of the nucleus-nucleus collision as the very hard process.

If we relate the derived formula to the photon radiation in cosmology we deduce that probably during the late phase of big bang the situation occured that the photons were produced by the plasma fluctuations. On the other hand the measured dependence of the relic radiation on frequency is in a harmony with Planckian law and it means that the contribution by the plasma fluctuations is very small. Nevertheless, the contribution of plasma fluctuations cannot be a priori excluded. Thus, it gives us the serious problem on the formation of plasma at the beginning of the Universe.

At the same time the existence of the Cerenkovian spectrum during the explosion of the supernova can inform us on the existence of the plasma phase arising during the explosion.

\section{References}

Bernard, C. W. (1974). Feynman rules for gauge theories at finite temperature, Phys. Rev. D 9, 3312.

Braaten, E. and Thoma, M. H. (1991). Energy loss of a heavy fermion in a hot QED plasma, Phys. Rev. D 44, No. 4, 1298.

Campo, S. del and Ford, L. H. (1988). Gravitation emission by a Thermal Bath of Photons, Phys. Rev. D 38, 3657. 
Dolan, L., Jackiw, R. (1974). Symmetry behavior at finite temperature, Phys. Rev. D 9, 3320.

Donoghue, J. F., Holstein, B. R. and Robinett, R. W. (1985). Quantum

Electrodynamics at Finite Temperature, Ann. Phys. (NY) 164 No. 2, 233.

Ford, L. H. (1982). Gravitational radiation by quantum systems,

Ann. Phys. (NY) 144, No. 2, 238.

Johansson, A. E., Peressutti, G. and Skagerstam, B. S. (1986). Quantum field

theory at finite temperature, Renormalization and radiative corrections,

Nucl. Phys. B 278, 324.

Pardy, M. (1989). Finite-temperature Čerenkov radiation, Phys. Lett. A 134, No. 6, 357.

Pardy, M. (1991). Production of photons by plasma fluctuations, Scripta Fac. Sci. Nat. Univ. Masaryk Brun. 21, Physics, 9.

Pardy, M. (1994a). The two-body potential at finite temperature, CERN-TH.7397/94.

Pardy, M. (1994b). Emssion of photons by plasma fluctuations, CERN-TH.7348/94.

Pardy M. (1994c). The Čerenkov effect with radiative corrections, Phys. Lett. B 325, 517.

Pardy, M. (1994d). The synchrotron production of photons with radiative corrections, Phys. Lett. A 189, 227.

Schwinger, J. Particles, Sources and Fields, Vol. I, (Addison-Wesley, Reading, Mass., 1970).

Schwinger, J., Tsai, W. Y. and Erber, T. (1976). Classical and Quantum

Theory of Synergic Synchrotron-Čerenkov Radiation, Ann. Phys. (NY) 96, No. 2, 303.

Schwinger, J. Particles, Sources and Fields Vol. II,

(Addison-Wesley, Reading, Mass., 1973).

Sitenko, A. G. The electromagnetic Fluctuations in Plasma,

(Kharkov University Press, 1965). (in Russian).

Tichonov A. N. and Samarskii, A. A. The equations of the

Mathematical Physics, (Nauka, Moscow, 1977). (in Russian).

Weinberg, S. (1974). Gauge and global symmetries at high temperature, Phys. Rev. D 9, 3357. 


\title{
The Lorentz transformations by way of the wave equations
}

\author{
Miroslav Pardy \\ Department of Physical Electronics \\ and \\ Laboratory of Plasma physics \\ Masaryk University \\ Kotlářská 2, 61137 Brno, Czech Republic \\ e-mail:pamir@physics.muni.cz
}

October 26, 2020

\begin{abstract}
We prove here, by the rigorous mathematical procedure, that so-called Lorentzian time in the special theory of relativity is defined by the wave equation, where the wave of time is the form of matter and not the Bergson physiological process in $S$ and $S^{\prime}$.
\end{abstract}

Key words. Special theory of relativity, simultaneity, wave equation.

We frequently learn that time in physics is defined by its measurement. Or, time is what a clock reads. In non-relativistic physics, it is a scalar quantity and, like length, mass, and charge, is considered as a fundamental quantity. Time can be combined mathematically with other physical quantities to derive other concepts such as motion, kinetic energy and time-dependent fields. In order to measure time, one can record the number of occurrences (events) of some periodic phenomenon. The sun was the arbiter of the flow of time.

Galileo, Newton, and others up until the 20th century thought that time was the same for everyone everywhere. This is the basis for timelines, where time is a parameter. The modern understanding of time is based on Einstein's theory of relativity, in which rates of time run differently depending on relative motion, and space and time are merged into spacetime. In this view time is a coordinate.

Einstein proved in his well known article and book (Einstein, 1905; 1919; 1922) that the simultaneity in the inertial system $S^{\prime}$ moving with velocity $v$ with regard to the inertial system $S$ is broken. Einstein writes (Einstein, 1905):

So we see that we cannot attach any absolute signification to the concept of simultaneity, but that two events which, viewed from a system of co-ordinates, are simultaneous, can no longer be looked upon as simultaneous events when envisaged from a system which is in motion relatively to that system. 
So, let us write the Lorentz transformation between system $S$ and $S^{\prime}$.

$$
\begin{gathered}
x^{\prime}=\gamma(x-v t), \\
t^{\prime}=\gamma\left(t-\left(v / c^{2}\right) x\right), \\
\gamma=\frac{1}{\sqrt{1-v^{2} / c^{2}}}
\end{gathered}
$$

We get from eq. (2) $t_{1}^{\prime}=\gamma\left(t-\left(v / c^{2}\right) x_{1}\right), t_{2}^{\prime}=\gamma\left(t-\left(v / c^{2}\right) x_{2}\right)$. So, if $x_{1} \neq x_{2}$, then $t_{1}^{\prime} \neq t_{2}^{\prime}$. So, we see that we cannot attach any absolute signification to the concept of simultaneity. The Einstein sofisticated experiment was ignored.

We prove here, by the rigorous mathematical procedure, that so-called Lorentzian time in the special theory of relativity is defined by the wave equation, where the wave is the form of matter and in no case the phlogiston.

We get from equation (2) the following elementary relations with $t^{\prime}=T$

$$
\begin{gathered}
\frac{\partial T}{\partial t}=\gamma=T_{t}, \\
\frac{\partial T}{\partial x}=-\gamma \frac{v}{c^{2}}=T_{x} .
\end{gathered}
$$

After comparison of eq. (4) with eq. (5) we get

$$
\left(\frac{\partial}{\partial t}+\frac{c^{2}}{v} \frac{\partial}{\partial x}\right) T=0
$$

After application of the operator $\left(\frac{\partial}{\partial t}-\frac{c^{2}}{v} \frac{\partial}{\partial x}\right)$ to the equation (6), we get

$$
\left(T_{t t}-\frac{c^{4}}{v^{2}} T_{x x}\right)=0,
$$

which is the partial differential equation describing motion of time as some medium. So, This is the mathematical prove that time is a form of matter.

If we perform the same analogous procedure with the x-transformation, we get the analogous quation with $x^{\prime}=X$. Or,

$$
\left(X_{t t}-v^{2} X_{x x}\right)=0 \text {. }
$$

So, we see that partial differential equatio for $T$ and $X$ is the standard wave equation of the form

$$
\frac{1}{a^{2}} \frac{\partial^{2} u(x, t)}{\partial t^{2}}-\frac{\partial^{2} u(x, t)}{\partial x^{2}}=0 .
$$

If we include the boundary conditions

$$
T(0, t)=0 ; \quad T(l, t)=0,
$$

we can prove that the solution of the wve equation is of the form: 


$$
T=\sum_{k=1}^{\infty}\left(a_{k} \cos \frac{k \pi a t}{l}+b_{k} \sin \frac{k \pi a t}{l}\right) \sin \frac{k \pi x}{l} .
$$

We can say that if the boundary conditions (10) are with the physical meaning, then the solution (11) is also of the physical meaning. Such statement is in agreement with the Wigner approach to physics because he speaks on the unreasonable effectivenses of mathematics in the natural sciences (Wigner, 1960).

The vector form of eqs. (1) and (2) is as follows (Fok, 2015):

$$
\begin{gathered}
\mathbf{x}^{\prime}=\mathbf{x}-\mathbf{v} t+(\gamma-1) \frac{\mathbf{v}}{v^{2}}(\mathbf{v} \cdot \mathbf{x}-\mathbf{v} t) \\
t^{\prime}=\gamma\left(t-\frac{1}{c^{2}}(\mathbf{v} \cdot \mathbf{x})\right)
\end{gathered}
$$

If we apply the analogous procedure with $\mathrm{x}$ - and t-transformation to $\mathrm{x}, t$, we get

$$
\begin{gathered}
\left(\frac{1}{v^{2}} \frac{\partial^{2}}{\partial t^{2}}-\Delta\right) \mathbf{X}=0 \\
\left(\frac{v^{2}}{c^{4}} \frac{\partial^{2}}{\partial t^{2}}-\Delta\right) T=0 \\
\gamma=\frac{1}{\sqrt{1-v^{2} / c^{2}}} .
\end{gathered}
$$

Our statements are in no case paradoxial and they are not involved in the collection of paradoxes of relativity (Goldblatt, 1972; Terletzkii, 1966) and in the relativistic paradoxes in American Journal of Physics. To our knowledge, our results (LorentzPardy equations (7-8) and (14-15) are not involved in any monograph of the relativity theory (Reichenbach, 1958; Mermin, 1968; Savitt, 2011). Nevertheless, the thinking of the relation of our results to the author results in the scientific physical journal (Pardy, 1969) is very useful.

There is no doubt that the discussion based on our wave equations for time and space will refresh the interest in the theory of relativity described by the Lorentz-Pardy equations of mathematical physics.

\section{References.}

Einstein, A. (1905). Zur Elektrodynamik bewegter Körper, Annalen der Physik, 17. See also The Principle of Relativity, published in 1923 by Methuen and Company, Ltd. of London. Most of the papers in that collection are English translations by W. Perrett and G.B. Jeffery from the German Das Relatitivitätsprinzip, 4th ed., published in 1922 by Teubner.

Einstein, A. (1919). Über die spezielle und die allgemeine relativitäts Theorie, Vierte Auflage, Vieweg \& Sohn, Braunschweig.; chapter 9.

Fock, V. (2015). The Theory of Space, Time and Gravitation, Pergamon; 2nd Edition 
Goldenblat, I. I. The time paradoxes in the special theory of relativity, (NAUKA, Moscow, 1972), (in Russian).

Mermin, N. D. Space and Time in Special Relativity (McGrawHill, 1968).

Pardy, M. (1969). A remark on the clock paradox, Phys. Lett. 28 A, No. 11, 766

Reichenbach, H. The Philosophy of Space and Time (Dover Publications, Inc., 1958).

Savitt, S. Time in the Special Theory of Relativity The Oxford Handbook of Philosophy of Time (Oxford, University Press, 2011), Edited by Craig Callende.

Terletzkii, Ya. P. The paradoxes of the special theory of relativity, (NAUKA, Moscow, 1966), (in Russian).

Wigner, E. The Unreasonable Effectivenses of Mathematics in the Natural Sciences, Reprinted from Communications in Pure and Applied Mathematics, Vol. 13, No. I. New York: John Wiley \& Sons, Inc. Copyright - 1960 by John Wiley \& Sons, Inc. 


\title{
Scalar Theory of Everything (STOE) unites the big, the small, and the four forces (GUT) by extending Newton's model
}

\author{
John C. Hodge \\ Retired, 477 Mincey Rd., Franklin, NC, 28734 \\ E-mail: jchodge@frontier.com
}

\begin{abstract}
Newton established a major physics advance that was confirmed by predicting the late return of Halley's comet. Newton identified three characteristics of bodies that have been identified as three characteristics of "mass". Current standard physical models have become very complex with divergent postulates for cosmology and quantum mechanics. Physics theory restarting from Newton's speculations and then describing the experiments of the 19th and 20th centuries results in a model of the big, the small, and the four forces (GUT) - the Scalar Theory of Everything (STOE).
\end{abstract}

keywords: TOE, GUT, Newton, mass

\section{INTRODUCTION}

Human physical models must begin with some postulates, evolve to explain observations, and make useful predictions. Newton created a theory of gravity with his three laws of motion [1]. This model related the motion of bodies on Earth and of the Moon. The key measurable characteristics of bodies were assumed. Later, Newton speculated on the common postulates for gravity and light - the big and the small. The predicted late return of Halley's comet confirmed Newton's model for the solar system scale. Thus, astronomical happenings were related to Earth-born experiments. A key characteristic of Newton's model is that it is simpler and describes a wider range of observations than the other models it replaced.

Newton identified three characteristics of bodies that are different views of mass characteristics. This is the postulates stage. Definitions become better defined as they are related to observations. Weight $\left(m_{\mathrm{w}}\right)$ was defined as a body's density times its volume and as the "quantity of matter" in a body. A body's density, volume, and innate force of matter are our everyday understood parameters. Inertial mass $\left(m_{\mathrm{i}}\right)$ was defined as a body's innate force of matter with 


\section{INTRODUCTION}

the power of resisting a change in its state of motion. This force is exercised only when another force impressed on the body changes the body's motion. Gravitational mass $\left(m_{\mathrm{g}}\right)$ was presented in his third book of the Principia. It is the body's characteristic that instantaneously impresses an attractive force on another body over a distance in absolute space. The electromagnetic forces were unaccounted in Newton's time. Fluid and other forces were outside Principia. Newton recognized that a gravity only model created a problem in cosmology requiring an infinite, eternal universe and requiring an infinite force as distances between centers of mass approached zero. The motion of the moon and Sun suggested instantaneous reaction to the force of gravity. A more complete description may be found in Assis [2, Section I and III].

Newton's model works by defining (mapping) forces that are exerted on matter then adding force vectors to arrive at a single force that predicts the mass's measurable motion by inverse mapping. This requires the mathematical constants of proportionality to be such that the body's motion is as observed.

Later, Newton expanded on how $m_{\mathrm{g}}$ may be impressed on another body and the relation of gravity and light, stated in modern terms [3]:

Qu. 1 Masses bend passing light by an amount inverse to distance.

Qu. 3 Light passing close to edges are diffracted in fringes.

Qu. 4 Light path begins to bend BEFORE reaching a body or slit.

Qu. 5 Light heats mass.

Qu. 6 Black bodies absorb all light.

Qu. 8 Black body radiation.

Qu. 11 Sun and stars are black body radiators.

Qu. 17 Light is corpuscles that are pushed around (divergence of the aether's density) by waves of the aether that "overtake" the rays of light. The waves in the aether travel faster than light - its not a big stretch to say MUCH faster than light. That is, gravity is not force. Gravity is the effect of the divergence of the aether, also.

Qu. 18 A Medium that refracts and reflects light also allows light to heat bodies. Newton also suggested light travels faster in the void (denser parts of the aether). This is the measured Shapiro delay.

Qu. 19 Refraction of light implies differing densities of the Medium (calls it "...this aether Medium..."). Density of the aether is GREATER in "...free and open spaces void of air and other grosser bodies...". How the aether became denser between bodies was unexplained.

Qu. 20 Increasing aether density (ie divergence) causes light refraction. 
Qu. 21 Aether rarer within dense bodies and increase with distance and "...thereby cause the gravity of those great bodies; every body endeavoring to go from the denser parts of the medium towards the rarer?". He also suggested the aether is so rare as to not impede the planets revolution (no aether wind).

Newton suggested a reductionism step by positing (1) an aether whose divergence exerted a force that caused gravity and that caused the diffraction, reflection, and refraction of light and (2) corpuscles as light and as components of matter. That is, support for the aether and corpuscles was because the model could explain several diverse observations then known but mysterious rather than by direct observation.

This Paper suggests the Scalar Theory of Everything (STOE) is a continuation of Newton's model. Section 2 briefly describes the deviation from Newton's path and some observations after Newton's time. Section 3 describes a STOE model of the three types of mass as independent physical effects. The Discussion and Conclusion are in section 4 .

\section{THE DEVIATION FROM NEWTON'S PATH}

Young's Experiment of interference was interpreted to indicate light was a wave rather than corpuscles and rather than the wave interference was caused by the aether (Newton used a rock-thrown-into-water analogy). This began the effort to attempt to explain observations of the small scale by waves, fields, etc. This effort has resulted in the very counterintuitive (no analogies with the classical world) Quantum Mechanics and the loss of the connection to gravity. This has resulted in the incompatibility of General Relativity and Quantum Mechanics.

Several experiments in electricity and magnetism were combined into Maxwell's Equations rather than discovering how Newton's three masses and a single, continuous aether could explain the experiments. Because the experiments were independently done, several simplifications resulted in incorrect descriptions $[4 ; 5 ; 6 ; 7]$. The electromagnetic signals have a speed of light. If light is a wave, then the speed of a wave is the speed of light. However, this has been falsified for the speed of coulomb fields [8].

The invention of the Hamiltonian and the Lagrangian that calculated a body's motion in terms of energy resulted in the distinction of the three masses being lost. The $m_{\mathrm{w}}$ had been considered as an $m_{\mathrm{i}}$ and these functions considered the distinction between kinetic energy and potential energy as caused by one type of mass. However, Newton argued the $m_{\mathrm{i}}$ and $m_{\mathrm{g}}$ were distinct but proportional which were included in the gravitational constant $G$. Models currently exist that suggest the $G$ varies across a galaxy such as MOND.

Mach's Principle, which is vague, suggested that the stars in the universe should influence measurements (inertia) on Earth. Mach's Principle is viewed as suggesting a total relativism and as a substitute for Newton's "absolute space". However, because the influence is by bodies, the higher aether density required by Newton (so the $m_{\mathrm{g}}$ can reduce the aether) is unaccounted. 


\section{THE STOE}

The well-known Einstein thought experiment of a measuring system in a (small) box (such as an elevator) being unable to determine if the box is in a gravity well or under acceleration of a rocket resulted in the Strong Equivalence Principle. But this is incorrect. Gravity acts as if from a point (center of mass). Therefore, gravity shows the force vectors as converging. The rocket shows force vectors as parallel. The "small" condition to achieve equality is more properly a measurement uncertainty. The "small" condition was ignored and the equality of acceleration and gravity was accepted.

The left side of the General Relativity Field equation (LHS) is a mathematical mapping of observed energy and momentum into $s$ and $t$ parameters called "spacetime". But like Newton's aether it has a high value where no mass exists such as between galaxies and depressed values around masses. From whence, this "spacetime"? That is, the "spacetime" (LHS) cannot be real. Therefore, it is a mapping that must be inverse-transformed to real energy and momentum measurements.

General Relativity and other metric theories are NOT Machian models although there have been several attempts.

Because the stars of galaxies are modeled as the source of the Machian influence, the background of all "spacetime" must decrease (like Newton's model). The Big Bang model suggests a high amount of the stuff of the universe between galaxies that infalls into galaxies. However, observations falsify the infall model for spiral galaxies. Rather, spiral galaxies eject matter. However, elliptical galaxies do have infall characteristics [9].

The discovery of phenomena suggesting an atomic structure resulted in attempting to describe the spectra as an orbital (angular momentum) characteristic of electrons [10]. This became untenable because radiation should be emitted and none was observed for stable structures. Later attempts became weirder and more complex by using Quantum Mechanics combined with many ad hoc exclusion rules.

Many observations suggest several parameters are "fine-tuned" such as the temperature of the microwave background. Fine-tuning remains unexplained.

The increase number and accuracy of observations has resulted in physical models becoming more complex and separated into at least 3 major incompatible disciplines - Relativity, Quantum mechanics, and subatomic particles (group theory) including the Grand Unified Theory (GUT).

\section{THE STOE}

The return to Newton's path started with the Quasi Steady State Cosmology (QSSC) [11; 12]. QSSC suggested a Source of the stuff of our universe at the center of galaxies. The rotation curves of spiral galaxies were explained as a medium density directing bodies to vary as $1 / d$ ( $d$ being the distance from the Source) according to the spherical principle. Note the positive value that causes an outward force on bodies. Matter moving outward combines to form heavier bodies that are gravitationally attracted inward in spiral galaxies. However, 


\section{THE STOE}

some matter escapes as the $1 / d$ pushes it beyond the galaxy's gravitational influence.

For the volume between galaxies to have low medium density, the universe must expand. Because the Sources adds the stuff of the universe, the QSSC is Machian. However, the QSSC fails when describing elliptical galaxy characteristics.

The STOE posits the components of the universe are discrete hods and a continuous plenum that is a medium that supports waves similar to Newton's aether. Because the plenum supports waves, it has the property of inertia [13; 14], has plenum density $\rho$, it directs hods, and it has waves with a speed much greater than light.

Hods are 2 dimensional, magnetic with a high $\rho$ on one side and $\rho=0$ on the other, and particles are assemblies of hods $[15 ; 16]$. Hods travel at the speed of light in the direction parallel to their surface and slower in a direction perpendicular to their surface.

The STOE adds Sinks to the QSSC that are elliptical galaxies in galaxy clusters that lowers the $\rho[17 ; 18 ; 19]$. The stuff of the universe flows into the Sinks which explains the many differences between spiral and elliptical galaxies [9]. The Sinks remove the need for an expansion of the universe and for infall into spiral galaxies.

The universe begins as a single Source that eject other Sources [19; 20]. The entire universe emerges (strong emergence) from the two components and their interaction [21].

The STOE suggested a Universal Equation $[22 ; 23 ; 24 ; 25]$. The plenum density at all points $\rho_{\mathrm{p}}$ in the universe is the sum of the effects of all galaxies and all hods,

$$
\begin{aligned}
\rho_{\mathrm{p}}= & K_{\epsilon} \sum_{i=1}^{N_{\text {source }}} \frac{\epsilon_{i}}{r_{i}}-K_{\eta} \sum_{j=1}^{N_{\text {sink }}} \frac{\eta_{j}}{r_{j}} \\
& \quad-K_{\text {hods }} \sum_{k=1}^{N_{\text {hods }}} \frac{m_{\mathrm{g}}}{r_{k}} \cos \left(\frac{2 \pi r_{k}}{\lambda_{\mathrm{T}}}-\pi\right) \exp ^{-j\left(\omega t_{k}\right)} \\
>0 & ,
\end{aligned}
$$

where $K_{\epsilon}, K_{\eta}$, and $K_{\text {hods }}$ are constants that relate the relative influence of the Sources, Sinks, and hods, respectively; $\epsilon_{i}, \eta_{j}$, and $m_{\mathrm{g}}$ are constants that relate the value of a measurable parameter such as a galaxy's B-band luminosity or hod gravitational effect for Sources, Sinks, and hods, respectively; $r_{i}, r_{j}$, and $r_{k}$ are distances from the center of each component to the point being evaluated; $\lambda_{\mathrm{T}}$ and $t_{k}$ are wave characteristics generated in the plenum by moving hods. The $\lambda_{\mathrm{T}}$ and $t_{k}$ depend on the $\rho_{\mathrm{p}}[26]$.

The $\rho$ as the $r$ increases, like a fluid, becomes smoothed in the direction perpendicular to $r$. This is the "spherical principle". The number of hods appear as if they were concentrated at the center of the structure (center of mass) as $r$ increases beyond a minimum value. The $K_{\text {hods }}$ term looks like the gravitational mass effect in Newtonian scale observations. 


\section{THE STOE} tions.

The $K_{\epsilon}$ and $K_{\eta}$ terms become predominate on cosmological scale observa-

The inclusion of all Sources, Sinks, and matter means the STOE is a Machian model.

Note the $r$ values are for the determination of distance for the $\rho$ calculation. Therefore, the time required for a change in $r$ to travel through the plenum determines the position of the emitting object for the calculation of $\rho$ at a point. The change-in- $r$ wave can be very much faster than the speed of light $[27]$.

The divergence of $\rho_{\mathrm{p}}$ is proportional to a force $\vec{F}_{\mathrm{s}}$ that acts on matter and directs a hod,

$$
\vec{F}_{\mathrm{s}}=K_{\mathrm{G}} \sum_{l=1}^{N_{\mathrm{hods} l}} m_{\mathrm{hod}}\left(\vec{n}_{l} \bullet \vec{\nabla} \rho_{\mathrm{p} l}\right) \vec{n}_{l},
$$

where $m_{\text {hod }}$ is the surface area of a hod that is the same for all hods and $\vec{n}_{l}$ is the unit vector perpendicular and centered on the hod's surface. .

For matter,

$$
\vec{F}_{\mathrm{s}}=G_{\mathrm{s}} m_{\mathrm{w}} \vec{\nabla} \rho_{\mathrm{p}}
$$

where the $G_{\mathrm{S}}$ is a proportionality constant analogous to the gravitational constant $G$ without the $m_{\mathrm{i}} / m_{\mathrm{g}}$ value. The $m_{\mathrm{w}}$ is experienced as the effective surface area of the particle, and the familiar negative sign is included in the $\vec{\nabla} \rho_{\mathrm{p}}$.

Because electromagnetic signals speed is that of light, electromagnetic signals are hods [5]. The amount of plenum captured by a hod is constant and is the cause of $m_{\mathrm{i}}$ of bodies. Photons are a column of hods [26]. Because hods are two dimensional, hods and photons experience no impressed force in their direction of travel. That is, for smaller than electron structures such as photons or neutrinos, there can be directions with varying force depending on direction and $m_{\mathrm{w}}=0$ in the direction of travel. Therefore, they travel at the maximum allowed speed of other bodies.

The structure of baryonic matter has hod surfaces facing all three directions such that the effective surface area is less than the number of hods times $m_{\text {hod }}$ $[15]$.

The inverse mapping produces the movement of a body:

$$
\vec{a}=\frac{\vec{F}_{\mathrm{s}}}{m_{\mathrm{i}}}
$$

where $m_{\mathrm{i}} \neq 0$ because it is the captured plenum around the hods in the body and $\vec{a}$ is the acceleration of the body. Reference frames result when some terms of Eq. 1 are ignored for calculation simplicity.

Newton's three masses are (1) $m_{\mathrm{w}}$ is the effective surface area on which the $\vec{F}_{\text {s }}$ is exerted, (2) $m_{\mathrm{i}}$ is the captured plenum which is proportional to the number of hods in a body, and (3) $m_{\mathrm{g}}$ is the deformation of the plenum caused by the hods and is proportional to the number hods in a body. Note the number of effective hods vary by type of assembly (photon, neutrino, or baryon [15]). 
The Universal Equation has quantitatively described many mysterious observations $[23 ; 25 ; 28]$ :

Microwave background temperature is due to a fine-tuning due to a feedback loop between Sources and Sinks [29]. This suggests that if fine-tuning is evident, then a physical feedback loop is present.

Redshift $(z)$ was calculated by considering each galaxy's effect on the photon [30]. That is, the $\rho_{\mathrm{p}}$ is calculated for points along the photon's path (line of sight) using Eq. 1. The correlation coefficient of model distance versus Cepheid distance for the best Doppler shift model is 0.80. The STOE model correlation coefficient for the same galaxies is 0.88 . The "Hubble Law" was recovered without invoking a Doppler shift.

Periodic redshift was calculated by considering the Sink's effect (the $K_{\eta}$ term) on redshift [30]. If a Sink is located between the target and the Earth, the $z$ is increased. If a Sink is located beyond the target from the Earth, the $z$ is decreased. A galaxy cluster is a shell of Source galaxies around a core of Sink galaxies [9]. Therefore, galaxy clusters appear to be elongated along the line-of-sight from Earth. This phenomenon is called "the fingers-of-God" pointing toward Earth.

Rotation curves (RCs) were calculated by considering the Source strength. The Source strength is the $\epsilon$ term minus the $m_{\mathrm{g}}$ term for the mass internal to the radius in Eq. 1. The advantage is that all types of RCs are described in addition to standard models that explain only flat RCs [31;32;33].

Asymmetric RCs, which are unexplained in standard models, were calculated by considering the galaxy's' strength and a neighbor galaxy's strength and position [31; 32;33].

Correlation of central massive object mass and central velocity dispersion was explained [34].

Pioneer Anomaly of all 10 characteristics (not just the general value of the blueshift) were calculated by considering solar system matter (hods) and the Milky Way Source [35]. The equation used derived from the equation for galaxy redshift. That is, the $\rho_{\mathrm{p}}$ is calculated for points along the signal's path (line of sight) using Eq. 1. For example, the annual periodicity is explained by the Sun's relative position to the signal's path, which is mathematically similar to the observed periodic redshift . Because the same equation as the redshift equation was used, the similarity and sign difference to the Hubble constant is explained.

Predictions made in 2006 about the Pioneer Anomaly were confirmed in 2013 [36].

Photon diffraction and interference intensity patterns of both Young's Experiment and experiments that reject wave models of light were duplicated using a toy model computer simulation $[26 ; 37 ; 38 ; 39 ; 40 ; 41 ; 42 ; 43]$. 
Particle structure models and how the structures differ relative to photons that determine speed were created [15].

Modifications to Maxwell's Equations that better agree with experiment were described. The Biot-Savart Law was restated based on experiment $[4 ; 5 ; 6 ; 44]$. There are two different types of magnetic field, each with the same symbol $(\vec{B})[7]$.

The "Planet 9" observations and spiral galaxy rotation curves are due to the Source effect at the center of the Milky Way [45]. The effect was predicted in 2006 when examining the Pioneer Anomaly by noting the orbit of Pluto and Neptune. This effect may also influence the perihelion advance of Mercury [46].

The "ether wind" measurements are explained as the divergence of the plenum rather than a "wind" [47]. The "wind" model failed because the indicated direction did not match any possible Earth celestial movement direction.

The STOE model of the hod as a permanent magnet qualitatively suggested how hods form particles, the nature of particles, and the four forces of the Grand Unified Theory (GUT).

Magnetism in the STOE model is postulated to emerge from the hods and is a gradient of the plenum. Magnetism is observed in small subatomic particles and light. Therefore, the hods are magnets [5]. The application of Eqs: 1 and 2 suggests the $\vec{\nabla} \rho$ follows the magnetic lines of force seen in iron filings at the macro scale. The observation of two types of magnetic fields [7] imply the hod is either rotating charges or is a permanent magnet. Because rotating charges would emit radiation energy, the rotating charge model is rejected in the STOE. Therefore, the hod is a permanent magnetic. The self-similar (fractal) postulate suggests disk permanent magnets are a macro object that is analogous to hods.

Repulsion was measured between 2 columns of disk permanent magnets. The measurements showed an asymmetry between South poles repelling and North poles repelling [48]. Further, the repulsion force along the axis was inverse-distance when the magnets were close, inverse distance-cubed a bit further, and inverse distance-squared still further apart. The force perpendicular and centered on the axis was attractive and inverse-cubed of the distance from the dipoles.

Particles' magnetic fields were studied [49] for structures suggested previously identified (photons, neutrinos, electrons).

Electromagnets did not show the asymmetry that the permanent magnets demonstrated [50].

Atomic structure in the standard model is orbiting electrons. The fundamental problem is that rotating charges should radiate and have a declining 
orbital radius. This is not observed. Also observed is that changing energy radiation is photons. Photons in the STOE are columns of hods. So, the STOE atomic structure is of rods of photons determining and magnetically holding electrons in position around the nucleus [51].

Gravity emerges from magnetic effects in hod structures [52]. However, magnetic attractive and repulsive effects determine atomic structures. Therefore the distance required before an only attractive force is at least the atomic scale of Angstroms. That is, the "gravity" at more than atomic scale is an approximation which becomes invalid at less than atomic scale rather than being present and merely too small. The distance at which this occurs may determine atomic size and may suggest instability in larger atomic (dominated by inverse square distances) and nuclear (dominated by inverse cube distances) size. The relative strength of the photon hod binding and the gravity speaks to the "hierarchy problem". The Newtonian problem of $r \rightarrow 0$ for gravity causing an infinite force is nonexistent.

Nuclear forces (weak and strong) are modeled as an assembly of hods into a spherical ball which is the proton and neutron [53].

Grand Unified Theory is, therefore, that the magnetic force evolves with distance into the four forces of the GUT.

\section{DISCUSSION AND CONCLUSION}

Like Newton, the STOE suggests a reductionism step by positing the characteristics that can explain many problematic, mysterious observations.

The intent of $\vec{F}_{\mathrm{s}}$ is that it be all inclusive. The development of the STOE to date has demonstrated the interference effects and gravity. The hod is a magnet so the possibility is that electromagnetic effects may be modeled as approximations as was gravity. However, the equation and effects for very small values of the $r$ 's in Eq. 1 are lacking. Therefore this is an area for continued experimental research. Perhaps the STOE could be developed to model atomic and nuclear decay and to improve the model of galaxy redshift by including QSOs as H. Arp suggests [20].

Physics theory restarting from Newton's speculations and then describing the experiments of the 19th and 20th centuries results in a model of the big, small, and the four forces (GUT) - the Scalar Theory of Everything (STOE).

ORCID iD

John C. Hodge: https://orcid.org/0000-0002-1520-2153 


\section{REFERENCES}

\section{References}

[1] Newton, I., 1999. The Principia Mathematical Principles of Natural Philosophy A new translation by I. Bernard Cohen and Anne Whitman (University of California Press, Berkley, CA., USA).

[2] Assis, A.K.T., 2014 Relational Mechanics and implementation of Mach's Principle with Weber's Gravitational Force (C. Roy Keys Inc., Montreal, Quebec, Canada)

[3] Newton, I., 1952. Opticks based on the 1730 edition (Dover Publications, Inc., New York).

[4] Hodge, J.C. 2018c. Experiment supports STOE model and rejects the traditional model of a coulomb field. IntellectualArchive, v.7(2), 11-14. http://intellectualarchive.com/?link=item\&id=1927.

[5] Hodge, J. C. 2018d. Magnetostatics relation to gravity with experiment that rejects Biot-Savart Law, IntellectualArchive v.7(3), P. 1-8, 2018. http://intellectualarchive.com/?link=item\&id=1945.

[6] Hodge, J. C. 2018e. Another experiment rejects Ampere's Law and supports the STOE model, IntellectualArchive v.7(4), P. 6-10. http://intellectualarchive.com/?link=item\&id=1956.

[7] Hodge, J. C. 2018f. Two different types of magnetic field. IntellectualArchive, v. 7 (4), P. 1-5. http://intellectualarchive.com/?link=item\&id=1964.

[8] de Sangro, R. et al., 2012, Measuring Propagation Speed of Coulomb Fields https://arxiv.org/abs/1211.2913

[9] Binney, J., and Merrifield, M., 1998, Galactic Astronomy Princeton, NJ: Princeton University Press.

[10] Hertzberg, G., 1944, atomic spectra and atomic structure, (ISBN 13: 9789-486-60115-1, (Dover Publications, Inc., New York, New York, USA).

[11] Hoyle,F., Burbidge, G., \& Narklikar, J.V., 2000, A different approach to cosmology, (ISBN 9781469987361, Cambridge Univ. Press, Cambridge).

[12] Narklikar, J.V. et al. 2015. Gravitational wave background in the QuasiSteady State Cosmology, Mon. Not. Astron. Soc. V.451(2), p. 1390-1395. preprint http://arxiv.org/abs/1505.05494.

[13] Hodge, J. C., 2016b. Inertia according to the STOE, http://intellectualarchive.com/?link=item\&id $=1676$.

[14] Hodge, J. C., 2017a. STOE inertia, IntellectualArchive, v.6(1), P. 158,http://intellectualarchive.com/?link=item\&id=1814. 


\section{REFERENCES}

[15] Hodge, J. C. 2016c. Structure and spin of the neutrino, electron, and positron. IntellectualArchive, v. $5,(2), \quad 1-8$. http://intellectualarchive.com/?link=item\&id=1694.

[16] Hodge, J. C. 2016f. STOE model of the electron spin 1/2 observation. IntellectualArchive, $\quad$ v. $5(4), \quad 1-7$. http://intellectualarchive.com/?link=item\&id=1735.

[17] Hodge, J. C. 2019a. QSSC model's next step is the STOE. IntellectualArchive, v. 8 (1), P. 9. http://intellectualarchive.com/?link=item\&id=2043.

[18] Hodge, J. C. 2019b. STOE beginnings. IntellectualArchive, v. 8(2), P. 11. http://intellectualarchive.com/?link=item\&id=2087.

[19] Hodge, J. C. 2020b. Nature of beginning. IntellectualArchive, v. 9 (2), P. 8. http://intellectualarchive.com/?link=item\&id=2343.

[20] Arp, H., 1998, Seeing Red: Redshifts, Cosmology and Academic Science Montreal, Quebc, Canada: Apeiron.

[21] Hodge, J. C., 2016g. STOE emergence, IntellectualArchive, v.5 (5), P. 1014, http://intellectualarchive.com/?link=item\&id $=1757$.

[22] Hodge, J. C. 2018g. Scalar Theory of Everything replacement of Special Relativity. IntellectualArchive, v.7(5), P. 1-8. http://intellectualarchive.com/?link=item\&id=1974.

[23] Hodge, J. C. 2012b. Theory of Everything: Scalar Potential Model of the big and the small(ISBN 9781469987361, available through Amazon.com).

[24] Hodge, J.C., 2018h, STOE replaces relativity and quantum mechanics, (ISBN 978-613-9-91465-4, (LAP LAMBERT Acedemic publishing, Mauritius, available through Amazon.com).

[25] Hodge, J. C., 2018i, STOE replaces relativity and quantum mechanics, IntellectualArchive, v.7(5), P. 98,. http://intellectualarchive.com/?link=item\&id=1979

[26] Hodge, J. C. 2012a. Photon diffraction and interference. IntellectualArchive, v. 1 (3), 31-60. http://intellectualarchive.com/?link=item\&id=597

[27] von Flandern, T., 1998. The speed of gravity-what the experiments say, Physics Letters A 250, 1.

[28] Hodge, J. C., 2010 Scalar potential model of galaxies: review and new speculations. Chapter 14 of Black Holes and Galaxy Formation, eds. A. D. Wachter and R. J. Propst, Nova Science Publishers, Inc (New York, USA).

[29] Hodge, J. C. 2006a. Scalar potential model of the CMB radiation temperature. https://www.arxiv.org/abs/astro-ph/0603140. 


\section{REFERENCES}

[30] Hodge, J. C. 2006b. Scalar potential model of redshift and discrete redshift. NewA, v.11 (5), 344-358. http://www.arxiv.org/PS_cache/astro$\mathrm{ph} / \mathrm{pdf} / 0602 / 0602344 \mathrm{v} 1$.pdf.

[31] Hodge, J. C. 2003a. Relationship Between Cepheid and Tully-Fisher distance Calculations. Presented at 202nd meeting of the AAS, session 40.08. https://www.arxiv.org/abs/astro-ph/0304030.

[32] Hodge, J. C. 2003b. Neighboring Galaxies' Influence on Rotation Curve Asymmetry. Presented at 202nd meeting of the AAS, session 40.08. https://www.arxiv.org/abs/astro-ph/0305022.

[33] Hodge, J. C. 2006c. Scalar potential model of spiral galaxy HI rotation curves and rotation curve asymmetry. http://www.arxiv.org/PS_cache/astro$\mathrm{ph} / \mathrm{pdf} / 0611 / 0611029 \mathrm{v} 2 . \mathrm{pdf}$.

[34] Hodge, J. C. 2006d. Scalar potential model of galaxy central mass and central velocity dispersion. http://www.arxiv.org/PS_cache/astro$\mathrm{ph} / \mathrm{pdf} / 0611 / 0611699 \mathrm{v} 1 . \mathrm{pdf}$

[35] Hodge, J. C. 2006e. Scalar potential model of the Pioneer Anomaly. http://www.arxiv.org/PS_cache/astro-ph/pdf/0602/0612567v1.pdf.

[36] Hodge, J. C. 2013a. Pioneer Anomaly predictions confirmed. http://intellectualarchive.com/?link=item\&id=1088.

[37] Hodge, J. C. 2015a. Single Photon diffraction and interference. IntellectualArchive, v. 4 (4), 1-11. http://intellectualarchive.com/?link=item\&id=1557

[38] Hodge, J. C. 2015b. Diffraction experiment and its STOE photon simulation program rejects wave models of light. IntellectualArchive, v. 4(6), 6-16. http://intellectualarchive.com/?link=item\&id=1603.

[39] Hodge, J.C., 2016d. Hodge Experiment distinguishes between wave and particle caused diffraction patterns, IntellectualArchive, v. $5(3)$, P. $7==10$, http://intellectualarchive.com/?link=item\&id=1712.

[40] Hodge, J. C., 2016e. STOE assumptions that model particle diffraction and that replaces $Q M$, IntellectualArchive, v.5(3), P. 1-6, http://intellectualarchive.com/?link=item\&id=1719.

[41] Hodge, J. C., 2017d. Hodge experiment (continued) with opaque strips and about the Afshar Experiment, IntellectualArchive, v.6(5), P. 7-18, http://intellectualarchive.com/?link=item\&id=1872.

[42] Hodge, J. C., 2017e. STOE simulation of photon spectrographic behavior, IntellectualArchive, v.6(6), P. 1-6, http://intellectualarchive.com/?link=item\&id=1884. 


\section{REFERENCES}

[43] Hodge, J. C. 2019e. Interference Experiment with a transparent Mask Rejects Wave Models of Light, Optics and Photonics Journal, v.9(6). DOI: 104236/opj.2019.96008. http://www.scrip.org/journal/paperinformation.aspx?paperid=93056.

See video: https://www.youtube.com/watch?v=A07bogzzMEI

[44] Hodge, J. C. 2018b. STOE electric charge. IntellectualArchive, v. 7 (2), 110. http://intellectualarchive.com/?link=item\&id=1917.

[45] Hodge, J. C. 2019c. STOE explains "Planet 9" . IntellectualArchive, v. 8 (2), P. 13. http://intellectualarchive.com/?link=item\&id=2089.

[46] Hodge, J. C. 2020a. Sgr.A* effect on Mercury and Trans-Neptune Objects. IntellectualArchive, v.9(1), P. 11. http://intellectualarchive.com/?link=item\&id=2266.

[47] Hodge, J. C. 2019d. STOE explaination for the "ether wind". IntellectualArchive, v.8(2), P. 15. http://intellectualarchive.com/?link=item\&id=2111.

[48] Hodge, J. C. 2019f. Magnetic field evolves to gravity field:1 Repulsion. IntellectualArchive, v.8(3), P. 17. http://intellectualarchive.com/?link=item\&id=2164.

[49] Hodge, J. C. 2019g. Magnetic field evolves to gravity field:2 particles. IntellectualArchive, v.8(3), $\begin{array}{lll}\text { P. } & 30 .\end{array}$ http://intellectualarchive.com/?link=item\&id=2170.

[50] Hodge, J. C. 2019h. Magnetic field evolves to gravity field:3 Electromagnetics. IntellectualArchive, v.8(3), P. 23. http://intellectualarchive.com/?link=item\&id=2193.

[51] Hodge, J. C. 2019i. Magnetic field evolves to gravity field:4 Atomic structure. IntellectualArchive, v. 8(4), P. 30. http://intellectualarchive.com/?link=item\&id=2199.

[52] Hodge, J. C. 2019j. Magnetic field evolves to gravity field:5 Final. IntellectualArchive, v.8(4), $\quad$ P. 37. http://intellectualarchive.com/?link=item\&id=2233.

[53] Hodge, J. C. 2020c. Magnetic field causes the strong and weak nuclear forces and is the GUT force. IntellectualArchive, v.9(3). http://intellectualarchive.com/?link=item\&id=2366. 


\title{
Properties of Composition Geometric Modelling
}

\author{
Kseniia Lysenko, graduate student \\ Viktor Vereshchaga, Doctor of Science, Professor
}

\author{
Bogdan Khmelnitsky Melitopol State Pedagogical University, \\ Melitopol, Ukraine
}

\begin{abstract}
It is indicated that in order to use the original geometric figure in compositional geometric modelling, it is necessary to unify it, that is, to divide it into geometric and parametric components. Examples of unification by drawing up geometric BN-matrices and examples of creating compositional geometric models are given.

Keywords. Compositional geometric modelling, B-figures, unified geometric figure, geometric figure image (GF-image), Baliuby-Naidysh calculus (BN-calculus).
\end{abstract}

Formulation of the problem. The use of compositional geometric modelling $[4,8]$ requires a certain preparation of the initial geometric information, by moving to a unified geometric figure. The process of unification of the original geometric figure is simple, but requires certain methodological explanations. On the examples of one-parameter geometric figures, a technique for unifying a geometric figure using BN-matrices is provided [3].

Analysis of recent research. Recently, point BN-calculus has been developing [3, 5, 6, $7,8,9]$, on the basis of which compositional geometric modelling was created [1], the greatest development of which is shown in the dissertation work of Adonyev Ye. [2]. However, in this work, the main capabilities of the compositional method of geometric modelling were developed, without much detail.

The works [1,2] indicate general provisions for the creation of B-figures [8] using $\mathrm{BN}$-matrices [3]. However, these works do not talk about the unification of the original geometric figure.

This article explains in detail the process of unifying the original geometric figure with its subsequent application to create B-figures in compositional geometric modelling.

Formulation of the goals of the article (problem definition). The purpose of this article is to detail the process of unification of the initial geometric figure and the construction of B-figures in $n$-dimensional $E^{n}$ space in compositional geometric modelling.

Main part. The initial information for compositional geometric modelling is always a geometric figure, represented by an ordered set of points determined by the coordinates of the $n$-dimensional space $E^{n}$ in the global $n$-dimensional coordinate system.

To use a geometric figure in compositional geometric modelling, it is necessary to unify it, that is, turn it into a unified geometric figure, which has two components:

- parametric, which is a configuration and establishes a one-to-one relationship between the points of the original geometric figure; the parametric component is and is written in the form of a geometric $\mathrm{BN}$-matrix parametric; the parametric component reproduces in parametric form the relative position of the points of the original geometric figure;

- geometric, which is the current shape of the geometric figure and defines a changing ordered set of points of the original geometric figure every second. This set is written in the 
form of a point geometric BN-matrix. The geometric component recreates the number and layout of points on the original geometric shape, that is, on the corresponding segment.

The specified process of dividing the initial geometric figure into two components parametric and geometric, which are suitable for use in compositional geometric modelling, will be called the unification of the original geometric figure, and the result obtained will be called a unified geometric figure.

A unified geometric figure is a prototype, which is based on: computer modelling (shaping) of the design of a geometric figure, in which a purposeful gradual change in the geometric component of a unified geometric figure will generate the desired GF-image.

Thus, obtaining the GF-image will be called computer-oriented compositional geometric modelling.

Let us give a scheme of computer-oriented compositional geometric modelling.

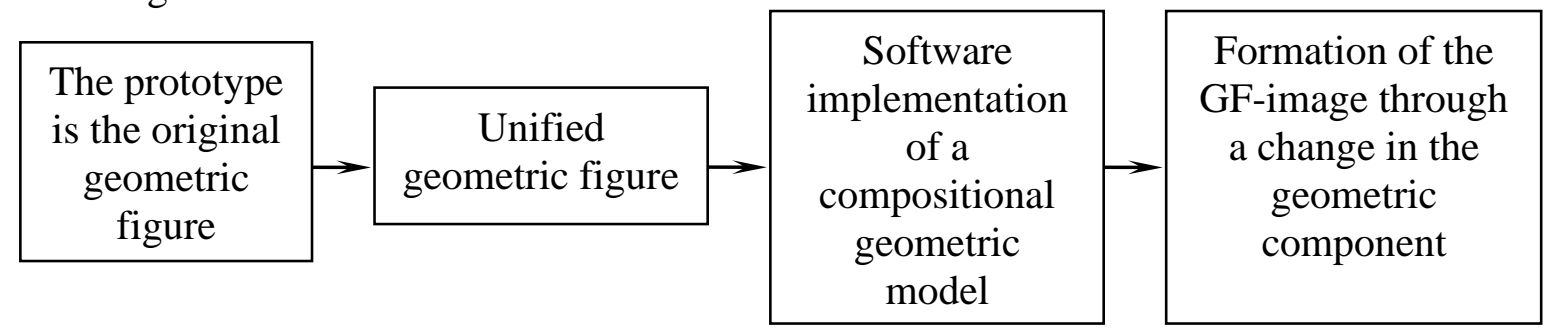

In the above diagram, one must understand:

- "Compositional geometric model" - BN-matrix parametric unified geometric figure;

- the shaping of the GF-image occurs due to computer experiments by purposefully changing the geometric component of a unified geometric figure and analyzing the results obtained in order to achieve the desired shape.

Here are some examples of unification.

1. Let the original geometric figure consist of three points, which represent a discrete curve. Let each of these three points be defined by ten coordinates. This triplet of points in the horizontal $U$ direction defines a discretely fed curve.

Based on the conditions of the problem, the point BN-matrix will look like:

$$
\left(\left(\begin{array}{lll}
A_{11} & A_{12} & A_{13}
\end{array}\right)\right) \text {. }
$$

Point BN-matrix (1) will correspond to ten coordinate BN-matrices-rows, according to the number of coordinates defining each of the initial points, $A_{1 j}$ for $j=\overline{1,3}$.

Let us present (2) the corresponding BN-matrices-rows coordinate:

$$
\begin{aligned}
& \left(\left(A_{11}(1) \quad A_{12}(1) \quad A_{13}(1)\right)\right) ;\left(\left(A_{11}(2) \quad A_{12}(2) \quad A_{13}(2)\right)\right) \text {, } \\
& \left(\left(A_{11}(9) \quad A_{12}(9) \quad A_{13}(9)\right)\right) ;\left(\left(A_{11}(10) \quad A_{12}(10) \quad A_{13}(10)\right)\right) \text {. }
\end{aligned}
$$

For the given example, the parametric BN-matrix will also have the form of a $\mathrm{BN}$ matrix-row:

$$
\left(\left(\begin{array}{lll}
P_{11} & P_{12} & P_{13}
\end{array}\right)\right), \text { where } \sum_{j=1}^{3} P_{1 j}=1,
$$

which will be the same for all coordinate $\mathrm{BN}$-matrices-rows from (2). 
Interpolation curve matrix $\left(M_{\Phi}\right)$ for a discretely submitted curve in the BN-matrix form should be defined as the product of $\mathrm{BN}$-matrices-rows (1) point and (3) parametric:

$$
M_{\Phi}=\left(\left(A_{1 j}\right)\right) \cdot\left(\left(P_{1 j}\right)\right), \text { for } j=\overline{1,3}
$$

or in expanded form:

$$
M_{\Phi}=\left(\left(\begin{array}{lll}
A_{11} & A_{12} & A_{13}
\end{array}\right)\right) \cdot\left(\left(\begin{array}{lll}
P_{11} & P_{12} & P_{13}
\end{array}\right)\right)=\left(\left(\begin{array}{lll}
A_{11} P_{11} & A_{12} P_{12} & A_{13} P_{13}
\end{array}\right)\right) .
$$

Interpolation curve $M$ for a discretely given curve in point form is defined as the sum of the elements of the BN-matrix (4):

$$
M=\sum_{j=1}^{3} A_{1 j} P_{1 j}
$$

Taking into account (2) and (4), we can compose coordinate equations for each of the ten axes:

$$
M(1)=\sum_{j=1}^{3} A_{1 j}(1) \cdot P_{1 j} ; M(2)=\sum_{j=1}^{3} A_{1 j}(2) \cdot P_{1 j} ; \ldots ; M(9)=\sum_{j=1}^{3} A_{1 j}(9) \cdot P_{1 j} ;
$$

$M(10)=\sum_{j=1}^{3} A_{1 j}(10) \cdot P_{1 j}$, where $A_{1 j}(n)$ - coordinate values of three points along the $n^{\text {th }}$ axis.

2. Let the original geometric figure consist of three points, which represent a discretely filed curve in 10-dimensional $E^{10}$ space in the transverse direction $V$ with respect to $U$ (example 1).

In this case, the starting points $A_{1 j}$, for $j=\overline{1,3}$ will be located in a column and the corresponding to this geometric figure $\mathrm{BN}$-matrix-point and parametric will be $\mathrm{BN}$-matrixcolumns.

$$
\left(\left(\begin{array}{l}
A_{11} \\
A_{21} \\
A_{31}
\end{array}\right)\right) .
$$

- BN-matrices are point towards $V$.

$$
\left(\left(\begin{array}{l}
P_{11} \\
P_{21} \\
P_{31}
\end{array}\right)\right) \text {. }
$$

- BN-matrices are parametric (for which $\sum_{i=1}^{3} P_{i 1}=1$ ) towards $V$.

For a point BN-matrix from (7), it is necessary to compose ten BN-matrices coordinate, which will correspond to ten coordinate axes, which will also be in the form of columns: 


$$
\left(\left(\begin{array}{l}
A_{11}(1) \\
A_{21}(1) \\
A_{31}(1)
\end{array}\right)\right)\left(\left(\begin{array}{l}
A_{11}(2) \\
A_{21}(2) \\
A_{31}(2)
\end{array}\right)\right) \cdots\left(\left(\begin{array}{l}
A_{11}(9) \\
A_{21}(9) \\
A_{31}(9)
\end{array}\right)\right)\left(\left(\begin{array}{l}
A_{11}(10) \\
A_{21}(10) \\
A_{31}(10)
\end{array}\right)\right) .
$$

The parametric $\mathrm{BN}$-matrix from (7) for all coordinate $\mathrm{BN}$-matrices (8) will be the same.

Thus, the geometric $\mathrm{BN}$-matrix $M_{\Phi}$ of the original geometric figure is defined as the product of two matrices from (7) and has the form:

$$
M_{\Phi}=\left(\left(\begin{array}{l}
A_{11} P_{11} \\
A_{21} P_{21} \\
A_{31} P_{31}
\end{array}\right)\right) .
$$

Interpolation curve $M$ for a discretely given curve in a point form for the direction $V$, is defined as the sum of the elements of the BN-matrix (9), [2] and has the form:

$$
M=\sum_{i=1}^{3} A_{i 1} P_{i 1} .
$$

Then the projections of the interpolation curve (10) onto each of the ten axes $E^{n}$ of the space will have the form:

$$
M(1)=\sum_{i=1}^{3} A_{i 1}(1) \cdot P_{i 1}-\text { for } 1 \text { st axis; } M(2)=\sum_{i=1}^{3} A_{i 1}(2) \cdot P_{i 1}-\text { for } 2 \text { st axis; } \ldots ;
$$

$M(9)=\sum_{i=1}^{3} A_{i 1}(9) \cdot P_{i 1}-$ for 9st axis; $M(10)=\sum_{i=1}^{3} A_{i 1}(10) \cdot P_{i 1}-$ for 10st axis, where $A_{1 j}(n)$ - coordinate values on the $n^{\text {th }}$ axis.

Conclusions. One of the main features of compositional geometric modelling is the need to create a unified geometric figure, which is a powerful toolkit for the formation of compositional models, contributes to a faster and more efficient shaping of the required geometric figure - decoupling.

As it was shown, the creation of geometric BN-matrices occurs in such a way that their elements are located in full accordance with the location of points on the original geometric figure. The lack of such a match leads to an erroneous solution to the problem.

The use of BN-matrices provides the possibility of fast and error-free obtaining of compositional geometric models and is an effective abbreviated record of point and calculated coordinate forms.

\section{References}

1. Vereshchaha V.M. Kompozytsiine heometrychne modeliuvannia: monohrafiia / V.M. Vereshchaha - Melitopol: FOP Odnoroh T.V., 2017.-108 s.

2. Adoniev Ye.O. Kompozytsiinyi metod heometrychnoho modeliuvannia bahatofaktornykh system: dys..dokt.tekhn.nauk. - K.: KNUBA, 2018. - 512 s. 
3. Adoniev Ye.O., Vereshchaha V.M., Naidysh A.V. Zastosuvannia heometrychnykh matryts dlia utvorennia tochkovykh rivnian B-poverkhon / Ye.O. Adoniev, V.M. Vereshchaha, A.V. Naidysh // Naukovyi visnyk Tavriiskoho derzhavnoho ahrotekhnolohichnoho universytetu. - Melitopol: TDATU, 2018. - Vyp. 8, T.1, s. 153-160.

4. Adoniev Ye.O., Vereshchaha V.M. Kontseptualni zasady vykorystannia kompozytsiinoho metodu heometrychnoho modeliuvannia pry formuvanni optymalnoho portfeliu proektiv $\mathrm{z}$ enerhozberezhennia $\mathrm{v}$ navchalnykh zakladakh. I Suchasni problemy modeliuvannia: zb. nauk. prats - Melitopol: Vydavnytstvo MDPU im. B. Khmelnytskoho, 2017. - Vyp. 9. - S. 3-10.

5. Lysenko K.Iu., Naidysh A.V., Vereshchaha V.M., Adoniev Ye.O. Osnovy kompozytsiinoho heometrychnoho modeliuvannia: navchalnyi posibnyk. MDPU im. B. Khmelnytskoho. - Melitopol, 2019. — 255 s.

6. Lysenko K.Iu., Vereshchaha V.M., Baliuba I.H., Naidysh A.V. Parametryzatsiia bahatovymirnykh heometrychnykh obiektiv metodamy tochkovoho chyslennia Baliuby-Naidysha / Suchasni problemy modeliuvannia: zbirnyk naukovykh prats / MDPU im. B. Khmelnytskoho. - Melitopol, 2019. - Vyp.15. - S. 51-57.

7. Lysenko K.Iu., Naidysh A.V., Vereshchaha V.M., Baliuba I.H. Kompozytsiina interpoliatsiia ploskoi dyskretno podanoi kryvoi / Suchasni problemy modeliuvannia: zbirnyk naukovykh prats / MDPU im. B. Khmelnytskoho. - Melitopol, 2019. - Vyp.14. - S. 113-121.

8. Vereshchaha V.M. Kompozytsiinyi metod utvorennia B-poverkhon / V.M. Vereshchaha, Ye.O. Adoniev // Naukovyi zhurnal «Kompiuterno-intehrovani tekhnolohii: osvita, nauka, vyrobnytstvo». - Lutsk.: Lutskyi natsionalnyi tekhnichnyi universytet - 2017, №26, S. 36-41.

9. Lysenko K.Iu., Vereshchaha V.M., Naidysh A.V. Baliuby-Naidysha interpoliatsiia chotyrokh tochok u ploshchyni / Suchasni problemy modeliuvannia: naukove fakhove vydannia / MDPU im. B. Khmelnytskoho. - Melitopol, 2019. - V.13. - S. 100-105. 


\title{
Innovative Design of Equipment and Tools. Innovative Systems with Elements of Artificial Intelligence and Neural Networks
}

\section{Dmitrii Shekhovtsov}

\begin{abstract}
A set of new and rather unusual conditions and requirements for all stages of design, pre-production and complex production itself, which aims to create the capabilities and specifics of so-called smart production, machines, transport, technologies and smart jobs in all industries, medicine, science, training of specialists and agriculture, make us reconsider the existing order of things and search for new organizational and technical solutions aimed at ensuring compliance with the newly emerged conditions. The author of the publication considers it important to consider this as a model within the sector of the technological field of medical equipment and its accompanying materials and technologies.
\end{abstract}

Keywords: smart production, Artificial Intelligence, medical equipment, neural networks

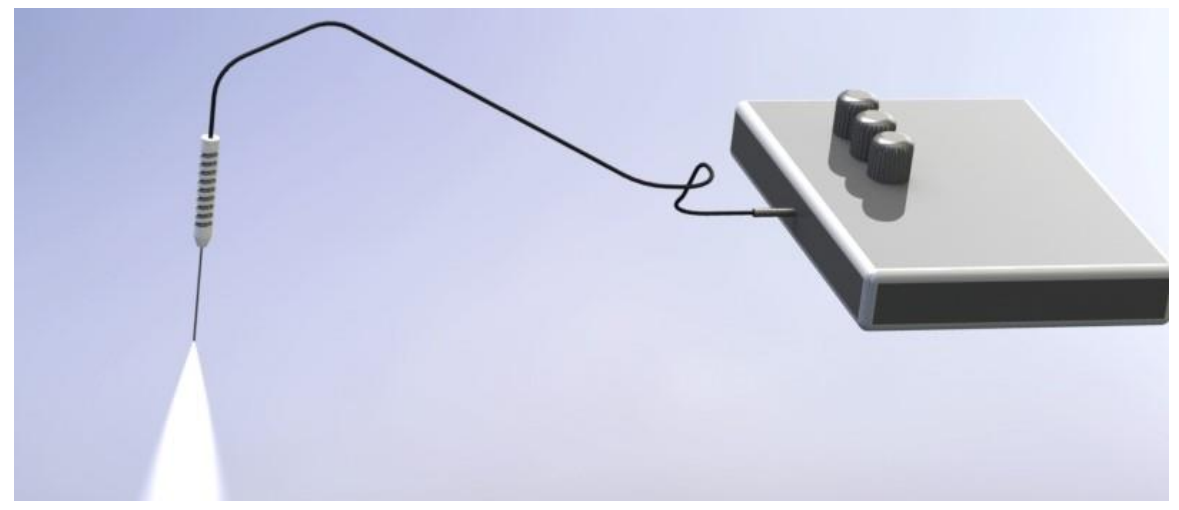

Рисунок 1. Инновационная надсистема комплексного лазерного инструмента для применения в офтальмологии

В системе используется одноразовый инструмент, связанный с источниками лазерного излучения при помощи прецизионного оптического кабеля с инструментом на одном конце и с кодирующим устройством на другом конце, причём в системе в целом применяются люминофоры , задачей которых является получения требуемого спектра излучения одновременно с смягчением влияния лазерного излучения высокой концентрации и интенсивности на физиологические параметры организма пациента.

Надо сказать, что за последнее время созданы инновационные интегративные сочетания передовых эффективных технологий , позволяющих при минимальных производственных затратах, соизмеримых с затратами на обычные носители и накопители информации, создавать надсистемы в которых носителями информации являются терабитные носители и их эквиваленты , причём системные связи носителей 
информации с элементами искусственного интеллекта и искусственными нейронными сетями в корне меняют параметры технических характеристик и технических возможностей надсистем и входящих в них иерархий структур подсистем.

Эти технологии параллельно сформированы группами разработчиков из нескольких стран, включая Японию и Южную Корею.

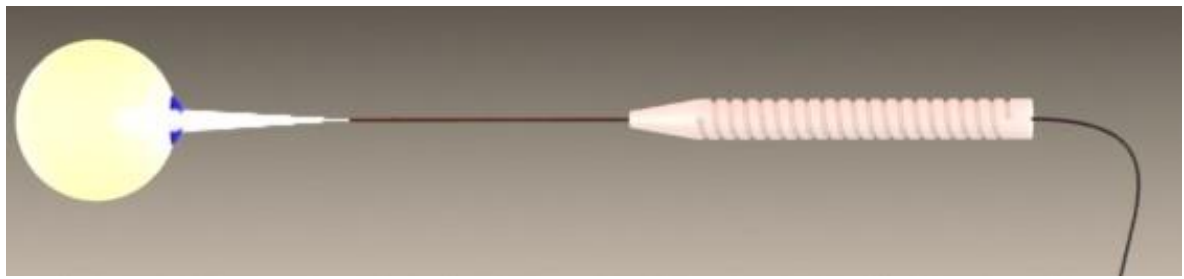

Рисунок 2. Одноразовый лазерный инструмент с схемой излучения в глазное яблоко пациента

На рисунке 2 показан одноразовый лазерный инструмент с схемой излучения в глазное яблоко пациента, у которого было выполнено несколько условий и приёмов оптимизации параметров и спектра излучения. Всё это было выполнено благодаря наличию специальных драйверов и оптических миксеров, позволяющих при использовании трёх лазерных диодов одинаковой мощности получить оптимальный вид, спектр и мощность излучения.

Как видно из рисунка, вследствие использования одноразового инструмента, возникает необходимость предельно точного кодирования для того, чтобы исключить возможность малейших ошибок при настройке и оптимизации параметров излучения, которые могут возникнуть при использовании поддельных одноразовых инструментов не имеющих требуемых параметров настройки и адаптации к условиям проведения операции.

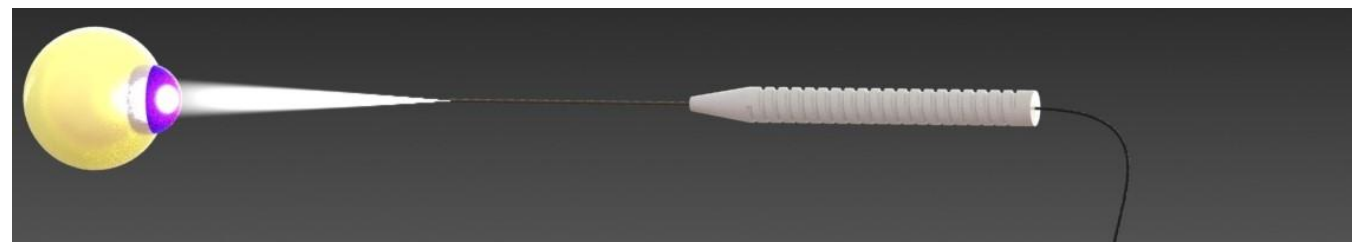

Рисунок 3. Вариант одноразового лазерного инструмента 
На рисунке показан вариант одноразового лазерного инструмента, формирующий, совместно с оптическими компонентами глазного яблока пациента районы оптической аберрации, способствующие более адаптивным включением активного интенсивного лазерного луча в сочетания оптических условий, возникших в обрабатываемом глазном яблоке пациента. Эти варианты оптической интеграции излучения одноразового инструмента инновационной надсистемы комплексного драйвера и других составляющих лазерного инструмента для применения в офтальмологии определены наличием постоянной функциональной связи между процессорами драйверов для каждого из трёх лазерных диодов и между элементами искусственного интеллекта и искусственными нейронными полями.

Показанная компоновочная гибкость во всей надсистеме позволяет при будущих модификациях рассчитывать на уверенное использование в системах управления и контроля также и квантовых компьютеров и их процессорных эквивалентов, возможно и в сочетании или в симбиозе с наиболее продвинутыми вариантами современной компьютерной и процессорной техники, в том числе и с электронными платами , произведёнными по РИТМ технологиям (техника размерного избирательного травления металла ).

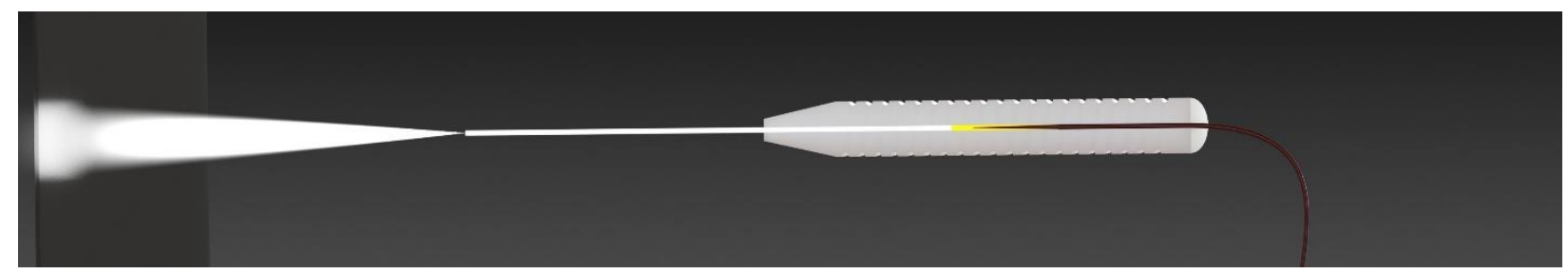

Рисунок 4. Вариант одноразового лазерного инструмента

На рисунке 4 также показан вариант одноразового лазерного инструмента, формирующий совместно с оптическими компонентами глазного яблока пациента районы оптической аберрации, способствующие более адаптивным включением активного интенсивного лазерного луча в сочетания оптических условий, возникших в обрабатываемом глазном яблоке пациента. Но в этом случае часть роли в комплексном процессе адаптации принимает на себя применение в обработке и покрытии оптического кабеля (волокна) различных видов люминофоров. Эти варианты оптической интеграции 
излучения одноразового инструмента инновационной надсистемы комплексного драйвера и других составляющих лазерного инструмента для применения в офтальмологии определены также дополнительным фактором влияния свойств и возможностей люминофора в сочетании с наличием постоянной функциональной связи между процессорами драйверов для каждого из трёх лазерных диодов и между элементами искусственного интеллекта и искусственными нейронными полями, на которые в данном случае накладывается дополнительная задача по скоростной детальной координации всех факторов формирующих конечную техническую характеристику одноразового инструмента.

Показанная компоновочная гибкость во всей надсистеме позволяет при будущих модификациях рассчитывать на уверенное использование в системах управления и контроля также и квантовых компьютеров и их процессорных эквивалентов с уже сегодня доказанным сверхвысоким быстродействием, возможно и в сочетании или в симбиозе с наиболее продвинутыми вариантами современной компьютерной и процессорной техники, в том числе и с электронными платами, произведёнными по РИТМ технологиям ( техника размерного избирательного травления металла ), которые только за счёт своей конструкции и, особенно за счёт расстояния между слоями печатной платы всего в 50 микрон, увеличивают быстродействие и скорость реакции в сотни раз.

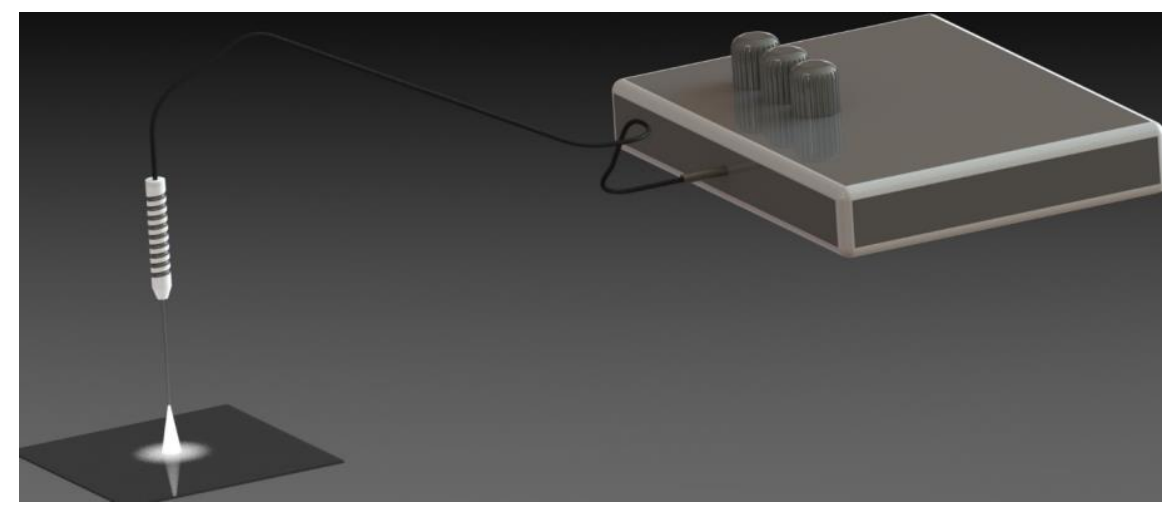

Рисунок 5. Инновационная надсистема комплексного лазерного инструмента для применения в офтальмологии 


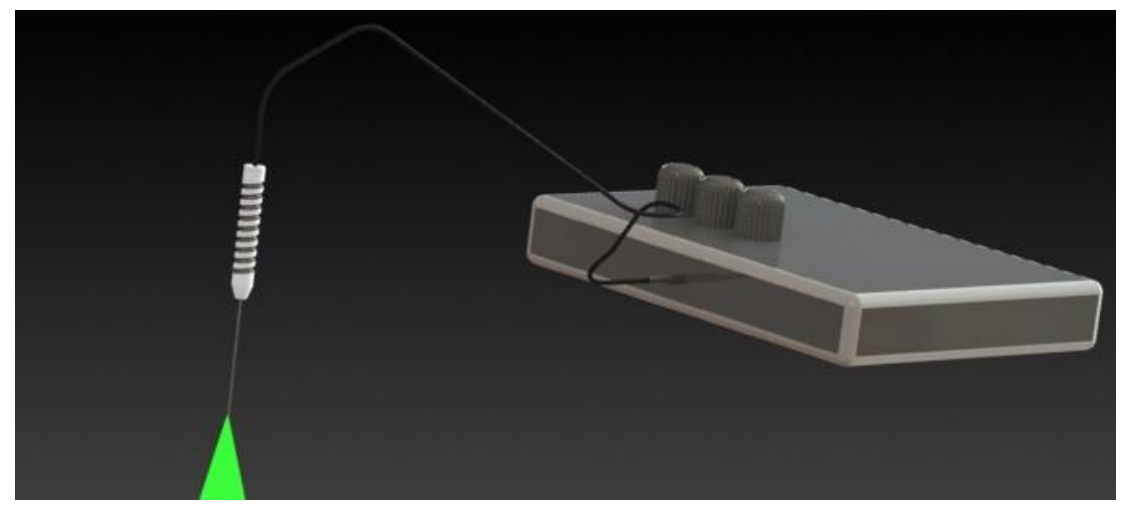

Рисунок 6. Инновационная надсистема комплексного лазерного инструмента для применения в офтальмологии

На рисунках 5 и 6 показана инновационная надсистема комплексного лазерного инструмента для применения в офтальмологии, работающая в режиме настройки и оптимизации параметров излучения. В системе одновременно работают три лазерных диода с различным цветом излучения, а также, как и в других примерах, используется одноразовый лазерный излучающий инструмент, причём этот инструмент, связан с указанными источниками лазерного излучения и их драйверами при помощи прецизионного оптического кабеля с инструментом на одном конце и с кодирующим устройством на другом конце, причём в системе в целом применяются люминофоры, задачей которых является получения требуемого спектра излучения одновременно с смягчением влияния лазерного излучения высокой концентрации и интенсивности на физиологические параметры организма пациента.

Для реализации комплексных решений в области специальных лазерных инструментов, одним из критичных факторов является ёмкость накопителей памяти и быстродействие всей цепочки - накопитель памяти - система управления и контроля исполнительный агрегат. Наличие значительных массивов информации требует также и необходимого уровня надёжности защитных технологий и их надёжной связи с накопителем памяти, в том числе и через элементы искусственного интеллекта и искусственные нейронные сети.

Для продолжения имеет смысл ознакомление с концептуальным решением по защитному кодированию, например оптического диска с инновационной многослойной структурой записи, увеличивающей ёмкость диска в тысячи раз. В качестве основного 
инструмента такой защитной системы выступает оптический диск, на котором нанесено кодирующее покрытие в кольцевой зоне, в которой в обычном диске нет информационной записи. В качестве вспомогательного инструмента выступает микросенсор, который встраивается в дисковод. Сигнал от микро-сенсора формируется при измерении толщины покрытия. Точность измерения - 100 ангстрем, и это величина, на которую отличается каждая группа дисков от другой группы. Сигнал от микро-сенсора является кодом для входа в массивы информации, размещённые в интернете.

Программное обеспечение должно давать возможность идентифицировать сигнал от микро-сенсора и в случае совпадения сигнала с эталонным открывать массивы информации и в процессе её скачивания продолжать контролировать достоверность сигнала до завершения процесса скачивания информации. Это даёт возможность предотвратить замену диска во время записи на нелицензированный. Подделать такой диск невозможно, так как толщина покрытия определяется при изготовлении, и, даже имея такой диск, невозможно им воспользоваться без микро-сенсора, настроенного на строго определённый характер сигнала. Диски и сенсоры могут выпускаться на любом сегодня существующем производстве оптических дисков; диски могут выпускаться сериями по 100 - 250 штук с одинаковой толщиной кодирующей ленты и с комплектом сенсоров. Каждый пользователь может приобрести одну или несколько серий дисков и использовать их при работе с интернетом. По такому же принципу программы и другая информация могут рассылаться пользователям, только в обратном порядке, что гарантирует полную конфиденциальность и защиту при нахождении в интернете от несанкционированных посланий и вирусов.

Это очень общая информация, и если её квалифицируют как заслуживающую внимания, то группа независимых изобретателей могла бы предельно точно детализировать этот проект. Ввиду того, что механическая часть этого проекта в принципе реализована, этот проект - это программное обеспечение, что может быть станет основой нового проекта в этом направлении также и с введением в проект элементов искусственного интеллекта и искусственных нейронных сетей. 


\title{
Strategic Importance of Rapid Identification of Smart Tools and Devices
}

\section{Dmitrii Shekhovtsov}

\begin{abstract}
The overall design of laser and optoelectronic systems has many interrelated elements, of which for the full development and optimization of this kind of technology, it makes sense to consider the following aspects and relationships.
\end{abstract}

Keywords: Smart tools, optoelectronic systems, composite material

В скоростной идентификации заинтересованы значительные массивы техники и технологии, которые в условиях современной инновационной экономики развиваются наиболее интенсивно.

Во-первых, необходимо отметить ускоренное развитие так называемых умных производств, технологий, машин, транспорта, медицины, биологии, промышленности композитных материалов и появление относительно новых направлений, таких как развитие высокоэффективных рабочих мест, развитие методик дистанционного обучения и т.п.

Начало внедрения в ближайшем будущем квантовых компьютеров с их фантастическим быстродействием, а также повсеместное внедрение и полноценное использование элементов искусственного интеллекта и искусственных нейронных сетей существенным образом меняющее границы возможностей инновационных технических решений, требует и соответственной адекватной системы защиты этих решений, начинающейся от системного кодирования одноразовых рабочих инструментов. Кроме того в связи с необходимостью пересмотра структурных форм инновационной экономики в рамках меняющихся условий глобализации, ужесточают и условия для конкуренции и требуют дополнительных защитных (в том числе и кодирующих) технологий, способных быть реализованными в рамках существующих сложившихся структур и процессов без привлечения значительных внешних ресурсов. 


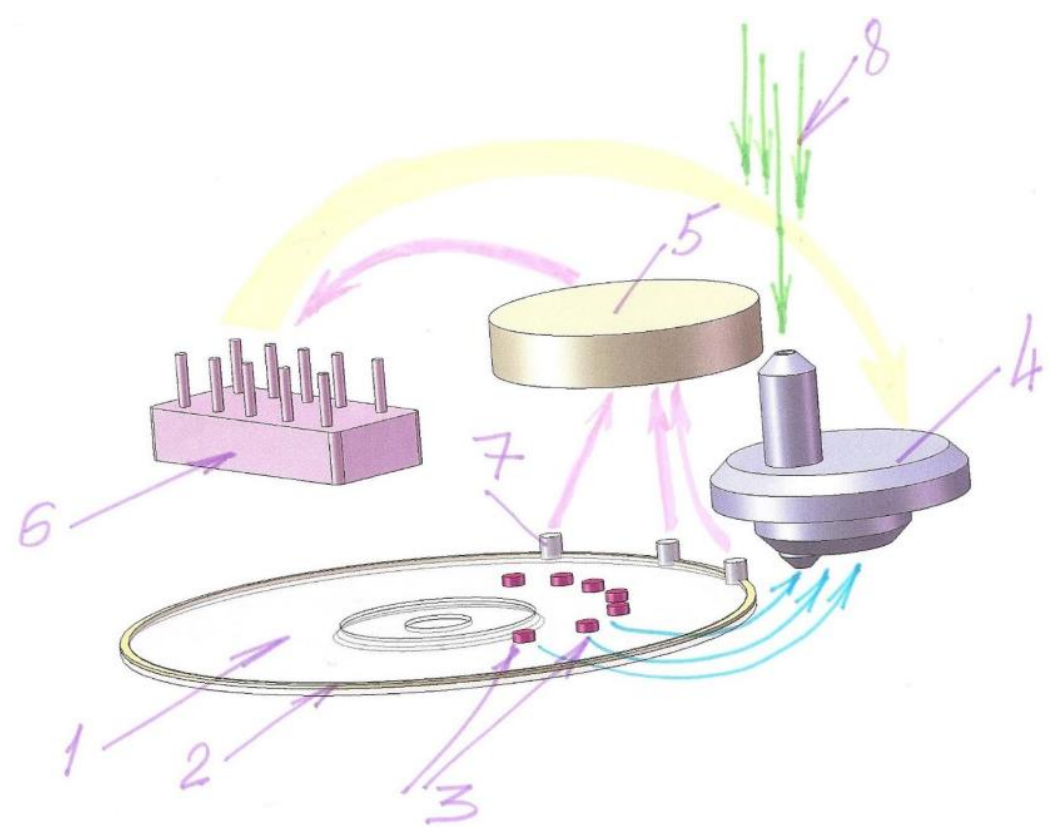

Рисунок 1. Характер взаимодействия компонентов системы идентификации, присущие корпусу модуля лазерного диода

На рисунке 1 показан характер взаимодействия компонентов системы идентификации, присущие корпусу модуля лазерного диода (взаимосвязи показаны стрелками).

Цифрами на рисунке показаны:

1. объект кодирования

2. гальваническое покрытие по наружному диаметру объекта кодирования

3. кодирующие точки по рабочему полю объекта кодирования

4. оптическая головка

5. контрольный и регулирующий процессор

6. драйвер

7. контрольные точки по наружному диаметру объекта кодирования

8. внешний световой поток 


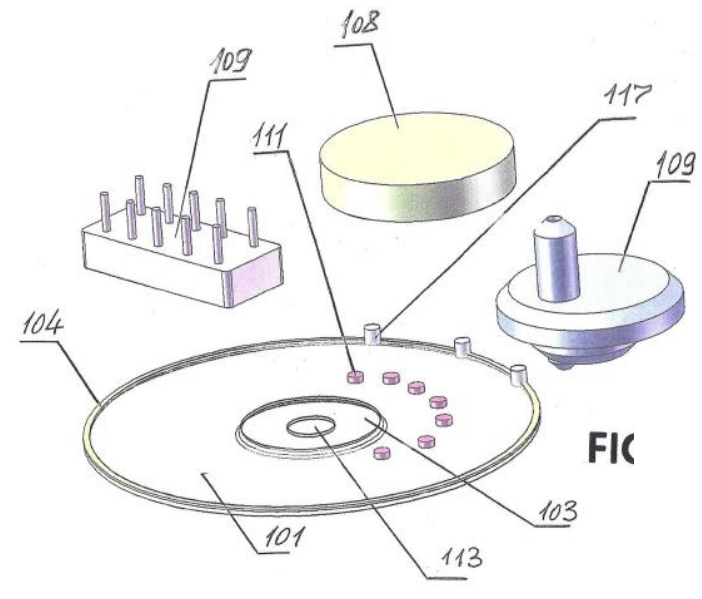

Рисунок 2. Модели компонентов, участвующих в процессе кодирования

На рисунке 2 показаны модели компонентов, участвующих в процессе кодирования. Цифрами на рисунке показаны:

101. объект кодирования, например оптический диск - накопитель памяти

103. центрирующий диск

104. контрольное кольцо

108. контрольный и регулирующий процессор

109. интегральная оптическая головка

111. кодирующие точки

113. посадочное отверстие

117. кодирующие точки

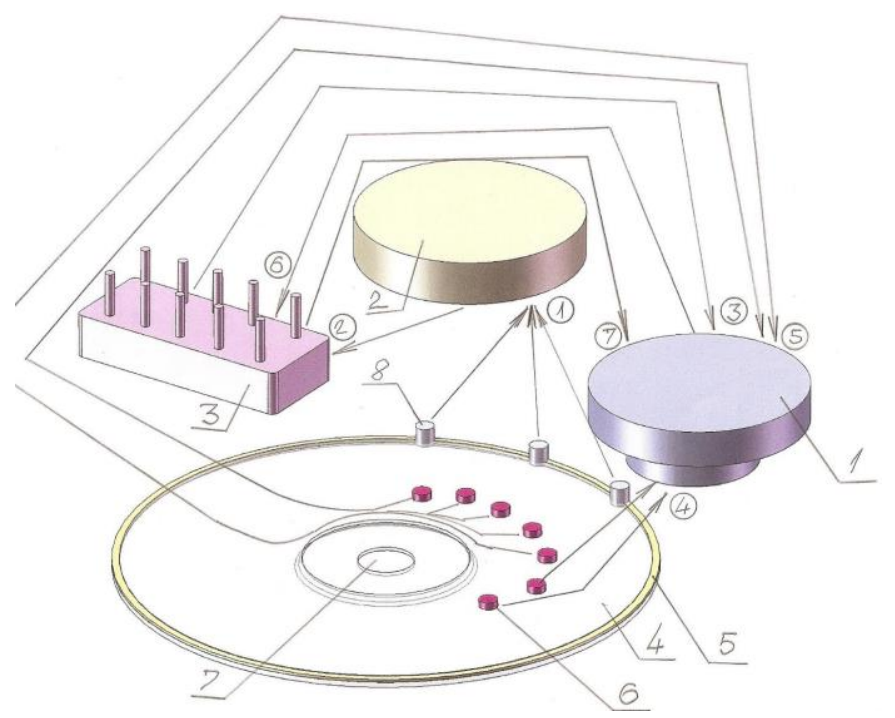

Рисунок 3. Варианты взаимосвязей между компонентами системы кодирования 
На рисунке 3 показаны варианты взаимосвязей между компонентами системы кодирования Цифрами на рисунке показаны:

1. блок оперативного управления и контроля в режиме реального времени

2. параллельный блок оперативного аналитического контроля в онлайн формате

3. драйвер

4. носитель информации

5. информационное кольцо

6. кодирующие цилиндры

7. посадочное отверстие

8. кодирующие цилиндры

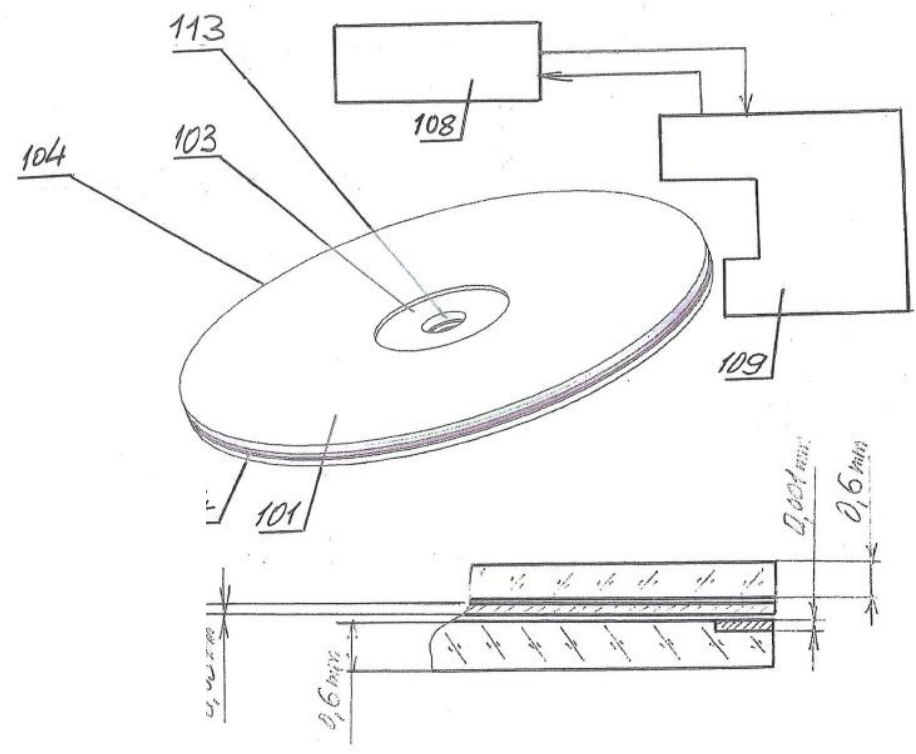

Рисунок 4. Размерные характеристики системы кодирования

На рисунке 4 показаны размерные характеристики системы кодирования. Цифрами на рисунке показаны:

101. многослойный накопитель информации

103. центрирующая расточка

104. кодирующее покрытие

108. система управления и контроля

109. сенсорный модуль

113. посадочное отверстие 
Надёжность в современных комбинированных интегративных устройствах в значительной степени зависит от надёжности поддержания стабильной рабочей температуры, исключающей возникновение излишних термических напряжённостей и не требующей дополнительных энергоресурсов. В условиях усложнения структурных схем устройств и систем управления и контроля, особенно при использовании в них элементов искусственного интеллекта и искусственных нейронных сетей, эти вопросы стали ещё острей.

Наиболее простой путь для решения этого вопроса — это использование исключительно эффективных материалов, рассеивающих тепло без привлечения дополнительных энергетических ресурсов. В этой связи автор предлагает рассмотреть вероятность использования в базовых конструкциях систем капсулированные композиционные конструктивные материалы. Что это за материал? Композитный материал, имеющий высокие теплопроводные свойства, имеющий при этом высокие электропроводные свойства, способный в течении очень коротких промежутков времени воспринять и рассеять значительные количества энергии; воспринять и передать значительные количества энергии на расстояние и имеющий при этом максимальную механическую прочность, обладающий максимальной надёжностью при сохранении точных геометрических форм под воздействием высоких концентраций температур, энергии и других видов вредных экстремальных воздействий.

Формулировка нового композитного материала, как продукта:

- композитный материал, имеющий развитую трёхмерную (объёмную) структуру, состоящую из множества одинаковых многоуровневых сферических оболочек, покрывающих сферические ядра; ядра с оболочками (капсулы) скреплены между собой посредством ряда последовательных технологических операций и имеют эквивалентную для всех капсул структуры форму контакта между собой;

- композитный материал имеет свойства сверх теплопроводности и сверхэлектропроводности;

- композитный материал имеет высокую механическую прочность, не склонен к возникновению внутренних механических и температурных напряжений и как следствие этих явлений, - возникновению внутренних деформаций; 
- композитный материал способен подвергаться воздействию высоких давлений и способен под воздействием этих давлений по крайней мере для части компонентов входить в режим хладно-текучести, что позволяет калибровать трёхмерную геометрическую форму структуры и обеспечивать с высокой степенью повторяемости очень точные геометрические размеры структуры;

Вариант коммерческого названия предложенного продукта как материала:

- композитный материал, являющийся одновременно проводником электрического тока и эффективным проводником тепла, имеющий развитую трёхмерную токопроводящую структуру, с равномерно распределёнными в ней узлами (микросферами) , точками максимальной теплопроводности, не являющимися проводниками электрического тока (то есть выполненными из материала с максимально возможной теплопроводностью, например алмаза, у которого коэффициент теплопередачи равен 1200, и который не является проводником электрического тока). Материал имеет вид трёхмерной решётки в узлах которой расположены алмазные сферы, которые являются лучшим из известных проводников тепла, отделённые в трёхмерном пространстве структуры друг от друга медными оболочками, являющимися отличным проводником и также проводником тепла.

Таким образом для электрического тока (наиболее важно для тока в импульсном режиме) композитная структура является неким псевдо-губчатым или псевдо-пористым объёмом, так как по всему указанному объёму токопроводящего материала, равномерно распределены диэлектрические сферические пространства, соизмеримые по размерам с размерами токопроводящего пространства.

Этот факт способствует достаточно быстрому и равномерному рассеиванию тока с одной стороны и быстрому, эффективному. равномерному рассеянию тепла с другой стороны. В качестве материала для оболочек предусмотрены самые пластичные из известных материалов, например - медь или серебро, которые обладают и максимальной из известных материалов электропроводностью; при воздействии высоким давлением в замкнутом объёме, указанные металлы возможно довести до состояния хладно-текучести.

При условии приложения высокого давления в трёхмерном замкнутом объёме, характер и форма взаимодействия между капсулами в структуре модифицируются, что 
позволяет формировать изделия с необходимыми техническими и технологическими кондициями, которые невозможно получить при применении обычных технологий.

Вариант названия и определения технологии производства, рассматриваемого композитного материала:

Метод изготовления псевдо-губчатого или псевдо-пористого композитного материала, представляющего собой множество нано-капсул, скреплённых между собой в трехмерную структуру, которая обработана на завершающей стадии изготовления,объёмной пластической калибрующей деформации в режиме хладно-текучести для материала пластичных оболочек нано-капсул. В качестве примера использования такого композитного материала, можно рассмотреть упаковку и корпус полупроводникового лазера (лазерного диода). Для примера можно рассмотреть лазерный диод с мультилучевым излучением и выходной оптической мощностью в 1 ватт.

Для управления работой аналогичного диода необходимо для получения выходной мощности в 1 ватт подать как минимум 1 Ампер тока. Напряжение, с учётом внутреннего сопротивления самого лазерного диода и управляющей электронной системы составит как минимум- 2 вольта. Таким образом общая потребляемая мощность составит 2 ватта, при реальной выходной мощности в 1 ватт. Коэффициент потерь мощности 50\% - это лучший показатель, известный на сегодня. То есть наименее нагруженный лазерный диод с мульти лучевым излучением (сечение луча составляет 300 микрон х 1-3 микрона) нуждается в рассеивании 1 ватта энергии. Стандартный корпус для такого типа диодов имеет обозначение SOT-148 и диаметр его монтажного фланца составляет 9 мм. Для того, чтобы рассеять такое громадное удельное количество тепла и нужен композитный материал, способный от гетероструктуры лазерного диода, размеры которой не превышают размеров стандартного объекта, полупроводникового кристалла интегральной схемы отвести тепло, возникающее от преобразования в тепло энергии мощностью в 1 ватт.

Проблема является гораздо более острой при необходимости отвести тепло от одно - лучевого диода, так как у такого типа диодов сечение луча представляет собой окружность диаметром не более 0,6 микрона. В этом случае концентрация энергии ещё более высокая и функция отвода и рассеивания тепла становится ещё более важной. Учитывая тот факт, что только для нужд всевозможных видео систем, систем 
оптической памяти, оптических накопителей памяти к персональным компьютерам и тому подобным изделиям необходима система лазерных источников света, в различных областях спектра, количество лазерных диодов, только для этих нужд составляет в год более 100 миллионов штук, при цене лазерного диода мощностью в 1 ватт более $\$ 1000$.

В основной массе сегодня оптическая мощность применяемых лазерных диодов составляет приблизительно 80 милливатт, однако для работающих в красном диапазоне спектра и одно - лучевых это не предел, так что применение нового эффективного композита является исключительно актуальным.

Предлагаемый композитный материал после завершения всех операций по его изготовлению , приобретает вид законченной геометрической структуры, например,призмы , которую необходимо рассматривать как токопроводящий объект, в объёме которого равномерно распределены диэлектрические сферы, изготовленные из синтетических алмазов. Сечение такого проводника достаточно велико, и благодаря развитой объёмной структуре, у такого проводника невысокое электрическое сопротивление. Поскольку в объёме проводящей электрический ток структуры имеются вкрапления из алмазных зёрен (сфер), которые не являются проводником тока, ток огибает эти зоны в теле структуры и проходит только в проводящий электрический ток объём. Такая схема рассеивания или распределения тока по относительно большому сечению позволяет резко снизить потери и ускорить прохождение тока.

В случае с необходимостью рассеять тепло, псевдо-пористая структура представляет собой узлы специфической решётки в узлах которой расположены алмазные сферы, термическое сопротивление которых в 4-5 раз ниже чем в целом по структуре, поэтому тепло устремляется в узлы указанной решётки и это обеспечивает очень быстрый отток( рассеивание ) тепла от источника его возникновения. То есть в обоих случаях создаётся феномен пятнистого трёхмерного распределения зон с различными удельными коэффициентами теплопроводимости и электрической проводимости. Кроме этого, размеры капсул в масштабе нанометров и финишная пластическая деформация в режиме хладно-текучести, позволяют значительно уменьшить зазоры между капсулами, что повышает эффективность отбора и рассеивания тепла и токовых импульсов. Расчётный и ожидаемый эффект при рассеивании тепла в 4-5 раз превышает самые лучшие показатели в существующих 
технических решениях. Виду того , что предлагаемое техническое решение затрагивает и может быть применено в целом ряде технологических направлений в самых разных сферах, для защиты указанного технического решения ,- так называемой базовой технологии, представляется целесообразным оформить базовый заявочный материал на патент, который необходимо выполнить в как можно более общей форме, применяя общие определения. По мере разработки аппликаций технологии и расширения области её применения, предусмотрен выпуск дополнительных патентных аппликаций.

Основные цели преследуемая и поставленная в базовом изобретении:

-повышение уровня эффективности материала в части теплопроводности и рассеивания тепла, скорости отвода тепла от источников нагрева и надёжности процесса отбора и утилизации тепла в течении длительной работы объекта, в котором стабилизируется уровень температурных пульсаций;

-повышение уровня эффективности материала в части электропроводности и рассеивания тока; исключения потерь тока при прохождении через структуру и надёжности процесса прохождения и рассеивания тока в течении длительного периода работы;

Технические решения, которые применяются для достижения целей:

-уменьшение диаметра капсул до минимума, позволяемого технологией их производства, (чем меньше, тем эффективнее);

-калибровка геометрической формы структуры за счёт пластической деформации оболочек капсул в режиме хладно-текучести; это уменьшает объём пустот в промежутках между капсулами, снижает электрическое и термическое сопротивление, улучшает механические характеристики структуры и удаляет внутренние напряжения в трёхмерной иерархии структуры.

Пример применения композитного материала в составе: бериллий - алюминий, магний - алюминий. Из этих композитов возможно изготовление основ жёстких магнитных дисков для накопителей памяти ЭВМ. Такие диски, благодаря своим техническим характеристикам, имеют возможность работать при частоте вращения до более чем 20000 RPM.

Эти материалы открывают новые возможности и в:

- создании гибридных дисков; 
- технологиях покрытий в микроэлектронике;

- создании активирующих присадок для топлива;

- процессах изготовления особо важных узлов и деталей.

Технология изготовления капсул предусматривает предельно точные размеры и предельные отклонения микросфер из синтетического алмаза, а также предельно точные размеры толщины покрытия на сферах полученного методами вакуумного напыления. Для однородного режима прессования по всему объёму требования одинаковых исполнительных размеров капсул является критичным.

Таким образом предельные отклонения размеров капсул определяют в дальнейшем при опрессовке в прессформе предельные отклонения центров микросфер из синтетического алмаза в структурной решётке пластины из указанного композитного материала.

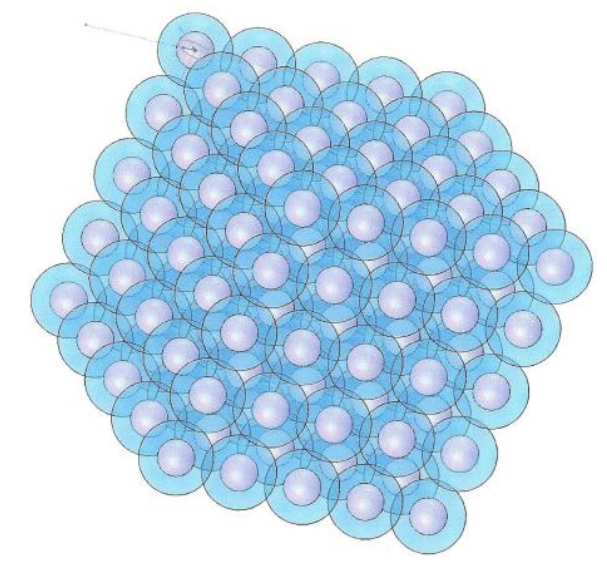

Рисунок 5. Загрузка капсул в прессформу перед опрессовкой в режиме хладнотекучести (микросферы из синтетических алмазов серого цвета, оболочки из пластичного металла голубого цвета)

\section{A list of references, patent and licensing information}

1. Smart absorbent article, components, and process of making [Electronic resource]: pat. US 20190167489 / Hellmold, Jens - Publ. date 06.06.2019. - Mode of access:http://appft.uspto.gov/netacgi/nphParser?Sect1=PTO1\&Sect2=HITOFF\&d=PG01\&p $=1 \& \mathrm{u}=\%$ 2Fnetahtml\%2FPTO\%2Fsrchnum.html\&r=1\&f=G\&l=50\&s 1=\%2220190167489\% 22.PGNR.\&OS=DN/20190167489\&RS=DN/20190167489. - Date of access: 18.09.2020.

2. Smart absorbent article, components, and process of making [Electronic resource]: pat. US 20190167489 / Hellmold, Jens - Publ. date 06.06.2019. - Mode of access:http://appft.uspto.gov/netacgi/nphParser?Sect1=PTO1\&Sect2=HITOFF\&d=PG01\&p 
$=1 \& \mathrm{u}=\% 2 \mathrm{Fnetahtml} \% 2 \mathrm{FPTO} \% 2 \mathrm{Fsrchnum} . \mathrm{html} \& \mathrm{r}=1 \& \mathrm{f}=\mathrm{G} \& \mathrm{l}=50 \& \mathrm{~s} 1=\% 2220190167489 \%$ 22.PGNR.\&OS=DN/20190167489\&RS=DN/20190167489. - Date of access: 18.09.2020.

3. Methods and system for managing intellectual property using a blockchain [Electronic resource]: pat. US 20180285996 / Moses T. Ma - Publ. date 04.10.2018. - Mode of access: http://appft.uspto.gov/netacgi/nphParser?Sect1=PTO1 $\&$ Sect $2=\mathrm{HITOFF} \& \mathrm{~d}=\mathrm{PG} 01 \& \mathrm{p}=1 \& \mathrm{u}=\% 2 \mathrm{Fnetahtml} \% 2 \mathrm{FPTO} \% 2 \mathrm{Fsrchnum} . \mathrm{html} \& \mathrm{r}=1 \& \mathrm{f}=\mathrm{G} \&$ $\mathrm{l}=50 \& \mathrm{~s} 1=\% 2220180285996 \% 22 . \mathrm{PGNR} . \& O S=\mathrm{DN} / 20180285996 \& \mathrm{RS}=\mathrm{DN} / 20180285996$. Date of access: 18.09.2020 


\title{
Application of Systems for Complex Integrative Automatic Assembly of Electronic Components Super Systems and Subsystems with Pre-Stamping of Incoming Parts and Elements
}

\author{
Dmitrii Shekhovtsov
}

\begin{abstract}
An essential part of any production process is to actively monitor the parameters of these processes in real time. The most promising method of active real-time monitoring is non-contact monitoring or monitoring in the mode of electromagnetic resonance spectroscopy. Since these methods are fundamentally new and are only being implemented in technological processes, it makes sense to consider them in more detail.

Keywords: non-contact monitoring, electromagnetic resonance spectroscopy
\end{abstract}

В современном производстве изготовление качественных компонентов систем оборудования является залогом финального качества надсистемы.

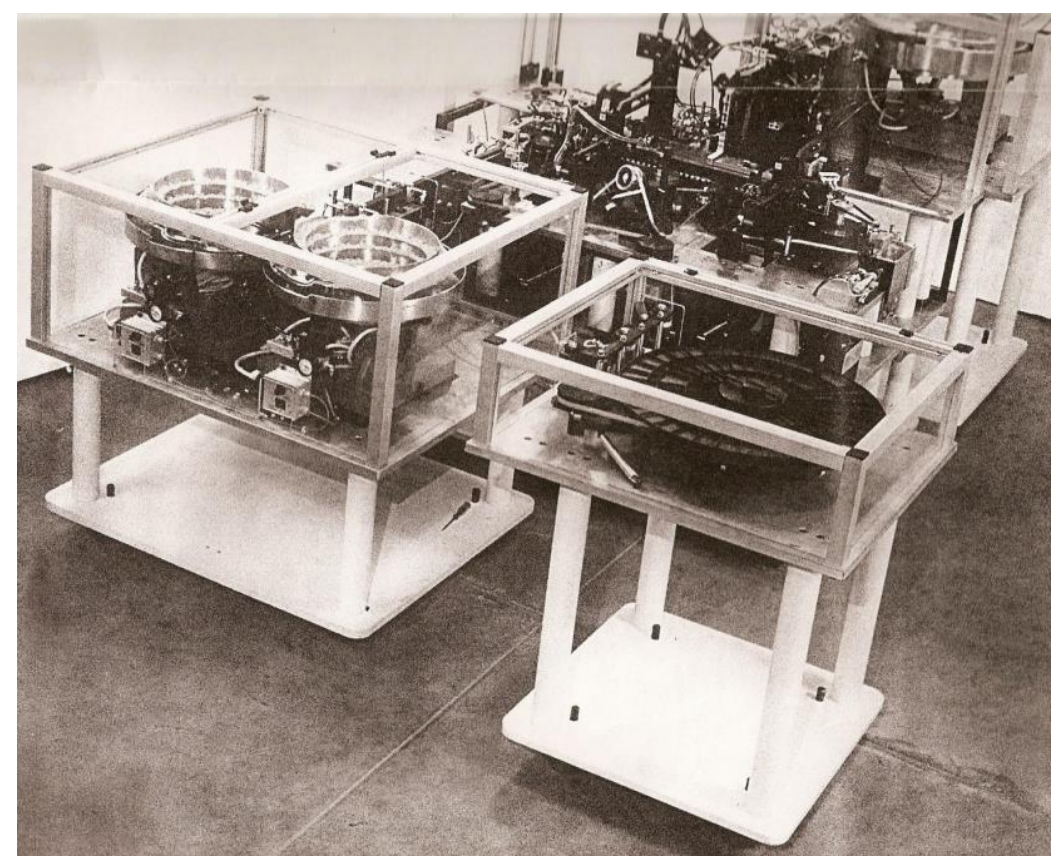

Рисунок 1. Автоматический производственный комплекс для изготовления, сборки и испытаний (контроля качества и работоспособности) контактных систем связи

Исходные технические требования контактных систем требуют, чтобы практически размерные параметры узлов и деталей контактных систем не отличались.

Такое требование заставляет применить соответствующий метод производства и сборки контактных систем, то есть штамповку входящих деталей (все размеры на всех штампованных деталях полностью идентичны) и передачу штампованных деталей на конвейер сборки автоматического производственного комплекса. 
Автоматический производственный комплекс построен таким образом, что штамповка деталей, включая пружинные контакты, ведётся на автономных установках, связанных конвейерами с центральным конвейером сборки и контроля (находится в центре производственной системы, показанной на рисунке).

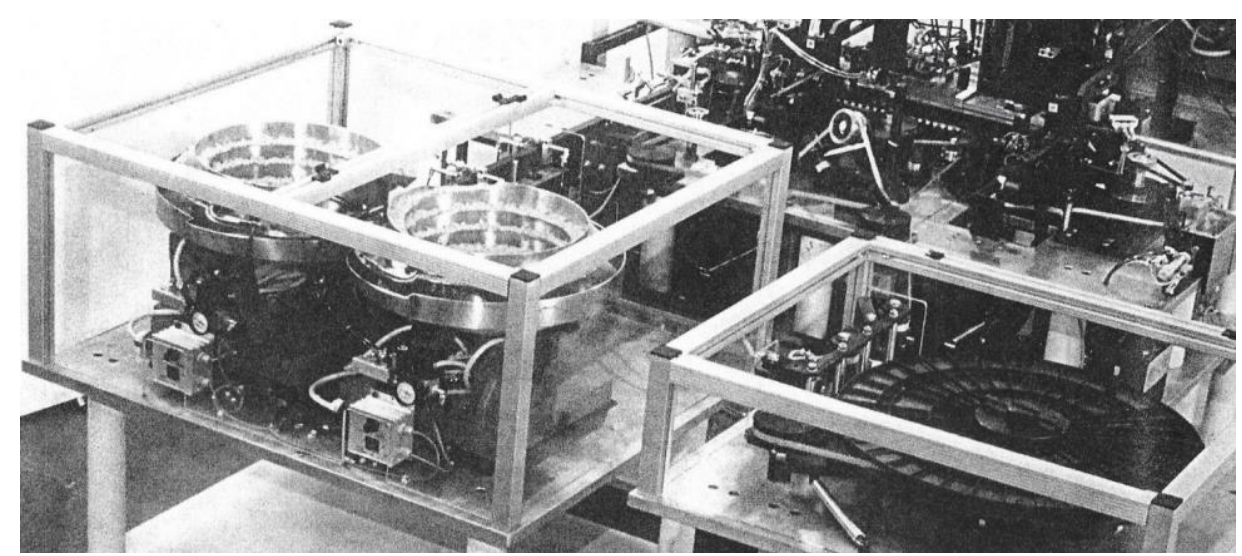

Рисунок 2. Автоматический производственный комплекс для изготовления, сборки и испытаний (контроля качества и работоспособности) контактных

\section{систем связи}

Как видно из рисунка, для штамповки деталей применяется автоматизированная технология штамповки из пружинной ленты, а для металлических деталей, полученных литьём под давлением, и для пластиковых деталей, полученных литьём на термопластавтоматах, применяются специальные бункера, откуда детали по локальным конвейерам поступают на центральный сборочный конвейер системы.

Рассмотрим применение в системах микроавтоматики микродвигателей, высокомоментных и при этом работающих на базе принципов обратного пьезоэлектрического эффекта.

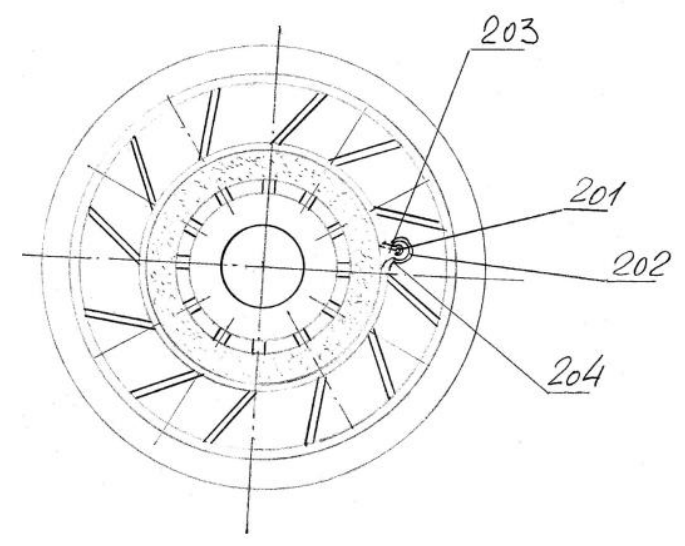

Рисунок 3. Пьезоэлектрический двигатель 
На рисунке 3 показан пьезоэлектрический двигатель в радиальном поперечном сечении. Цифрами на рисунке обозначены:

201. ось замка, фиксирующего упругую ленту с профилированными рабочими лепестками на наружном диаметре пьезокерамического кольца

202. элементы дизайна пружинного замка, фиксирующего и ориентирующего упругую ленту с профилированными рабочими лепестками на наружном диаметре пьезокерамического кольца

203. элементы дизайна пружинного замка, фиксирующего и ориентирующего упругую ленту с профилированными рабочими лепестками на наружном диаметре пьезокерамического кольца

204. элементы дизайна пружинного замка, фиксирующего и ориентирующего упругую ленту с профилированными рабочими лепестками на наружном диаметре пьезокерамического кольца

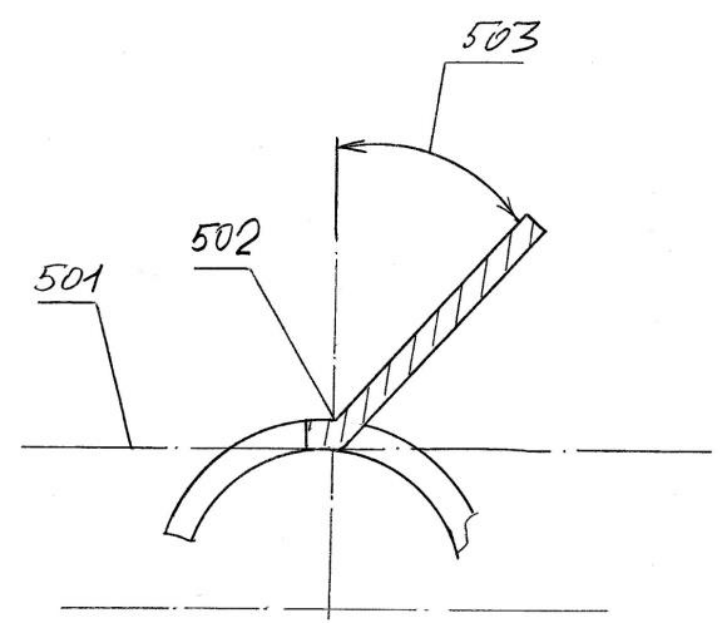

Рисунок 4. Фрагмент формирования рабочего лепестка пружинной ленты двигателя

На рисунке 4 показан фрагмент формирования рабочего лепестка пружинной ленты двигателя. Цифрами на рисунке обозначены:

501. ось поворота плоскости упругого профилированного рабочего лепестка 502. внешний радиус поворота

503. угол изгиба ленты у основания рабочего лепестка по отношению к вертикальной плоскости 


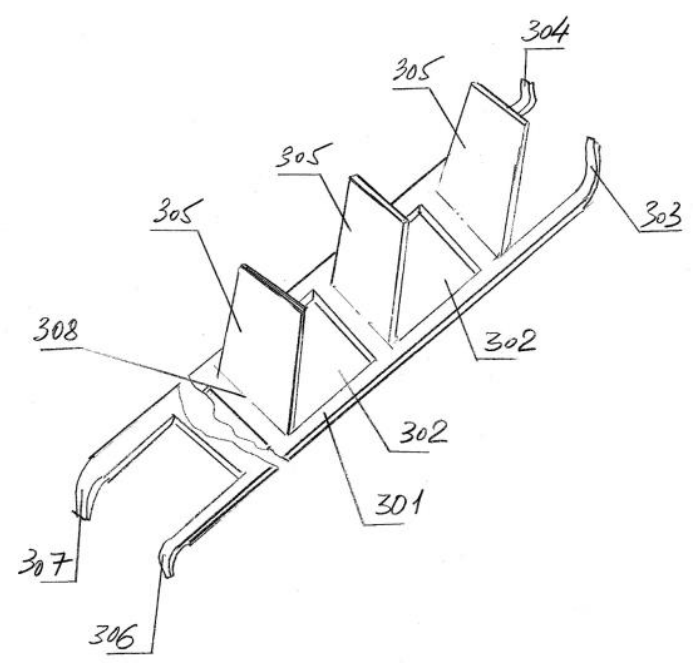

Рисунок 5. Пружинная лента пьезоэлектрического двигателя с рабочими лепестками

На рисунке 5 показана пружинная лента пьезоэлектрического двигателя с рабочими лепестками. Цифрами на рисунке обозначены:

301. пружинная лента, которая обжимается на пьезокерамическом кольце

302. окно в пружинной ленте, оставшееся после вырубки контура рабочих лепестков

303. концы пружинной ленты при сборке на пьезоэлектрическом керамическом кольце формирующие пружинный замок

304. концы пружинной ленты при сборке на пьезоэлектрическом керамическом кольце формирующие пружинный замок

305. рабочие лепестки

306. концы пружинной ленты при сборке на пьезоэлектрическом керамическом кольце формирующие пружинный замок

307. концы пружинной ленты при сборке на пьезоэлектрическом керамическом кольце формирующие пружинный замок

308. внешний радиус поворота рабочего лепестка 


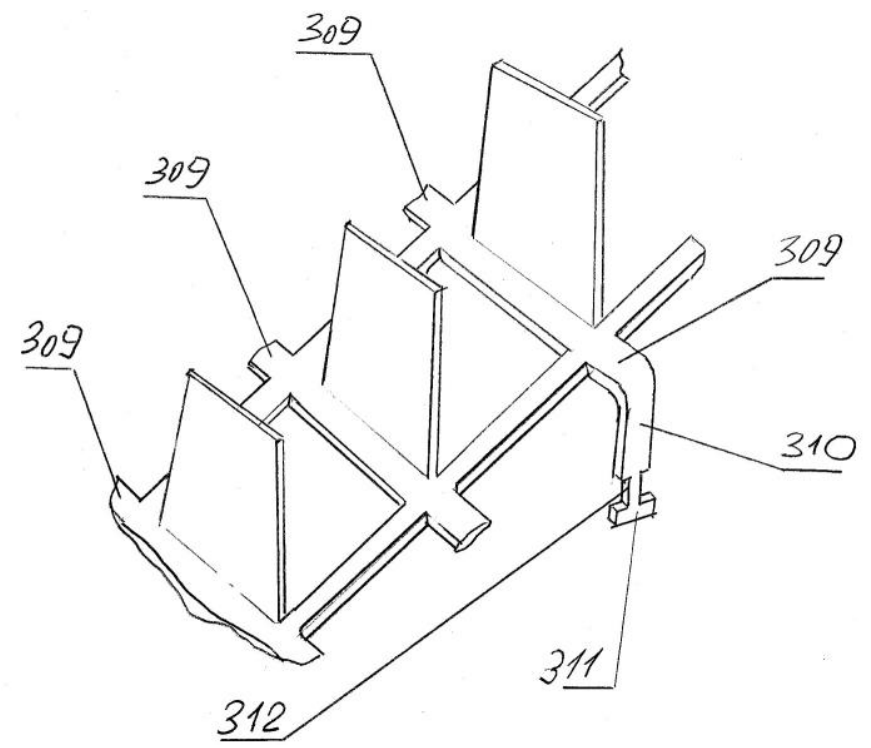

Рисунок 6. Фрагмент пружинной ленты пьезоэлектрического двигателя с рабочими лепестками

На рисунке 6 показан фрагмент пружинной ленты пьезоэлектрического двигателя с рабочими лепестками. Цифрами на рисунке обозначены:

309. дистанционные элементы пружинной ленты

310. элементы пружинного замка

311. элементы пружинного замка

312. элементы пружинного замка

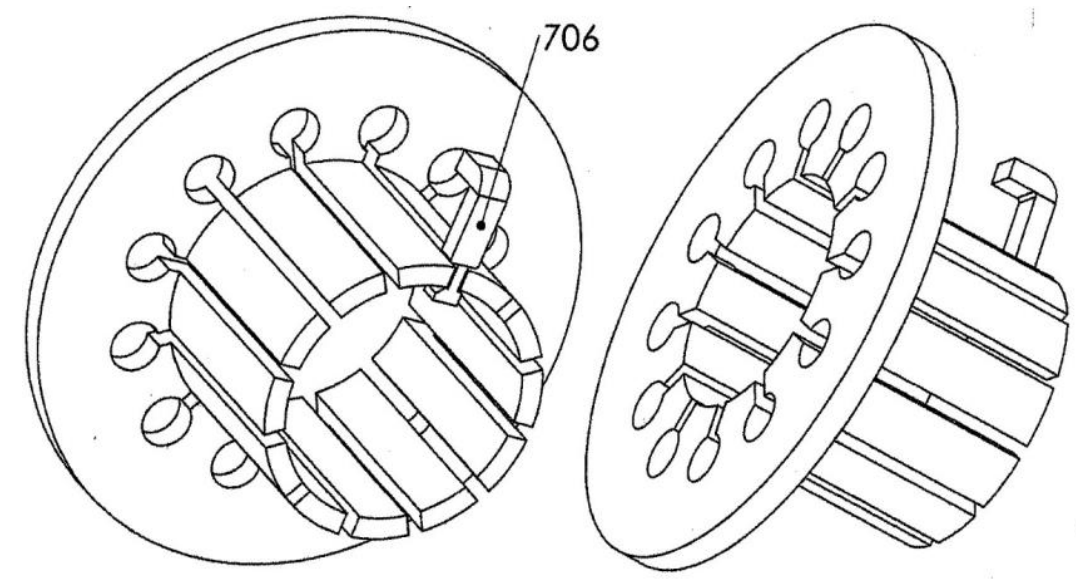

Рисунок 7. Пружинная ось пьезоэлектрического двигателя 


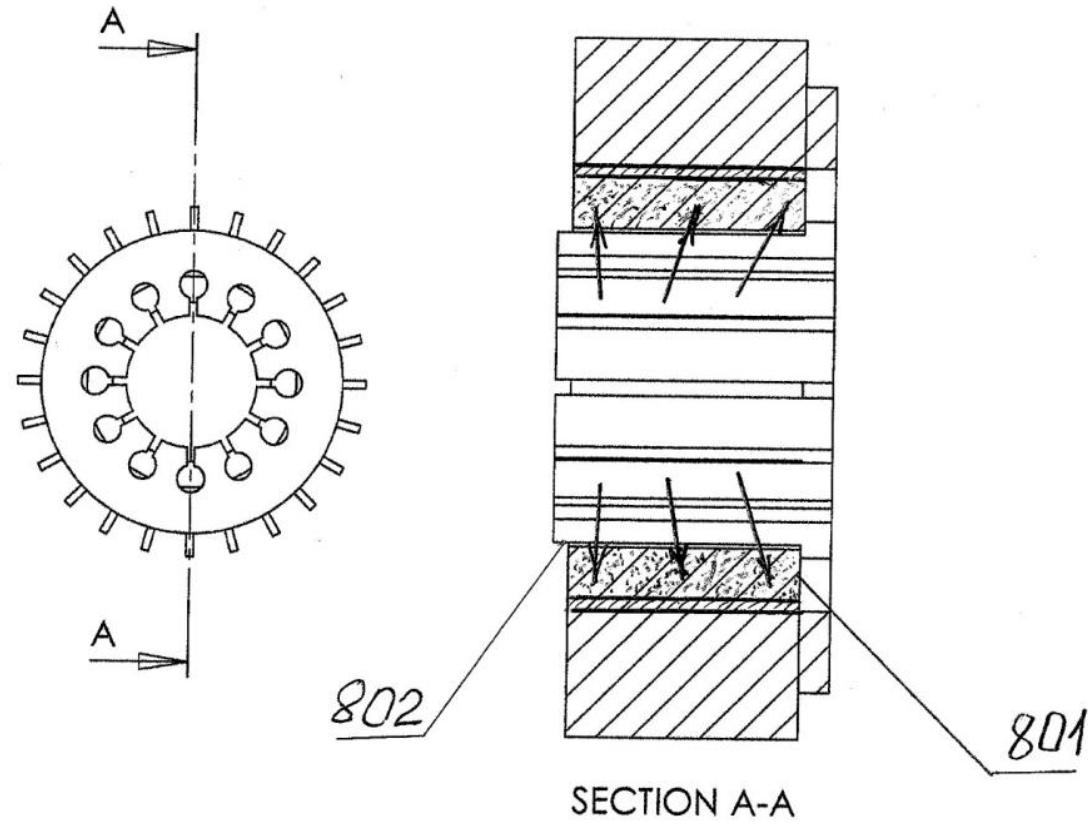

Рисунок 8. Фрагмент пьезоэлектрического двигателя

На рисунке 8 показан Фрагмент пьезоэлектрического двигателя. Цифрами на рисунках обозначены:

706. элементы пружинного замка

801. торец пьезоэлектрического кольца

802. взаимодействие пружинной оси с пьезоэлектрическим кольцом

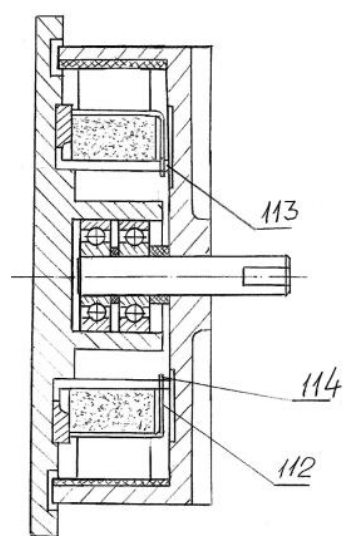

\section{Рисунок 9. Пьезоэлектрический двигатель в осевом сечении}

Цифрами на рисунке обозначены:

112. элементы фиксирующего дистанционного кольца пружинной ленты с рабочими лепестками

113. элементы фиксирующего дистанционного кольца пружинной ленты с рабочими лепестками 
114. элементы фиксирующего дистанционного кольца пружинной ленты с рабочими лепестками

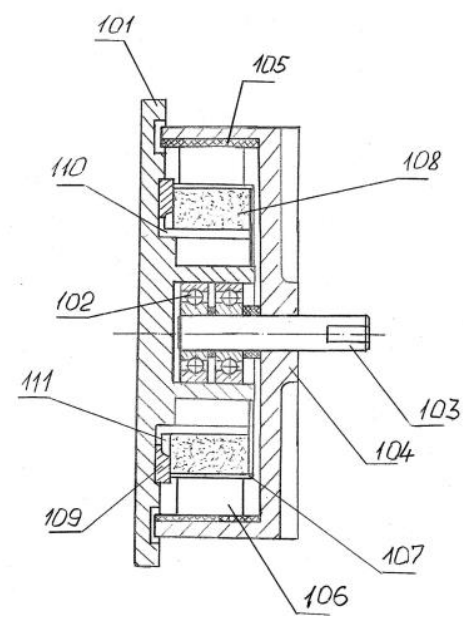

Рисунок 10. Пьезоэлектрический двигатель в осевом сечении

На рисунке 6 показан пьезоэлектрический двигатель в осевом сечении. Цифрами на рисунке обозначены:

101.фланец пьезоэлектрического двигателя

102.центральный подшипник

103. вал пьезоэлектрического двигателя

104.ротор пьезоэлектрического двигателя

105. фрикционное кольцо

106. рабочие лепестки

107.элементы фиксации пружинной ленты с рабочими лепестками на пьезоэлектрическом керамическом кольце

108. пьезоэлектрическое керамическое кольцо

109. опорный дистанционный фланец пружинной оси пьезоэлектрического двигателя

110. пружинная цапфа пружинной оси пьезоэлектрического двигателя

111.базовая канавка - проточка в фланце пружинной оси пьезоэлектрического двигателя 


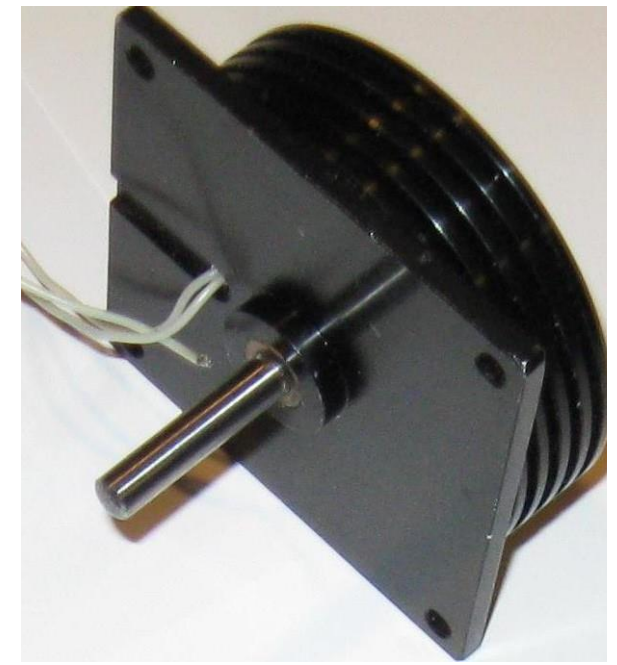

Рисунок 11.

\section{Пьезоэлектрический}

двигатель в сборе

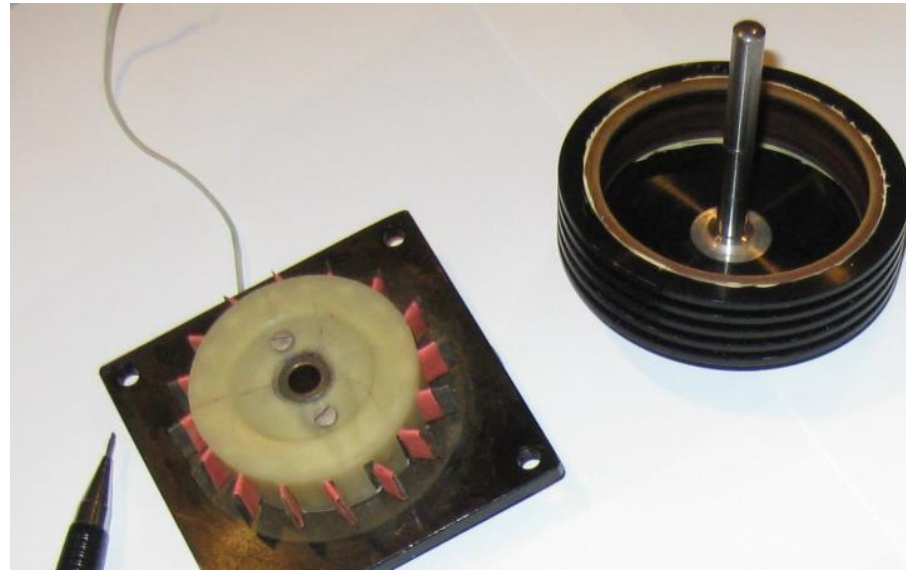

Рисунок 11. Пьезоэлектрический двигатель в разобранном виде и в маситабном факторе

На рисунке 11 показан пьезоэлектрический двигатель в разобранном виде и в масштабном факторе. В правой части рисунка показан ротор пьезоэлектрического двигателя с выходным валом двигателя (запрессован по оси ротора). На корпусе ротора выполнены канавки, играющие роль радиаторов охлаждения и стабилизаторов равномерного вращения ротора под воздействием рабочих лепестков. В корпус ротора запрессовано фрикционное кольцо, через которое рабочие лепестки передают вращающий момент на ротор. В центре рисунка показан установочный и несущий фланец пьезоэлектрического двигателя, на котором закреплена пружинная ось двигателя с пьезоэлектрическим керамическим кольцом с , закреплённым на его пружинной цапфе пьезоэлектрическим кольцом и с пружинной лентой с пружинными лепестками (на рисунке - красного цвета), через фрикционное кольцо находящиеся в упругом фрикционном контакте с ротором двигателя. Такая конструкция двигателя обеспечивает ему и его рабочему методу использования обратного пьезоэлектрического эффекта универсальность, согласно которой двигатель может работать и как двигатель, и как шаговый двигатель.

Переход от одного варианта к другому может осуществляться посредством команд - импульсов от драйвера и не требует никаких модификаций конструктива двигателя. 


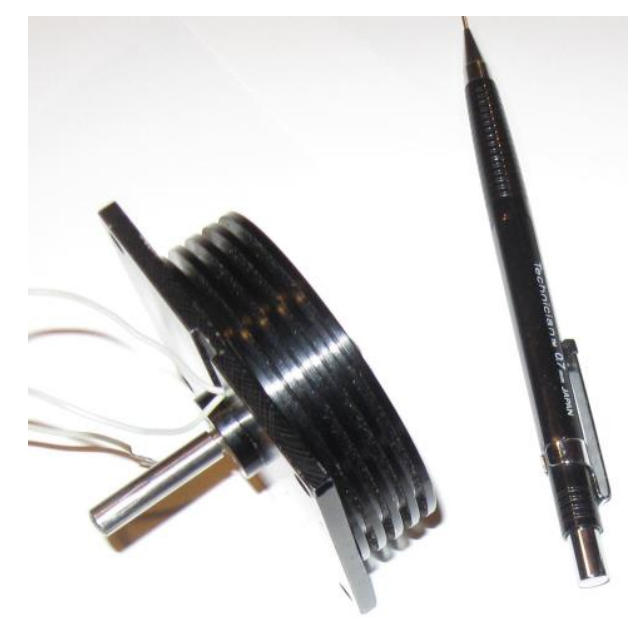

Рисунок 12. Пьезоэлектрический двигатель

На рисунке 12 показан пьезоэлектрический двигатель, работающий по принципу обратного пьезоэлектрического эффекта, в масштабном факторе.

Этот тип двигателя наиболее эффективен в системах автоматики и в автоматических модулях, входящих в гибкие производственные системы, когда необходимы качества шагового двигателя в части точности и стабильности работы, но нет необходимости в электромагнитных компонентах и их производных, создающих множество электронных помех и совершенно не пригодных к работе в условиях применения электромагнитной резонансной спектроскопии.

\section{A list of references, patent and licensing information}

1. Smart absorbent article, components, and process of making [Electronic resource]: pat. US 20190167489 / Hellmold, Jens - Publ. date 06.06.2019. - Mode of access:http://appft.uspto.gov/netacgi/nphParser?Sect1=PTO1\&Sect2=HITOFF\&d=PG01 $\& \mathrm{p}=1 \& \mathrm{u}=\% 2 \mathrm{Fnetahtml} \% 2 \mathrm{FPTO} \% 2 \mathrm{Fsrchnum} . \mathrm{html} \& \mathrm{r}=1 \& \mathrm{f}=\mathrm{G} \& \mathrm{l}=50 \& \mathrm{~s} 1=\% 2220190167$ 489\%22.PGNR.\&OS=DN/20190167489\&RS=DN/20190167489. - Date of access: 18.09.2020.

2. Smart absorbent article, components, and process of making [Electronic resource]: pat. US 20190167489 / Hellmold, Jens - Publ. date 06.06.2019. - Mode of access:http://appft.uspto.gov/netacgi/nphParser?Sect1=PTO1\&Sect2=HITOFF\&d=PG01 $\& \mathrm{p}=1 \& \mathrm{u}=\% 2$ Fnetahtml\%2FPTO \%2Fsrchnum.html\&r=1\&f=G\&l=50\&s1=\%2220190167 489\%22.PGNR.\&OS=DN/20190167489\&RS=DN/20190167489. - Date of access: 18.09.2020.

3. Methods and system for managing intellectual property using a blockchain [Electronic resource]: pat. US 20180285996 / Moses T. Ma - Publ. date 04.10.2018. - Mode of access: http://appft.uspto.gov/netacgi/nphParser?Sect1=PTO1 $\&$ Sect $2=$ HITOFF $\& \mathrm{~d}=\mathrm{PG} 01 \& \mathrm{p}=1 \& \mathrm{u}=\% 2$ Fnetahtml $\% 2$ FPTO $\% 2$ Frchnum.html $\& \mathrm{r}=1 \& \mathrm{f}=$ $\mathrm{G} \& \mathrm{l}=50 \& \mathrm{~s} 1=\% 2220180285996 \% 22 . \mathrm{PGNR} . \& O S=\mathrm{DN} / 20180285996 \& \mathrm{RS}=\mathrm{DN} / 20180285$ 996. - Date of access: 18.09.2020 


\title{
Humans as Genetic Information Carriers in the Pandemic Conditions (Criminal, Criminal Legal, and Civil Legal Aspects)
}

\author{
Pavlovska Nataliia \\ PhD of Juridical Sciences, Associate Professor, Professor of Department \\ of Civil Law and Process of the National Academy of Internal Affairs, Kiev, \\ Ukraine \\ ORCID ID 0000-0003-3311-0364 wwwpav@gmail.com
}

\section{Kulyk Maryna}

PhD of Juridical Sciences, Associate Professor of Forensic Support and Forensic Expertise of the National Academy of Internal Affairs, Kiev, Ukraine ORCID ID 0000-0003-1373-6749 coolss777@ukr.net

\section{Tereshchenko Yuliia}

PhD of Juridical Sciences, Professor of Criminal Law Disciplines and Operative and Investigative Activities of the Precarpathian Department of the National

Academy of Internal Affairs, Kyiv, Ukraine ORCID ID 0000-0002-5353-0887 vladysikter@ukr.net

\section{Strilets Halyna}

PhD of Judicial Sciences, Associate Professor of the Departament of Law of Prydunai Branch of Private Jointstock Company «Higher Educational Institution of Interregional Academy of Personnel Management», Izmail, Ukraine

ORCID ID 0000-0002-1067-0820 galinastrelets2018@ gmail.com

\section{Filipova Natalia}

Asistant of the Departament of Law of Prydunai Branch of Private Jointstock

Company «Higher Educational Institution of Interregional Academy of

Personnel Management», Izmail, Ukraine

ORCID ID 0000-0001-7132-8343 filinatalja2310@gmail.com

\footnotetext{
Abstract

It has been for the most part difficult and almost impossible to establish the origin of biological material from a particular person, as traditional methods of examining biological traces only with little probability can
} 
establish the relative chances of origin of such traces from a particular person and not their equivalence or identity.

The development and implementation in the expert practice of new methods of research of human biological traces are aimed at increasing the level of identification capabilities. Major successes in this area have been achieved first of all due to molecular genetics. The importance of such research cannot be overestimated. Many of the notable advances we witness today in forensics and the biological sciences depend on our knowledge of the structure of deoxyribonucleic acid (DNA).

Key words: DNA research, physical evidence, biological traces of man, blood, hair, saliva, semen, urine, sweat, genome, molecular genetic research.

\section{Introduction The substance of DNA profiling.}

The object of the DNA profiling can be DNA obtained from blood, secretions (sperm, saliva, buccal and other epithelium, etc.), hairs (if they retain hair follicles with root sheath), as well as fragments of organs and tissues of a human body. Cut hair, urine and sweat are not suitable for examination by these methods as they lack cells with nuclear DNA.

It is known that the DNA molecule retains its inherent individual specificity in any nuclear cell of the organism (only monozygotic twins have identical DNAs) and does not change throughout human life. Therefore, it is possible to identify within a DNA profiling a certain number of features that make it possible, with a high probability of $99 \%$, to establish that human biological traces belong to a particular person, as well as the biological affinity of persons. Besides, DNA profiling makes it possible to identify the sex of persons whose items are being examined [12].

The latest achievements in the field of molecular genetics have been gradually introduced into the practice of the Department of Medical and Biological Expertise of the State Research Forensic Centre (SRFC) of the Ministry of Internal Affairs of Ukraine which made it possible to perform DNA profiling examinations at the world level. The European Association of Forensic Sciences has confirmed the high quality of DNA research there by issuing its international certificate [1].

\section{Factors influencing the suitability of DNA for a polymerase chain reaction.}

The examination of the Department's best practices made it possible to establish that difficulties in the DNA extraction from the items to be examined were mainly related to the following factors: putrefactive changes in blood samples (from corpses); improper extraction, storage and transportation of items; adding anticoagulants to liquid blood samples; various diseases related to the immune system [11]. 
It is imperative to keep in mind that collecting material for genetic analysis requires that blood samples for comparison be taken carefully, with sterile instruments, using masks and gloves.

\section{Grounds for a DNA forensic examination (research).}

Provisions of orders to appoint the examination of traces of biological origin should be drafted, taking into account the purposes of the investigation, the circumstances of the crime, and expert opportunities. This means that, in each criminal proceeding, there should be close contact between the investigator, who appoints a DNA examination, and a specialist (forensic technician), preferably with a degree in biology and forensics, and such contact should provide for the joint appropriate selection of physical evidence for examination, determination of expertise opportunities, with due account of the evidence available to investigators, and the agreement on requests to be put before the expert $[3,15]$.

The main objectives of such examination are:

1) establishing the belonging of items of biological origin (blood, sperm, saliva, hair, muscle and bone tissues) to a certain person,

2) establishing whether traces of biological origin may belong to a certain person,

3) whether the DNA profile of a certain person is present in mixed traces of biological origin (blood, sperm, saliva, epithelial cells, etc.).

If the identity of the remains needs to be established when a corpse [9] is dismembered and if victims should be identified whose close relatives are living, the main questions are

1) can certain individuals be the biological parents of the person whose corpse's remains are to be examined;

2) can certain people be the parents of a child in cases of disputed paternity, infanticide, child abduction or substitution;

3) can certain individuals be the biological parents of a particular child?

\section{Current opportunities for the DNA research of human biological traces in times of pandemics.}

Today, DNA profiling is a fundamentally new type of scientific knowledge that opens up reliable prospects for solving problems related to identification in criminal proceedings and the development of the evidence base and has a number of advantages over traditional serological methods of human biological traces research, which are as follows: 
the presence of DNA molecules in every nuclear cell of the human body;

the increased resistance of the DNA structure to physical and chemical environmental factors;

no impact from the carrier;

mixing of biological materials from two or more persons can be established;

micro traces can be examined; mixed traces can be differentiated (for example, sperm and epithelial cells of a victim if sex crimes are investigated);

conclusions on the belonging of traces to a certain person are highly reliable;

expert conclusions presented in court are reliable and illustrative [10];

public confidence in criminal proceedings is growing.

As DNA profiling is highly developed nowadays, it should be used to solve and investigate offences against persons.

For over 20 years, the Unit of Biological Research of the SRFC MIA of Ukraine has been using the DNA profiling to perform examinations in the proceedings on serious crimes (murder, rape, etc.) and to establish blood kinship (disputed paternity). The latest achievements in the field of molecular genetics have been gradually introduced into the practice of the SRFC MIA of Ukraine and made it possible to perform examinations by DNA profiling at the world level. ABI Avant genetic analyzers (3100, 3130, and 3500) manufactured by APPLIED BIOSYSTEM (USA) and modern sets of reagents that allow identifying a person with a high degree of probability (1:10 billion) are used to perform research in compliance with the world standards. Now the Unit of Molecular Genetic Research of the SRFC MIA of Ukraine performs the most sophisticated and complex examinations, as well as the examination of mitochondrial DNA.

At present, it is important to perform complex research, which should include both investigative methods and comparative identification mentioned above, as precisely the combination of these provides the greatest effectiveness of crime detection. The lessons learned demonstrate that comprehensive examination of physical evidence seized during the inspection of the scene is the most effective method [14].

The most important requirement is the priority application of such methods, where physical evidence retains as much as possible traces for further research. Also, the quantitative characteristics of an item and the quality of its condition are crucial for the 
examination.

Besides, modern reagents allow isolating DNA from various organs and tissues (bones) of the human body (for example, when dismembered, skeletal or charred corpses are found), which currently allows establishing genetic traits of bones in $95 \%$ of cases.

Currently, the expert service has tested a technique that makes it possible, while detecting 2-5 or more papillary lines with no individual signs, to examine the presence of epithelial cells and establish their DNA profile. This examination method allows establishing the DNA profile of fingerprints after treating trace objects with certain fingerprint powders (nozzle soot, zinc oxide and the solution of ruthenium (IV) oxide) [5].

In the course of DNA research, no specific features pertinent only to a given individual are identified. Each feature has only group membership properties, but together they make it possible to individualize the object. However, this does not preclude that several people may exist at the same time with features identical to that of the object under examination. The allele is the main identifier.

To assess identification significance of such features, probabilistic and statistical processing of research results should be performed, based on the laws of probability theory. The distribution of alleles in the population is probabilistic, meaning that the frequency of occurrence of a particular allele in the examined population can be assessed with an established degree of reliability. The number of individuals in a given population with a particular allele determines the frequency (probability) of that allele, which is established experimentally. Occurrence frequency data make it possible to calculate the probability of identifiers.

If the DNA profile of the object coincides with the genotypes of the suspect and the victim and none of the hypotheses can be excluded, the issue has no solution.

One way to use microsatellite sequence polymorphism analysis is to solve the disputed parentage of children. Such analysis is ordered in civil law proceedings as a rule. However, the expert practice has cases when the origin of a child from a particular individual is required to be established in connection with criminal offences. The most typical situations are the following:

establishing paternity if rape resulted in the victim's pregnancy (with subsequent childbirth or premature termination of pregnancy); 
establishment of maternity in examinations in cases of infanticide;

determining the child's parentage from specific persons in case of child substitution or abduction.

Disputed paternity is the case category which most frequently requires the examination of a disputed origin of children.

\section{Obtaining biological samples in times of pandemic.}

Nowadays, the study of human genetic material is the core of forensic DNA profiling, which has increased public confidence in the criminal justice and judiciary and the reliability of evidence before the court [3].

However, in performing such examinations, it is important to research not only objects of biological origin, but also relevant samples to fully identify traces found during crime scene inspections, and obtain appropriate biological samples to establish paternity or family ties. The legislator poses here no limits on the experts, having provided, on the contrary, in Article 245 of the Criminal Procedure Code of Ukraine, the right to obtain samples for examination $[2]$.

In particular, if samples for the examination should be taken, it is done by the party to the criminal proceedings which applied for the examination or at whose request the investigating judge has appointed such examination. If a court has ordered the examination, then the court itself or a professional involved on its behalf should take samples for it. However, samples of blood and other secretions of the human body should be taken only in health institution settings and in due compliance with the sanitary standards excluding any harmful consequences for a person whose samples are being taken. While taking samples, the investigator should be governed by relevant instructions and methodological guidance.

Biological samples should be taken for examination under the procedure established in Article 241 of the Criminal Procedure Code (CPC) of Ukraine for the examination of an individual. Biological samples should be taken upon the order of a public prosecutor and, if necessary, with the participation of a forensic medical examiner or a physician, or individuals capable of performing such procedure [2].

Obtaining biological samples accompanied by denudation of the individual as well as the relevant procedures should be performed by individuals of the same sex, except for a situation when they are performed by a physician and upon the consent of the individual 
whose samples are being taken. Investigators and prosecutors have no right to be present when biological samples are taken from an individual of other sex if it involves the denudation of the individual.

The individual should be presented with the prosecutorial order before taking biological samples. The individual is afterwards requested to give his or her biological samples voluntarily. When biological samples are taken from an individual, it shall be not permitted to humiliate honour and dignity or endanger his or her health. The record should be drawn up when biological samples are being taken from an individual.

If an individual refuses to give his or her biological samples voluntarily, then a party to criminal proceedings may file a motion to an investigative judge or a court to request to obtain biological samples. Such motions are considered under the procedure provided in Articles 160-166 of the CPC [2].

Having considered the motion, the investigative judge or court allows the investigator or prosecutor to take biological samples forcibly or obligates them to take them forcibly if the defence has filed the motion. The individual whose biological samplings are forcibly taken should be presented with the copy of the record of such procedure.

Given that human biological samples are inextricably linked to the integrity of the organism (blood, skin, epithelial tissue, other tissues, etc.), their forced extraction without the consent of a person, involves the moral or physical impact on such person. Furthermore, Article 43 of the Fundamentals of Health Care Legislation of Ukraine clearly provides that voluntary consent of the person is a necessary condition for any preliminary medical intervention [4].

Thus, the provision of the CPC where the legislator provided for the forced obtaining of biological samples, is quite a novelty. In particular, Article 245 (3) of the CPC of Ukraine provides that, should the person refuse to voluntarily provide biological samples, an investigating judge or a court, upon a motion of a party to criminal proceedings, considered in accordance with the procedure established in Articles 160-166 of the Code, shall have the right to give permission to the investigator or public prosecutor to take biological samples in a compulsory manner (or to oblige them to do so if the motion was filed by the defence). However, as of today, the procedure for such action is left without legal regulation, and this, 
in general, provides grounds for the violation of constitutional human rights and freedoms related to personal integrity $[7,8]$.

In particular, Article 29 of the Constitution of Ukraine provides that every person shall have the right to personal inviolability. Therefore, the mentioned amendment to the Code is too "sensitive" and requires clear legal regulation, as such forced action if non-compliant with the procedure established in the CPC, including mandatory involvement of disinterested persons (official witnesses), etc., gives rise to significant violations of the provisions of criminal procedural law, and accordingly may call into question the impartiality of the results of such expert examination.

In light of such concerns, the issue of forcible taking biological samples for expert examinations requires further consideration and visibility provided by both scientists and practitioners.

Conclusions Human biological traces always played a great role in the detection and investigation of serious crimes. As the number of crimes against persons keeps growing, the application of such traces as carriers of forensically relevant information requires professional approaches [6].

The DNA profiling is only one of the identification stages, as a statistical analysis of data received is necessary to obtain final results, which is crucial if genotypes of an offender and a victim coincide, as sometimes in such cases human lives are at stake. For probabilistic and statistical evaluation of the results of the relevance of established genetic traits for the purposes of identification, the frequencies of their occurrence need to be established.

As of today, DNA profiling (DNA fingerprinting) is one of the most prospective areas of forensic development; its results provide quite reliable evidence of a certain person's involvement in a crime. Due to its unique opportunities, DNA profiling (fingerprinting) became a powerful tool in investigating crimes [13].

Therefore, the effectiveness of a successful solution of each criminal case in the fight against crime at both the local and national levels depends on the effectiveness of law enforcement, which can be increased only with constant cooperation and coordination between operational and investigative units and the expert service of the Ministry of Internal Affairs of Ukraine. International cooperation in exchanging DNA profiles between European countries would contribute to improving international police collaboration. 


\section{References}

1. The Law of Ukraine "On National Police" of 2 July 2015, Bulletin of the Verkhovna Rada of Ukraine, 2015, Nos. 40-41, p. 379.

2. The Criminal Procedure Code of Ukraine of 13 April 2012, Bulletin of the Verkhovna Rada of Ukraine, 2013, Nos. 9-10, 11-12, 13, p. 88.

3. The Law of Ukraine "On forensic examination" of 25 February 1994, Bulletin of the Verkhovna Rada of Ukraine, 1994, No. 28, p. 232.

4. The Law of Ukraine "Fundamentals of Health Care Legislation of Ukraine" of 19 November 1992, No. 2801-XII, retrieved from http://zakon4.rada.gov.ua/laws/show/2801-12.

5. The Regulation on the Expert Service of the Ministry of Internal Affairs of Ukraine, approved by the Order of the Ministry of Internal Affairs of Ukraine of 3 November 2015 No. 1343, retrieved from http://zakon3.rada.gov.ua/laws/show/z1390-15.

6. The Instruction on the procedure for involving the police pre-trial investigation officers and the Expert Service of the Ministry of Internal Affairs of Ukraine in the scene examination, approved by the Order of the Ministry of Internal Affairs of Ukraine of 3 November No. 1339, retrieved from http://zakon3.rada.gov.ua/laws/show/z1392-15.

7. The European Convention on Human Rights (the Convention for the Protection of Human Rights and Fundamental Freedoms) of 4 November 1950, Human Rights and Professional Standards for Legal Professionals in the Documents of International Organisations, Amsterdam, Kyiv, 1996, pp. 12-17.

8. Kotliarenko, L. T. Biological human rights: fundamentals, reality or an experiment, Forensics: current status and prospectives for the development, round table materials (23 April 2015). Kyiv, NNIFEKP NAVS, 2015, pp. 193-196.

9. Kotliarenko, L. T. Certain aspects of a corpse examination: the role of forensic experts and specialists, Issues relevant to forensic support to criminal proceedings, round table materials (10 April 2014), Kyiv, 2014, pp. 130-132.

10. Kotliarenko, L. T. Legal regulation of obtaining biological samples for expert examination, L. T. Kotliarenko, Issues relevant to technical and forensic support of criminal proceedings, round table materials (21 November 2013), Kyiv, 2013, pp. 171-173.

11. Utility model patent "The Box for Items of Biological Origin", No. 116198. URL: http://elar.naiau.kiev.ua/jspui/handle/123456789/2316

12. Forensic research of human biological traces. URL: http://elar.naiau.kiev.ua/jspui/handle/123456789/2993

13. Forensic research of biological items. URL: http://elar.naiau.kiev.ua/jspui/handle/123456789/1705

14. The participation of a forensic expert in some investigative actions. URL: http://elar.naiau.kiev.ua/jspui/handle/123456789/16325

15. Forensics: lecture notes, Kobylianskyi, O. L., Kofanov, A. V., Kyiv, 2019. 


\title{
Evidential Value of Microobjects in Criminal Proceedings and Forensic Rules for Handling Them
}

\author{
Svoboda Eugenia \\ PhD of Juridical Sciences, Associate Professor, Professor of Department of \\ Forensic Support and Forensic Expertise of the National Academy of Internal \\ Affairs, Kiev, Ukraine \\ ORCID ID 0000-0002-8639-8333 jeechka@ukr.net
}

\section{Pavlovska Nataliia}

PhD of Juridical Sciences, Associate Professor, Professor of Department of Civil Law and Process of the National Academy of Internal Affairs, Kiev, Ukraine ORCID ID 0000-0003-3311-0364 wwwpav@gmail.com

\section{Herasymenko Larysa}

PhD of Juridical Sciences, Associate Professor, Head of Department of Economic Security and Financial Investigations of the National Academy of Internal Affairs, Kiev, Ukraine

ORCID ID 0000-0001-6340-1061 lora-gera@ukr.net

\section{Morhun Nadiia}

PhD of Juridical Sciences, Professor of Department of Economic Security and Financial Investigations of the National Academy of Internal Affairs, Kyiv, Ukraine

ORCID ID 0000-0002-2997-9975 Morgun.nadiy@gmail.com

\section{Kutsyi Roman}

PhD of Juridical Sciences, Senior Teacher of Criminal Law Disciplines and Operative and Investigative Activities of the Precarpathian Department of the National Academy of Internal Affairs, Kyiv, Ukraine ORCID ID 0000-0002-1979-7019 romakrv2009@ukr.net

\footnotetext{
Abstract

The use of micro-objects in the process of investigating crimes has been considered for many decades an independent area of forensic expertise. Among physical evidence subject to microscopic examination, a special place has always been occupied by various material small bodies (objects) in the form of dust and soil
} 
compounds, various fibres (hairs) of human, animal and plant origin, paint and sawdust particles, stains, various types of contamination, pollen and plant particles as well as substances of various origin, which are as a rule associated with the crime.

Key words: the concept and classification of micro-objects;value, detection, fixation, removal, packaging, possibilities of forensic examination of microobjects.

Introduction The study of micro-objects for the purposes of criminal proceedings has been widely reflected in the works of domestic forensic scientists: V. H. Honcharenko, H. L. Hranovskyi, N. I. Klymenko, O. A. Kyrychenko, N.O. Prokopenko, O. V. Nenia and many others.

Micro-objects are classified into many types; they have multi-dimensional links with events under investigation and contain significant investigative and probative information. Micro-objects can be barely visible or invisible; thus, they are difficult to destroy while hiding traces of a crime. This is especially important as modern criminals are "well-educated" and it is widely known how to identify persons by fingerprints, weapons, by traces on bullets and bullet casings or to identify the author of a hand-written text by his or her handwriting, and achievements in forensic face recognition and other traditional types of forensic examination are well-known.

\section{The forensic examination of micro-objects and its opportunities.}

First of all, micro-objects can be preliminarily examined directly on the scene. Such examination is not regulated by law, and it is a non-procedural way of dealing with material items. An important requirement concerning the preliminary examination of micro-objects is that they should be stored in the same form in which they were removed. Micro-objects may be destroyed or wasted only if there are large quantities of homogeneous objects. If microobjects are removed, transferred or extracted, this can completely devalue the fact of their detection as evidence.

Preliminary examination of micro-objects is done to meet the following objectives:

their detection on the carrier;

tentative identification of their nature (to search for comparative samples);

finding out how they were formed;

comparison with the material of specific items (to decide whether it is feasible to submit them for further examination) [1]. 
Preliminary examination of micro-objects facilitates making decisions to open criminal proceedings; suggesting versions in the case; developing investigative measures and tactics of specific actions; ordering forensic examination and formulating relevant questions.

An example. There are no rope fibres on the victim's arms. The suicide version is called into question. This was usually followed by references to a comment to Articles 115 of the $\mathrm{CrCU}[2]$.

To conduct an expert examination, it is necessary to prepare the relevant materials properly:

provide control and comparative samples (preferably the entire source);

provide additional initial data (aspects of their use, origin, conditions under which they were extracted, information on whether any changes occurred during the identification period);

the relevant order should indicate what items were removed, the place, time and circumstances of their removal, contacts, actions before and after removal, conditions under which they were used and stored following the crime;

the order should also adequately define the objectives, areas and scope of the examination.

It is important to correctly determine the type of expert examination of micro-objects and the main expert institution [3].

Preliminary research of micro-objects is still best done in a laboratory, because, as a rule, lab-based stationary facilities and method are necessary to obtain information that is important for the detection of a crime [17].

Qualified professionals with relevant expertise are needed to conduct preliminary examinations. Therefore, an investigator who knows typical traces which different crimes leave and the ways they are being left is obliged to select a professional with necessary qualifications to handle micro-objects, as the results of preliminary examinations conducted by a forensic expert are not always of significant help in the detection and investigation of a crime [4].

It should be kept in mind that micro-objects may render identification possible if it is established that the object of identification is the source of them or if it is concluded that there 
has been a contact interaction. Indirect identification of the perpetrator or the victim is carried out by establishing the link between the objects of identification and these persons [16].

With the help of micro-objects, it is possible to identify perpetrators if such objects are found on the body and personal belongings of the suspect and are characteristic of the scene or are inherent to the clothes and body of the victim, his or her belongings found on the scene; on weapons or other items which were left on the scene and are typical of the suspect or his belongings; or if homogeneous extraneous microparticles are found on both the suspect and the victim [5].

The examination of the properties of micro-objects also helps to identify signs pointing to the perpetrator and the victim, their appearance, sex, clothing (micro-objects of hair, nails, secretions, powder, lipstick, fibres, nail polish fragments, etc.) [14].

For example, in November 2008, criminals who robbed a farm and killed its guard in the Mykolaiv region made almost every possible effort to destroy traces left by them by getting rid of gloves and footwear in which they committed the crime. However, such a little detail as the fibres from the gloves left on the instruments, albeit thrown away later, of the crime made it possible to quickly identify the witness (the seller in the store where the criminals bought their gloves). The officers together with the expert made facial composites of criminals, which made it possible to determine correct investigative avenues, identify criminals and solve the crime later on (O. V. Nenya, 2011). This was usually followed by references to a comment to Articles 115 and 186, 187 of the $\mathrm{CrCU}$ [2].

It is possible to identify the blood type of a person by the layering of the sweat and grease deposit substance of his/her fingerprint and compare it with the data of forensic examination of the suspect's blood.

Micro-objects can be used to identify the place of a crime [15].

The place of the crime can be identified by the particles of soil or paint, which have been stuck to the clothes (body) of the victim or suspect, other contaminants originating from a certain area, microparticles of items belonging to the scene or broken obstacles [6].

Particles found on the scene and detached from clothing, footwear, vehicles (fragments of paint and headlights, drops of fuel and lubricants, dirt), indicate that such items have been present in a particular place. Therefore, the detection of microparticles on the items on the scene makes it possible to determine how the offender got there, the routes of his/her 
movements, whether specific items have been moved, etc. The following example is quite interesting as it involves professionals of the expert unit of the Ministry of Internal Affairs of Ukraine (hereinafter, MIA) who preliminarily investigated the found particles which made it possible to narrow as much as possible the search for the crime site and quickly identify the victim and his residence. In September 2008, human body fragments were found in the Lviv region. Examination of the scene around one of the body fragments revealed stains of brown substance (the research found them to be human blood), mostly oval in shape. It was assumed judging from the form of the stains that they possibly fell down from an object that moved from one of the residential buildings where stains ended. Therefore the officers inspected this building and the adjacent ones and interviewed their residents. On the walls of that building, between the second and third floors, dark smears were found, resembling human blood, and the residents of this building recognized the victim as their neighbour. The flat of the victim was inspected, and another human body fragment was found, a number of items were retrieved to be examined, among them 22 stretches of sticky transparent tape with handprints. Following the research and checks on the basis of the retrieved handprints, two suspects were apprehended who, after being presented with the evidence, confessed to this crime and named their five accomplices (Nenia O. V., 2011). This was usually followed by references to a comment to Articles 115 of the CrCU [2].

The absence of micro-objects where, as the situation suggests, they should have been detected, or the presence of micro-objects with other (unexpected) properties can be regarded as a negative circumstance and provide the ground for suspecting faking, false testimony, deliberate changes of the crime scene. Identification of various objects involved in the crime by their micro-objects is important for the investigation process. It is possible to identify them either when an expert confirms that the item (the group of items) to be identified was the source of such micro-objects or if there is a conclusion that the items had a contact interaction between them. People are indirectly identified by establishing links between these items and the offender or victim [7].

Items are often identified when micro-objects are examined on weapons or the tools that caused injuries. 
In the practice of investigating traffic accidents, it is common to identify repaired or painted vehicles by multi-layer microparticles of paint [18]. This was usually followed by references to a comment to Articles 286 of the $\mathrm{CrCU}$ [2].

Micro-objects are important for establishing the fact of contact interaction, especially in the investigation of crimes such as rape, murder or grievous bodily harm. Such facts are established based on micro-objects which translocated from the clothes (bodies) of the suspect and victim. These may be tissue fibres, drops of blood, sperm, saliva, sweat, other secretions, extraneous contaminants originating from the victim and the assailant; particles from the weapon used which remained on the clothes of the offender and on the body and clothes of his/her victim [8]. This was usually followed by references to a comment to Articles 152, 115 and 121 of the $\mathrm{CrCU}$ [2].

Micro-layers of sooting between the little and the ring finger and between thumb and forefinger (detected by examination in infrared rays) confirm that shots have been made from handguns. If a revolver was used, stippling can be revealed, in addition to sooting. The use of long guns can be proved by micro-layers of sooting on the hands, face and clothing of the shooter; besides, they provide information about the type of the weapon used [13].

Microparticles found on the crime weapon make it possible to establish the fact of its use in the crime under investigation. For example, if the blade of a puukko knife contains microfibres from various items of clothing of the victim, blood stains (particles) and epithelial cells of the injured organs, this suggests that the weapon was actively used in this crime.

In March 2009, textile fibres were found on the clothes of two victims of stab wounds in Zaporizhzhia, one of whom died; the general type of these fibres coincided with the type of textile fibres that were part of the fabric of the sweater seized from the suspect. The suspect, after being informed of the expert research results, pleaded guilty (Nenia, O. V., 2011). This was usually followed by references to a comment to Articles 121 of the $\mathrm{CrCU}$ [2].

It is possible to identify, on the basis of micro-objects, the vehicle which has caused injuries. Microfibres of the victim's outerwear, stains of his/her blood, etc., often remain on those parts of the car, which contacted with the victim [18]. This was usually followed by references to a comment to Articles 286 of the $\mathrm{CrCU}$ [2].

Micro-objects can inform the investigator of the skills and professional abilities of persons involved in the crime. Various particles (tobacco, metals, wood (sawdust, shavings), 
micro-pollution by various substances and materials (paint, lubricants and building materials, etc.) and micro-objects of the soil of plant and animal origin can indicate occupation or profession [9].

Micro-objects play an important role in establishing the time of the crime. Time can be determined by examining microparticles of biological origin: microorganisms that have developed, in particular, on the corpse; pollen, seeds of plants, algae, etc., found on it [10].

Sometimes it is possible to find the perpetrator by the "microparticles of smell", i.e. the molecules of complex compounds contained in any excretions of a human body or such that can be exhaled with the air. Specially trained dogs are used as analysers for that. An example of this can be the incident that occurred in February 2008 in the Vinnytsia region, where an unknown person broke into the premises of a gas station and wounded the cashier with a firearm. A pistol was found on the scene and traces of odours on the handle of the weapon. The police also found a pistol magazine with three bullets and traces of odours from the seats of a car found not far from the scene. A suspect was apprehended following the investigation. The experts who conducted forensic odorology proved the complete coincidence of the odour traces extracted from the pistol grip and the car seat with the sample taken from the detainee. The forensic firearm examination revealed that the cartridge case found during the inspection of the scene was fired from the pistol left on the scene. The suspect, after being informed of the results of forensic examinations, pleaded guilty (Nenia, O. V., 2011). This was usually followed by references to a comment to Articles 187 and 263 of the $\mathrm{CrCU}$ [2].

Micro-objects may facilitate proposing and verifying investigation avenues. For example, microfibres left by the offender on the scene or while moving, help to get an idea about his/her outerwear. This can narrow the number of potential suspects and facilitate the investigation [11].

Micro-objects are also widely used to determine the causes of fires and explosions and to investigate aircraft crashes. This was usually followed by references to a comment to Articles 194, 263 and 276, 416 of the $\mathrm{CrCU}$ [2] .

It should also be noted that the significance of micro-objects as evidence can be compromised or even totally lost if rules regulating their search, fixation, extraction, storage and examination are violated. Physical evidence can be substituted, micro-objects formed at 
the time of the crime can be lost, and other micro-objects can appear with no connection to the event under investigation [12].

Conclusions To sum up, micro-objects can be extremely widely used. As a rule, micro-objects can be found during the investigative inspection of the crime scene, the corpse and the places where physical evidence are most likely to be found, with due regard to the specific circumstances and modalities of a crime.

Micro-objects are material formations which under certain circumstances can be physical evidence used in proceedings; therefore, they should be detected and fixed following the established procedures. In particular, all the circumstances related to the detection of micro-objects, their characteristics, fixation methods, whether and in what way they were added to the record, should be reflected in the record of the investigation in compliance with Articles of the Criminal Procedural Code [19].

If micro-objects are intended to become physical evidence then the inquirer, investigator, prosecutor or the court should issue an order that all found micro-objects and the items which are assumed to be the carriers of micro-traces, should be added to the case file [20].

Therefore, from the point of view of the criminal process, micro-objects can be used as material evidence only if detected, described and extracted during the investigative inspection, and in case of their latency as traces on the carrier (a piece of material evidence), their detection, description and extraction should be carried out by an expert entrusted with the relevant examination. At the same time, a mandatory condition for the recognition of microobjects as the physical evidence is that the investigator should add them to the case file following the procedural order. Moreover, the preliminary recognition of micro-objects as material evidence includes, as a necessary stage, the procedure of their examination to establish their linkage with the crime. As micro-objects are carriers of evidential information, such their status determine a specific range of objectives to be achieved during their expert examination.

To sum up, one of the most promising avenues to enhance the efficiency of law enforcement is the extensive use of micro-objects, which, regardless of the offender's intentions, almost always remain on the scene and contain important forensic information 
which can be obtained during their preliminary investigation on the scene and following their comprehensive expert research.

\section{References}

1. Instruction on the procedure for involving employees of pre-trial investigation bodies of the police and the Expert Service of the Ministry of Internal Affairs of Ukraine as specialists to participate in the inspection of the scene, approved by the order of the Ministry of Internal Affairs of Ukraine of 3 November 2015 № 1339. URL: http://zakon3.rada.gov.ua/laws/show/z1392-15

2. Criminal Code of Ukraine. URL: https://zakon.rada.gov.ua/laws/show/2341-14\#Text

3. Nenia, O. V., The forensic importance of micro-objects in the investigation of crimes, Visnyk Akademii advokatury Ukrainy, 2011, No. 2(21), pp. 139-145.

4. Prokopenko, N. O., Theoretical principles and practice of research of microscopic traces and reflections, abstract of the thesis, Kyiv, 2009.

5. Forensic support of crime-solving and investigation: practice, experience, problems, Krasiuk, I. P. (ed.), Kyiv, DNDEKTS MIA of Ukraine, 2009, No. 14.

6. Forensic support of crime-solving and investigation: practice, experience, problems, Krasiuk, I. P. (ed.), Kyiv, DNDEKTS MIA of Ukraine, 2009, No. 15-16

7. Honcharenko, V. H., Issues related to the use of micro-objects in proving, Advokat, 2008, No. 4(91).

8. Forensic support of crime-solving and investigation: practice, experience, problems, Krasiuk, I. P. (ed.), Kyiv, DNDEKTS MIA of Ukraine, 2008, No. 13

9. Klymenko, N. I. The use of micro-objects to investigate crimes: methodological textbook, Klymenko N. I., Liniuchev H. V., Krasiuk, I. P. (ed.), Kyiv, DNDEKTS MIA of Ukraine, 2008.

10. Davydova, O. O. Forensic examination of materials, substances and products, Lecture series, Kyiv, KNT, 2008.

11. Zinin, A. M., Forensics, a textbook, Zinin, A. M., Mailis, N.P., Moscow, 2002.

12. Vander, M.B., The use of microparticles to investigate crimes, St. Petersburg, Piter, 2001

13. Ishchenko, P. P. Micro-objects in the investigative and expert practices, Volgograd, the High Investigative School of the MIA of the USSR, 1987.

14. Klymenko, N. I. The use of micro-objects to investigate crimes: methodological guidance for the law students, Kyiv, KGU, 1984.

15. Klymenko, N. I. Micro-objects as physical evidence: methodological guidance for investigators, Klymenko, N. I., Bovsunovskyi, V. M., Kyiv, Editorial department of the MIA of the Ukrainian Soviet Socialist Republic, 1984.

16. The participation of a forensic expert in some investigative actions. URL: http://elar.naiau.kiev.ua/jspui/handle/123456789/16325 
17. Forensics: lecture notes, Kobylianskyi, O. L., Kofanov, A. V., Kyiv, 2019.

18. Forensic studies of paint and varnish materials. URL: http://elar.naiau.kiev.ua/jspui/handle/123456789/2991

19. General principles of forensic research of materials, substances and products. URL: http://elar.naiau.kiev.ua/jspui/handle/123456789/2997

20. Practical aspects of forensic research of materials, substances and products. URL: http://elar.naiau.kiev.ua/jspui/handle/123456789/2996 


\title{
Characteristics of Social Work with Children with Disabilities in Great Britain
}

\author{
Rizak Iryna \\ Postgraduate \\ Borys Grinchenko Kyiv University (Ukraine, Kyiv)
}

\begin{abstract}
The article describes the features of social work for children with disabilities in the UK. Defined the concept of children with disabilities. Described the interpretation of the concept of children with disabilities according to the medical and social model. Presented the main structures that can provide social services in the UK to children with disabilities. Analyzed the peculiarities of British social work with children with disabilities in the activities of the Centers for Social Services. Determined the main types of social services provided by such centers are described. The concept of independent living and activities of the centers independent living are described. The types of services provided to children with disabilities and their families (information; counseling; legal; housekeeping services, home support, leisure organization, guardianship services) are identified. The programs implemented at the state level to provide support are given and providing social assistance to children with disabilities and their families. Pointed out the orientation of state programs and their provision of social services to improve the educational outcomes of children with disabilities. The main directions of social work for children with disabilities in the United Kingdom are described. Characterized medical and social work (basic care) and social work with children and families.

Key words: children with disabilities, social services, types of social services in the UK, forms of social work for children with disabilities, the concept of independent living, British programs to support children with disabilities.
\end{abstract}

Актуальність дослідження. Актуальним питанням та нагальною соціальною проблемою українського суспільства є стан здоров’я дітей та молоді. За даними звіту 2018 року Міністерства соціальної політики та Міністерства охорони здоров’я України кількість дітей з інвалідністю з 2015 по 2019 рр. збільшилась (2015 р. - 151,1 тис. осіб; 2016 р. - 153,5; 2017 p. - 156,1; 2018 p. - 159,0; 2019 р. - 161,6 тис. осіб). Статистика свідчить, що на 01.01.2019 в Україні налічується 161600 осіб дітей з інвалідністю до 18 років [2].

Досить розгалужене сучасне законодавче забезпечення соціальної роботи з дітьми з інвалідністю не вирішує низку сучасних проблем та актуальних питань, які стосуються недосконалості соціальної роботи 3 даною категорією. А саме, важливим $\epsilon$ вдосконалення та пошук шляхів ефективності рівня соціальної роботи 3 дітьми 3 інвалідністю, розширення та вдосконалення моделей, методів та форм соціальнопедагогічної роботи з такими дітьми. 
Прагнення України до побудови високих соціальних стандартів, розширення іï співпраці та взаємодії з зарубіжними країнами визначають актуальність вивчення зарубіжного досвіду соціальної та соціально-педагогічної роботи з дітьми з інвалідністю. А саме, багаторічний досвід соціальної роботи з дітьми з інвалідністю Великої Британії, що характеризується створенням потужної мережі наукових доробок та досліджень.

Вивчення досвіду соціальної роботи з дітьми з інвалідністю у Великій Британії, його особливостей, специфіки, основних технологій соціальної роботи 3 даною категорією, побудовою соціальних програм може стати корисним для української науки та впровадження елементів такого досвіду в українську систему практичної соціальної роботи.

Вивченню зарубіжного досвіду соціальної роботи присвячено низку досліджень: Л. Гордієнко (соціалізація молоді Великобританії); О Романовська О. (фостерна сім’я Великої Британії як соціальне середовище для дитини); М. Зубілевич (гендерне виховання у Великобританії); М. Гурій (громадське виховання школярів у Великій Британіі); І. Братусь (робота з юними матерями в США та Великобританії); О. Загайко (підготовка соціальних працівників в Англії); Н. Мороз (система виховної роботи у навчальних закладах Великобританії); О. Бойко (професійна підготовка фахівців із соціальної роботи третього рівня вищої освіти у Великій Британії).

Окремі аспекти соціальної роботи з дітьми з інвалідністю розглянуто у роботах зарубіжних науковців Дж. Аделлізі, Д. Бейкер, У. Берніс, П. Бюрк, А. Веб, М. Вергас, Д. Гловер, Т. Губі, К. Девіз, Джк. Кінгслей, М. Леповскі, Л. Мавис, Б. Мондей, М. Олівер, Дж. Паркер, Дж. Скотт, Н. Тімс, К. Франкель, С. Ханвай, К. Химпрей, М. Хорізон, Л. Шульман, П. Янг.

В останнє десятиріччя в Україні здійснено низку досліджень, які присвячені роботі 3 дітьми 3 інвалідністю, зокрема: інтегрування дітей 3 функціональними обмеженнями в сучасне середовище (Н. Мирошніченко, В. Скрипник); реабілітація осіб 3 обмеженнями життєдіяльності (Є Агеєв, Л. Боброва, В. Бондар, Г. Гаврюшенко, О. Граборов, Н. Сайко, О. Поліщук, М. Чайковський, А. Шевцов); соціально-педагогічна підтримка дітей з інвалідністю (О. Міщенко, В. Тесленко); соціально-педагогічна робота 3 дітьми з особливими потребами (І. Іванова); корекція різних порушень у дітей з вадами розвитку (О. Зинов’єв, А. Кіссе, М. Мога, В. Синьов); формування соціальної 
компетентності осіб з обмеженими можливостями (В. Ляшенко, О. Позднякова, О. Хорошайло); соціальна підтримка батьків дітей 3 інвалідністю (Н. Грабовенко, I. Макаренко, Т. Соловйова, Т. Чечко) тощо.

Проте аспект використання британського досвіду, форм та методів соціальної роботи з дітьми з інвалідністю в Україні не знайшов достатнього відображення в теорії та методиці соціальної роботи.

Тому метою нашої статmі обрано деталізацію форм соціальної роботи з дітьми з інвалідністю у Великій Британії, як можливого досвіду використання в українській соціальній роботі.

Виклад основного матеріалу. Соціальна система Великої Британії сформувалась та розвивалась шляхом модифікації, розширення і перетворилась на важливий сектор надання соціальних послуг. Сучасна соціальна політика даної держави пронизує всі сфери суспільного життя, а саме вона пов'язана з економічною, освітньою, культурною, медичною, екологічною та іншими сферами.

Інвалідність у дітей означає істотне обмеження життєдіяльності, вона призводить до соціальної дезадаптації, що зумовлена порушеннями в розвитку, труднощами в самообслуговуванні, спілкуванні, навчанні, оволодінні професійними навичками. Освоєння дітьми з інвалідністю соціального досвіду, включення їх в існуючу систему суспільних відносин вимагає від суспільства значних організаційних, економічних i правових заходів.

У Великій Британії поняття «діти з інвалідністю» розглядається з точки зору двох моделей, а саме: медичної та соціальної моделі.

3 точки зору медичної моделі «діти з інвалідністю - це неповнолітні особи, які мають фізичні або психологічні хвороба/порушення, що обмежує здатність або діяльність дитини і може знизити якість їхнього життя.

Соціальна модель розглядає «дітей з інвалідністю - неповнолітні особи, які стикаються з соціальними бар'єрами, що утруднюють їх індивідуальні можливості та створюють особливі потреби» $[11$, с. $3 ; 7 ; 8$, с. 72-76; 12].

Діяльність британської соціальної роботи з особами з інвалідністю, включаючи і дітей 3 інвалідністю будується на міжнародній класифікації функціонування, інвалідності та здоров’я (МФК). Вона використовується як інструмент для планування 
та формування соціальної політики, щодо осіб з інвалідністю, в тому числі і дітей 3 інвалідністю.

Система соціальної роботи з дітьми з інвалідністю у Великобританії пов'язана 3 наданням соціальних послуг даній категорії клієнтів. Соціальні послуги в даній країні можуть надаватись дітям з інвалідністю, а саме тим які мають фізичні, розумові вади та хронічні захворювання. Соціальні послуги надаються такими структурами як: департаментами соціальної роботи, місцевою владою, волонтерськими (громадськими) організаціями. При цьому всі перераховані організації мають спільну мету та ставлять однопланові завдання, які спрямовані на допомогу дітям з інвалідністю вести повноцінне життя та максимально сприяти їх соціалізації та інтеграції у громаду.

Крім перерахованих вище структур, значне місце при наданні соціальних послуг дітям 3 інвалідністю та сім'ям, що їх утримують і виховують надається Центрам соціальних служб Великобританії.

Центри соціальних служб у Великобританії переважно надають допомогу у дома, в денних центрах, денних школах. У всіх цих установах основна увага приділяється формуванню та навчанню дітей з інвалідністю, розвиток у них навичок спілкування, навчанню правилам поведінки у різних соціумах (на вулиці, громадських місцях тощо). Для старших підлітків організовуються спеціальні профорієнтаційні заняття, а для підлітків з розумовою відсталістю функціонують центри професійної підготовки [9, c. $115-120]$.

Важливим завданням роботи перерахованих вище структур $з$ дітьми 3 інвалідністю є розвиток у таких дітей оптимального рівня незалежності в середовищі, а саме розвиток іiї фізичної, психічної та соціальної складової.

Соціальний працівник Департаменту соціальних служб Великобританії може надавати допомогу у вигляді консультацій, підтримки по особистих питаннях особи 3 інвалідністю та їх родин; розробляє індивідуальні програми реабілітації; займається організацією їх дозвілля.

Як було вище сказано однією із форм роботи з дітьми з інвалідністю є робота в домашніх умовах. Сюди зараховують послуги 3 ведення домашнього господарства (доставка харчів, прання) та послуги з довготривалої або короткотривалої опіки, які переважно надаються батькам, що займаються утриманням та вихованням дітей 3 
інвалідністю. Окремо існує послуга опіки над дітьми з інвалідністю під час відпустки батьків чи на вихідні. Деякі соціальні інституції пропонують реабілітаційні програми для дітей з інвалідністю та їх батьків, які перебувають у лікарні. А також існує послуга підтримки вдома для збільшення у дітей домашньої активності та безпеки.

Досить розповсюдженою у британській системі соціальної роботи 3 дітьми 3 інвалідністю $є$ використання концепції підготовки до незалежного життя. Дана концепція розглядається з двох позицій: перша - це підготовка особистості до того, що вона є повноправним членом суспільства та має право активно брати участь у його житті, а з іншої - формування навичок самостійного життя.

Для впровадження такої концепції створюються Центри незалежного життя, які виступають однією із моделей соціального обслуговування інвалідів. Часто такі центри організовуються громадами, вони можуть бути громадськими, некомерційними, управління може здійснюватися особами з інвалідністю. Частіше всього такі центри надають наступні види послуг: інформаційні (надання довідкової інформації) дітям та їх батькам; консультативні; індивідуальне консультування по захисту прав та інтересів осіб 3 інвалідністю та їх родичів; надання послуг (ведення домашнього господарства, підтримки у дома, організація дозвілля, послуги опіки) [3].

Прикладом такого центру у Великій Британії є центр незалежного життя у м. Глазго. Даний центр реалізує наступні проекти та надає такі види послуг: інформаційні (існує комп’ютерна база даних дітей з інвалідністю, центрів допомоги та їх реабілітації); тренінги для дітей з інвалідністю; програми по відновленню та захисту прав осіб з інвалідністю; заняття з профорієнтації; ресурсний центр для сліпих; заняття для громадян 3 формування толерантного ставлення до осіб 3 інвалідністю; юридична допомога та консультування; формування навичок самообслуговування та здобуття соціальних умінь (робити покупки, готувати їжу, користуватися громадськими місцями, поводитися з грішми тощо). У центрах організовуються заняття з малювання, рукоділля, фізкультури тощо [10, с. 209-211]. Такі центри є комплексною інноваційною моделлю системи соціальних служб, які створюють для людей з інвалідністю умови рівних можливостей. Ці центри допомагають людям з інвалідністю бути інформованими 3 питань їх прав та можливостей, з психологічних питань, з особистих питань та питань особистих інтересів тощо. Також Центри незалежного життя можуть надавати послуги 
особам з інвалідністю по догляду за домом, надання інформації про певні можливості для людей з інвалідністю, допомога в пересуванні та організації переїздів тощо. Такі центри спрямовані на надання інформаційної, юридичної допомоги, вирішують питання доступності та власності житла для осіб з інвалідністю, питання працевлаштування, впроваджують програми для підготовки молодих лідерів, що мають інвалідність та програми підготовки до незалежного життя.

Отже на рівні держави у Великій Британії існує ряд програм щодо роботи та надання соціальних послуг дітям з інвалідністю та їх сім'ям. Одна із таких програм є програма «Якість захисту» (Quality Protects programme). Вона спрямована на підтримку сімей, які виховують та доглядають за дітьми з інвалідністю. Програма забезпечує надання послуг з ведення домашнього господарства, домашньої допомоги. Крім цього пріоритетними завданнями даної програми є покращення результатів освіти дітей 3 інвалідністю, доступність закладів загальної середньої освіти для таких дітей, партнерське налагодження співпраці між соціальним працівником на рівні громади та 3 батьками які виховують дитину з інвалідністю, здійснення ранньої підтримки та втручання, програма забезпечує виділення коштів для оплати додаткових відпусток для батьків, що виховують дітей 3 інвалідністю. В рамках цієї програми функціонує національний інформаційний центр для сімей дітей з інвалідністю.

Ще однією державною програмою $є$ програма «Дія» (PROGRAMME OF ACTION). Ця програма спрямована на надання освітніх послуг дітям з інвалідністю, а саме: раннє виявлення та втручання, сприяти розкриттю потенціалу дітей з інвалідністю, забезпечення інклюзивності навчання, доступ до закладів загальної середньої освіти дітей з інвалідністю [4].

Не менш цікавою є британська програма, яка реалізується на державному рівні це програма «Охорони здоров’я в школах» (HEALTH CARE IN SCHOOLS). В рамках цієї програми передбачається підтримка з боку медичних та соціальних служб в школах. Заклади освіти в межах цієї програми зобов’язані погоджувати індивідуальний план охорони здоров’я $з$ шкільною медсестрою для здійснення діагностики індивідуальних потреб у здоров’і дитини та для розробки навчальної програми для таких дітей враховуючи їх потреби та ефективному їх включенню у шкільне життя. 
У Великобританії на даний час найпоширенішим заходом щодо підтримки рівня життя людей з інвалідністю є надання певної матеріальної допомоги, різних пільг і дотацій. У більшості розвинутих країн допомога, що виплачується інвалідам, складається з двох частин: компенсація втраченого заробітку та відшкодування витрат на послуги, що пов'язані з інвалідністю. Так у Великобританії право на допомогу та ії розмір встановлюються залежно від віку особи, обсягу необхідної допомоги та ступеню непрацездатності (інвалідності).

Основними напрямами соціальної роботи 3 дітьми з інвалідністю у Великій Британії є: медико-соціальна робота, основний догляд (Community Care) надається переважно особам 3 розумовою відсталістю, особам 3 фізичними вадами, особам 3 проблемами психічного здоров'я; соціальна робота 3 дітьми та сім'ями (Children and Families' Social Work). Надається дітям з інвалідністю та сім'ям, що їх виховують. В межах даного напряму забезпечуються такі види соціальних послуг: няньки-вихователі, дитячі садки (денний догляд), дитячі садки та ясла (ігрові групи не на весь день), дитячі центри, підтримка в дома, групи/клуби продовженого дня, центри дозвілля, гуртожитки з наглядом, підтримка молодих батьків, які виховують дітей з інвалідністю, захист прав дітей з інвалідністю, клуби домашньої роботи, консультування у галузі навчання тощо.

Висновки. Таким чином нами було здійснено характеристику британської системи надання соціальних послуг дітям з інвалідністю та їх сім'ям. Система надання соціальних послуг даній категорії у Великій Британії містить поєднання медичної та соціальної моделей, які передбачають підготовку до самостійного життя осіб 3 інвалідністю та формування у них навичок самообслуговування. Вся система соціальної роботи з дітьми з інвалідністю у Великій Британії поєднує принцип підтримки таких осіб у всіх сферах суспільного життя.

Перспективними напрямами дослідження з обраної нами проблеми можуть стати виявлення умов організації соціальної роботи з дітьми з інвалідністю; обгрунтування змісту та форм підготовки фахівців соціальної роботи, виявлення чинників та факторів формування толерантного ставлення до осіб з інвалідністю.

\section{References}

1. Denesiuk O. Profesiina pidhotovka maibutnikh sotsialnykh pedahohiv ta fakhivtsiv sotsialnoi sfery do zdiisnennia sotsialno-pedahohichnoi pidtrymky batkiv, yaki vykhovuiut ditei 
$z$ invalidnistiu [Professional training of future social educators and social specialists for the implementation of socio-pedagogical support for parents raising children with disabilities]. Naukovi zapysky Nizhynskoho derzh. un-tu imeni M. Hoholia. 2016. No. 1. Pp. 173-177.

2. Derzhavna sluzhba statystyky. Sotsialnyi zakhyst naselennia Ukrainy [State Statistics Service. Social protection of the population of Ukraine]. Statystychnyi zbirnyk / vidpovidalna za vypusk Karmazina O.O. Kyiv. 2018. 121 p.

3. Komar I. Normatyvno-pravove zabezpechennia sotsialnoi roboty $z$ ditmy $z$ funktsionalnymy obmezhenniamy u Velykii Brytanii [Regulatory support for social work with children with disabilities in the UK]. Visnyk Chernihivskoho natsionalnoho ped. un-tu. Seriia pedahohichni nauky. Vol. 1. Issue 104. Chernihiv : ChNPU, 2012. Pp. 137-142.

4. Komar I. Sotsialna pidtrymka ditei iz funktsionalnymy obmezhenniamy u Velykii Brytanii [Social support for children with disabilities in the UK]. Pedahohichna osvita: teoriia i prakytyka. Psykholohiia. Pedahohika: zbirnyk nauk. prats. Kyiv: Kyivskyi un-t imeni Borysa Hrinchenka, 2013. No. 20. Pp. 58-62.

5. Liakh T., Spirina T., Rohozhynska V. Pryntsypy mizhdystsyplinarnoi vzaiemodii u sotsialnii roboti [Principles of interdisciplinary interaction in social work]. Aktualni pytannia humanitarnykh nauk. 2020. Vol. 3. No. 27. P. 224-228.

6. Petrochko Zh. Teoretyko-kontseptualni osnovy sotsialno-pedahohichnoho zabezpechennia prav ditei [Theoretical and conceptual foundations of socio-pedagogical support of children's rights.] Aktualni problemy derzhavnoho upravlinnia, pedahohiky ta psykholohii: zbirnyk naukovykh prats / za red. V. Butenko. Kherson : Khersonskyi NTU, 2011. Pp. 314-321.

7. Pet'ko L. V. Anhliys'ka mova dlya studentiv-psykholohiv ta defektolohiv. Dydaktychnyy material dlya praktychnykh zanyat' ta samostiynoyi roboty studentiv $z$ inozemnoyi movy zi spetsial'nostey: 6.010105 «Korektsiyna osvita (za nozolohiyamy)», 6.030102 «Psykholohiya», 6.030103 «Praktychna psykholohiya [English for students with specialization Psychology and Special Education". Didactic material for practical classes and independent work of students in a foreign language specialties 6.010105 "Special Education", 6.030102 "Psychology", 6.030103 "Practical Psychology" : navch. posibnik dlya studentiv ta vykladachiv VNZ. Kyiv : Talkom, 2015. 160 p.

8. Pet'ko L.V. Anhliys'ka mova dlya vstupnykiv do mahistratury zi spetsial'nosti 8.01010501 "Korektsiyna osvita (za nozolohiyamy)» [English for entrants to the master's degree in the specialty 8.01010501 "Correctional education (by nosology)"] : navch. posibnyk dlya studentiv, bakalavriv ta aspirantiv VNZ. - 3-ye vyd., stereotypne / L.V.Pet'ko, V.V.Nikolayenko, S.M.Dyshleva ; za red. Honcharova V.I., Syn'ova V.M. Kyiv : Un-t «Talkom», 2014. 199 p.

9. Piesha I., Mikheieva O. Porivnialna kharakterystyka pidhotovky sotsialnykh pedahohiv, shcho pratsiuiut $z$ pryiomnymy simiamy: ukrainskyi ta zakordonnyi dosvid [Comparative characteristics of training of social educators working with foster families: Ukrainian and foreign experience]. Visnyk Cherkaskoho un-tu. 2020. Issue 183. Vol. 2. Pp. 115-120.

10. Yarskaya-Smirnova E., Naberushkina E. Sotsialnaya rabota $s$ invalidami [Социальная работа с инвалидами]. Sankt-Peterburg. Piter. 2004. 316 p. P. 209-211. 
11. Children and Young People with Disabilities - July, 2018. P. 3

12. McLinden, M., Lynch, P., Soni, A. et al. Supporting Children with Disabilities in Low- and Middle- Income Countries: Promoting Inclusive Practice within Community-Based Childcare Centres in Malawi through a Bioecological Systems Perspective. IJEC 50, 159-174 (2018). https://doi.org/10.1007/s13158-018-0223-y

Translation of the Title, Abstract and References to the Author's Language УДК 364.4-056.26 - 053.2 (410)

\section{Британії.}

Різак І. Характеристика соціальної роботи 3 дітьми 3 інвалідністю у Великій

У статті охарактеризовано особливості соціальної роботи з дітьми з інвалідністю у Великій Британії. Визначено поняття діти з інвалідністю. Представлено трактування поняття діти 3 інвалідністю відповідно до медичної та соціальної моделі. Охарактеризовано основні структури, які можуть надавати соціальні послуги у Великій Британії дітям з інвалідністю. Проаналізовано та визначено особливості британської соціальної роботи 3 дітьми 3 інвалідністю в діяльності Центрів соціальних служб. Описано основні види соціальних послуг, що надаються такими центрами. Презентовано концепцію незалежного життя та діяльність центрів незалежного життя. Визначено види послуг, що надаються дітям з інвалідністю та сім'ям, що їх виховують (інформаційні; консультативні; юридичні; послуги ведення домашнього господарства, підтримки у дома, організація дозвілля, послуги опіки. Охарактеризовано програми, які впроваджуються на державному рівні для забезпечення підтримки та надання соціальної допомоги дітям 3 інвалідністю та сім'ям, що їх виховують. Проаналізовано спрямованість державних програм та забезпечення ними надання соціальних послуг щодо покращення результатів освіти дітей з інвалідністю, доступність закладів загальної середньої освіти для таких дітей, партнерське налагодження співпраці між соціальним працівником на рівні громади та з батьками які виховують дитину з інвалідністю, здійснення ранньої підтримки та втручання, програма забезпечує виділення коштів для оплати додаткових відпусток для батьків, що виховують дітей 3 інвалідністю. Охарактеризовано основні напрямами соціальної роботи 3 дітьми 3 інвалідністю у Великій Британії (медико-соціальна робота (основний догляд) та соціальна робота 3 дітьми та сім'ями.

Ключові слова: діти з інвалідністю, соціальні послуги, види соціальних послуг у Великій Британії, форми соціальної роботи 3 дітьми 3 інвалідністю, концепція незалежного життя, британські програми підтримки дітей з інвалідністю.

\section{Jimepamypa}

1. Денесюк О. Професійна підготовка майбутніх соціальних педагогів та фахівців соціальної сфери до здійснення соціально-педагогічної підтримки батьків, які виховують дітей з інвалідністю. Наукові записки Ніжинського державного університету імені М. Гоголя. 2016. №1. С. 173-177.

2. Державна служба статистики. Соціальний захист населення України. Статистичний збірник / Відп. за випуск Кармазіна О. О. Київ. 2018. 121 с. 
3. Комар I. Нормативно-правове забезпечення соціальної роботи 3 дітьми 3 функціональними обмеженнями у Великій Британії. Вісник Чернігівського національного педагогічного університету. Серія педагогічні науки. Том 1. Вип. 104. Чернігів : ЧНПУ, 2012. C. $137-142$.

4. Комар I. Соціальна підтримка дітей із функціональними обмеженнями у Великій Британії. Педагогічна освіта: теорія і пракитика. Психологія. Педагогіка: збірник наукових праць. Київ : Київський університет імені Бориса Грінченка, 2013. № 20. C. $58-62$.

5. Лях Т., Спіріна Т., Рогожинська В. Принципи міждисциплінарної взаємодії у соціальній роботі. Актуальні питання гуманітарних наук. 2020. Том 3. № 27. С. 224-228.

6. Петрочко Ж. Теретико-концептуальні основи соціально-педагогічного забезпечення прав дітей. Актуальні проблеми державного управління, педагогіки та психології: зб. наук. праць ; за ред. В. Бутенко. Херсон : Херсонський НТУ, 2011. С. 314-321.

7. Петько Л В. Англійська мова для студентів-психологів та дефектологів. Дидактичний матеріал для практичних занять та самостійної роботи студентів 3 іноземної мови зі спеціальностей: 6.010105 «Корекційна освіта (за нозологіями)», 6.030102 «Психологія», 6.030103 «Практична психологія»: навч. посібник для студентів, магістрантів, аспірантів. Київ : Талком, 2015. 160 с.

8. Петько Л. В. Англійська мова для вступників до магістратури зі спеціальності 8.01010501 «Корекційна освіта (за нозологіями)»: навч. посібник для студентів, бакалаврів та аспірантів ВНЗ. - 3-є вид., стереотипне / Л.В.Петько, В.В.Ніколаєнко, С.М.Дишлева ; за ред. Гончарова В.І., Синьова В.М. Київ: Ун-т «Талком», 2014. 199 с.

9. Пєша I., Міхеєва О. Порівняльна характеристика підготовки соціальних педагогів, що працюють 3 прийомними сім'ями: український та закордонний досвід. Вісник Черкаського університету. 2010. Том 183. Вип. 2. С. 115-120.

10. Ярская-Смирнова Е., Наберушкина Э. Социальная работа с инвалидами. Санкт-Петербург : Питер. 2004. 316 с. С. 209-211.

11. Children and Young People with Disabilities - July, 2018. P. 3.

12. McLinden, M., Lynch, P., Soni, A. et al. Supporting Children with Disabilities in Low- and Middle- Income Countries: Promoting Inclusive Practice within Community-Based Childcare Centres in Malawi through a Bioecological Systems Perspective. IJEC 50, 159-174 (2018). https://doi.org/10.1007/s13158-018-0223-y 


\title{
Theoretical Aspects of Future Social Workers' Professional Self-Development
}

\author{
Karpenko Olena \\ Doctor of Pedagogical Sciences, Full Professor \\ Dragomanov National Pedagogical University (Kyiv, Ukraine) \\ Ostapchuk Victoria \\ Postgraduate \\ Dragomanov National Pedagogical University (Kyiv, Ukraine)
}

\begin{abstract}
The article defines and reveals the essence of the concepts "professional self-development", "selfdevelopment", presents the essence and ways of forming professional self-development in the future social worker; "self-education" as a component in the development of the future social worker is revealed and substantiated. The authors point out that the most important thing in personal development is consistency. The authors present the ways of forming self-development of future specialists' in the social sphere in the conditions of professional higher education institutions by means of extracurricular activities; theoretical directions of forming students' professional self-development by use of forms and methods of extracurricular activity are given.

Key words: students, social worker, institution of professional higher education, activity, extracurricular activity, self-development, professional self-development, self-analysis, self-assessment, selfeducation.
\end{abstract}

Актуальність дослідження. У контексті нашого дослідження ми визначаємо, що основним завданням формування професійно-особистісних якостей в особистості $€$ постійна робота над своїм самовдосконаленням, самопізнанням, а, також, готовність до безперервної самоосвіти та освіти своїх професійних якостей. Головними особливостями підготовки майбутніх соціальних працівників є зокрема сформувати професійну спрямованість яка б тісно відбувалася у формуванні особистості, а також безперервні процеси розвитку, самопізнання та саморозвитку.

Метою cmammi є аналіз змісту таких основних понять, як професійний саморозвиток, самопізнання у майбутніх соціальних працівників, самовиховання як складові майбутнього соціального працівника. Поняття «саморозвитку», зміст та його складові розглядалася в працях українськи та зарубіжних науковців: А. Грецова, Г. Артемчука, А. Маркової, С. Гончаренка, В. Кременя, В. Фокіної, А. Шаповалова та ін. Так, науковець А. Бистрюкова виокремила структуру професійного саморозвитку майбутнього спеціаліста, яка складалася з особистісних якостей та сукупності видів компетенції, розкриття яких відбувалося послідовно на етапі самовизначення студентом способу самоорганізації i потім забезпечування самореалізації спеціаліста як професіонала. А також вона виділила зовнішні та внутрішні 
чинники та сприяння у формуванні готовності до професійного саморозвитку майбутніх фахівців [9, с. 7-8; 8].

Динамізм соціально-економічних перетворень в нашому суспільстві визначається в даний час необхідністю розробки нових технологій, орієнтованих на розвиток в особистості активності, творчої індивідуальності, професійноособистісного потенціалу. Ці зміни в суспільстві викликають зміни і в системі освіти. Вони пов'язані, перш за все, з демократизацією і гуманізацією процесу навчання, освоєнням в практиці особистісно-орієнтованого, розвивального підходу, пошуком форм і методів педагогічної і психологічної допомоги та підтримки майбутніх соціальних працівників у їх розвитку і саморозвитку професійної майстерності.

Вітчизняна дослідниця Р. Вайнола визначила професійний розвиток особистості як неперервний процес залучення до професійної самореалізації, професії, відбувається вдосконалення особистості як суб'єкта певної професійної діяльності [1, с. 16].

Професійний саморозвиток розкривається лише тоді, коли особистість хоче володіти необхідними якостями. Вони можуть бути такі: професійні завдання, внутрішня мотивація, розуміння особливостей змісту саморозвитку, досягнення високих результатів, мотивація на себе. Саморозвиток може сформуватися досить швидко якщо розвивати основні складові такі як самовиховання та професійне пізнання.

В цілому, професійно-особистісний саморозвиток $\epsilon$ найважливішим елементом професійної діяльності соціального працівника. Професійний саморозвиток соціального працівника розглядається як цілісний багатокомпонентний та професійно-особистісний процес цілеспрямованої діяльності соціального працівника свідомо керувати своїм професійним розвитком, вибір цілей завдань, усвідомлення досвіду власної діяльності є засобом самопізнання.

Розкриваючи особливості професійно-особистісного саморозвитку студентів, можна визначити основні завдання, види діяльності, форми, методи стимулювання в майбутніх соціальних працівників в освітньому просторі. До завдань професійноособистісного саморозвитку відносяться: вироблення навичок і обгрунтування власних позицій та життєвих цінностей, сформування у студентів здатності мислити неординарно, уміння співпрацювати, вступати в партнерський діалог, виявляючи при цьому толерантність, доброзичливість, педагогічний такт тощо. 
Дана проблема є актуальною для вищої освіти, тому що заклад вищої освіти стає середовищем розвитку особистості для багатьох випускників шкіл, частка яких змирилася з беззмістовністю життя і незатребуваності їхніх сутнісних сил внаслідок обумовленого відходу освіти від мети виховання - формування унікальної, цілісної і вільної особистості, здатної усвідомлено створювати свою якість життя, вибудовувати і здійснювати власний життєвий шлях.

Зародження поняття «саморозвитку» почалося ще в Давній Греції, піфагорійці розглядали саморозвиток як свідомий процес. Сократ був одним із перших, хто розкрив проблему самопізнання та саморозвитку. Він вважав що людина $є$ центром наукового пізнання і тому метою самопізнання є розвиток задатків і почуттів, які спрямовані на розвиток добра та почуттів людини.

Проблематика саморозвитку на різних історичних етапах була розглянута та розкрита різними педагогічними школами і філософами в яких відображалися практики саморозвитку, досвід роботи вчених на різних історичних етапах розкрив соціальну та індивідуальну значущість самовиховання, самоосвіти, самовдосконалення. Мислителі протягом тривалого часу відтворювали у своїх концепціях усвідомлення сутнісних рис та форм саморозвитку особистості, спрямованість і залежність від домінуючих цінностей, створювалися також і релігійні доктрини (Аристотель, Конфуцій, Платон, Сенека, Сократ та ін.).

Отже, досліджуючи особливості саморозвитку (самовдосконалення, самоосвіта, самовиховання) особистості (що розглядалися в другій половині 21 століття), визначилися три основні напрямки: філософській, соціологічний та психолого-педагогічний, тому зауважимо, що значний внесок у розробку психологопедагогічного напрямку саморозвитку зробили О. Богданов, О. Ковальов, О. Кочетков, Ю. Самарін, В. Селіков, В. Сухомлинський, Л. Рувінський та ін.

У цілому саморозвиток соціального працівника як майбутнього спеціаліста розкривається за таких основних напрямках: розвиток здібностей, удосконалення психічно-особистісних процесів, підвищення почуття обов'язку, прояв почуття самовідповідальності, зміцнення професійної спрямованості, формуються необхідні якості такі як: зростання загальної зрілості та стійкості, зміцнення професійних якостей та готовності до майбутньої професійної діяльності соціального працівника $[4$, с. $75 ; 3 ; 4 ; 12 ; 13]$.

Основна роль значення самопізнання у професійній діяльності розглядалася та досліджувалася Т. Веретенко, Л. Мельничук, Л. Мітіної, М. Ткач, О.Степановою та 
ін. Самопізнання визначається як свідомий процес управління своїми особистісними якостями та здібностями.

Розглядаючи питання професійного самопізнання, вітчизняні вчені О. Степанова та М. Ткач стверджують, що самопізнання існує під впливом мотивацій, особливостями спілкування, і є своєрідною діяльністю [10, с. 37].

Загалом професійне самопізнання набуває особливої актуальності у період навчальної діяльності, а саме в даний період формуються мотиваційні цінності, когнітивні і рефлексивно-діяльнісні аспекти професійного саморозвитку особистості. Таким чином важливим завданням навчального закладу $\epsilon$ стимулювання особистісних потреб саморозвитку майбутніх соціальних працівників [7, с. 43].

Аналізуючи наукові дослідження, можна стверджувати, що процес професійного самопізнання є важливою складовою професійного саморозвитку, який вступає в процеси планування, реалізації планів та контролю. Через що, в процесі самопізнання, студент виокремлює свої здібності та можливості в обраному напрямку, а також має змогу підвищувати рівень свого професійного розвитку.

На думку I. Мельничук, професійне пізнання повинно здійснюватися в декількох напрямах: самопізнання себе в системі соціально-психологічних стосунках та навчально-діяльнісних стосунків, які передбачають самопізнання особистих якостей, що здійснюються шляхом самоспостереження, самоаналізу, поведінки, самоперевірки, самооцінки, вияву умінь якостей особистості, що забезпечує критичне ставлення майбутнього соціального працівника до своїх досягнень і недоліків. А мотиваційний компонент професійної моделі майбутнього фахівця соціальної сфери характеризується наявністю пізнавального інтересу до професії, пізнавальною активністю, що зумовлюється прагненням до виявлення таких професійних позицій, які можна і потрібно покращити, тобто, спрямованістю до саморозвитку [7 с. 99].

Висновок. Отже, професійний саморозвиток майбутнього соціального працівника - це комплексний підхід, у процесі якого майбутній соціальних працівників забезпечує високу якість професійного саморозвитку. Майбутній фахівець соціальної сфери має бути готовим до непередбачуваних ситуацій, кризових умов, уміти приймати правильне рішення в екстремальних умовах. Професійний саморозвиток соціального працівника розкривається як цілісний багатокомпонентний та професійно-особистісний процес цілеспрямованої діяльності соціального працівника, його здатності свідомо керувати своїм професійним розвитком, вибором цілей і завдань, усвідомленням досвіду власної діяльності як 
засобом самопізнання. Основним чинником цих вимог є професійний саморозвиток та самовиховання.

Слід зазначити, що саморозвиток та самовиховання $\epsilon$ складовими професійного саморозвитку у формуванні необхідної роботи над собою. Слід зауважити, що на етапі професійного самопізнання формується мотиваційний компонент професійної моделі майбутнього соціального працівника.

\section{References}

1. Vainola R. Kh. Pedahohichni zasady osobystisnoho rozvytku maibutnoho sotsialnoho pedahoha u protsesi profesiinoi pidhotovky [Pedagogical principles of personal development of the future social pedagogue in the process of professional training]: dys. ... d-ra ped. nauk: 13.00.04 «Teoriia i metodyka profesiinoi osvity». Kyiv, 2009. 542 p.

2. Hlavatska O. L. Osnovy samovykhovannia osobystosti [Fundamentals of selfeducation of the individual] : navch.-metod. posib. Ternopil : Knyha, 2008. 206 p.

3. Karpenko O. H. Rol pedahohichnykh mozhlyvostei u protsesi hromadianskoho stanovlennia studentiv [The role of pedagogical opportunities in the process of civic formation of students]. Naukovyi chasopys Natsionalnoho ped. un-tu imeni MP Drahomanova. Seriia 11: Sotsialna robota. Sotsialna pedahohika. 2018. Issue 24 (2). Pp. 224-231.

4. Karpenko O. H. Teoretyko-metodolohichni pidkhody do pidhotovky maibutnikh sotsialnykh pratsivnykiv $u$ vyshchykh navchalnykh zakladakh [Theoretical and methodological approaches to the training of future social workers in higher education]. Naukovyi chasopys Natsionalnoho ped. un-tu imeni M. P. Drahomanova. Seriia 11 : Sotsialna robota. Sotsialna pedahohika: zb. nauk. prats. Kyiv : Vyd-vo NPU imeni M. P. Drahomanova, 2018. Issue 25. Pp. 73-79.

5. Karpenchuk S. H. Samovykhovannia osobystosti [Self-education of the individual] : navch. posib. Kyiv : IZMN,1998. 216 p.

6. Lozovyi V. O., Sidak L V. Samorozvytok osobystosti u filosofskii refleksii ta sotsialnii praktytsi [Self-development of personality in philosophical reflection and social practice] : monohrafiia. Kharkiv : Pravo, 2006. 256 p.

7. Melnychuk I. Teoriia i praktyka profesiinoi pidhotovky maibutnikh sotsialnykh pratsivnykiv zasobamy interaktyvnykh tekhnolohii [Theory and practice of professional training of future social workers by means of interactive technologies] : monohrafiia. Ternopil : Ekonomichna dumka, 2010. 326 p.

8. Petko L.V. Vyklyky XXI stolittia dlia osvitnoho prostoru Ukrainy. Naukovi pratsi ChNU: nauk. zhurnal [The challenges of educational space in the 21- ${ }^{\text {st }}$ century] / Chornom. Nats. un-t im. Petra Mohyly; red. Kol.: O.P.Meshchaninov (holova) [ta in.]. Mykolaiv: Vydvo ChNU imeni Petra Mohyly, 2017. Issue 303. Vol. 291. Pp. 10-14.

9. Tymoshenko N.Ie. Vstup do spetsialnosti: sotsialna robota. Modul 2 [Introduction to the specialty: social work] : navch. posib. Kyiv : Kyiv. un-t imeni Borysa Hrinchenka, 2014. 264 p.

10. Tkach M. V., Stepanova O. H. Pro sutnist profesiinoho samopiznannia [On the essence of professional self-knowledge]. URI : http://www.rusnauka.com. 
11. Trotsenko N. Ie. Profesiine samovdoskonalennia sotsialnykh pratsivnykiv $u$ resursnykh tsentrakh [Professional self-improvement of social workers in resource centers] : dys... kand. ped nauk : 13.00.05. Luhansk, 2011.243 p.

12. Karpenko O. G. The formation of professionalism in future social workers in the conditions of higher school // Geopolitical processes in the world today: Collection of scientific articles. - «East West» Association for Advanced Studies and Higher Education. Vienna (Austria). 2016. Pp. 301-304.

13. Pet'ko Lyudmila. Developing students' creativity in conditions of university // Research: tendencies and prospects: Collection of scientific articles. - Editorial Arane, S.A. de C.V., Mexico City, Mexico, 2017. Pp. 272-276.

\section{Translation of the Title, Abstract and References to the Author's Language}

\section{УДК 377.027.7}

Карпенко Олена, Остапчук Вікторія. Теоретичні аспекти професійного саморозвитку майбутніх соціальних працівників.

У статті визначено та розкрито суть понять «професійний саморозвиток», «саморозвиток», представлено сутність та шляхи формування професійного саморозвитку в майбутнього соціального працівника; розкривається та обгрунтовується «самовиховання» як складова розвитку майбутнього соціального працівника. Автором вивчаються питання саморозвитку майбутніх фахівців соціальної сфери в умовах закладу фахової передвищої освіти засобами позанавчальної діяльності; надаються теоретичні напрямки формування професійного саморозвитку у студентів шляхом використання форм та методик позанавчальної діяльності

Ключові слова: студенти, соціальний працівник, діяльність, позанавчальна діяльність, саморозвиток, професійний саморозвиток, самоаналіз, самооцінка, самовиховання.

\section{Лimepamypa}

1. Вайнола Р. Х. Педагогічні засади особистісного розвитку майбутнього соціального педагога у процесі професійної підготовки : дис. ... доктора пед. наук: 13.00 .04 «Теорія і методика професійної освіти». Київ, 2009. 542 с.

2. Главацька О. Л. Основи самовиховання особистості : навч.-метод. посіб. Тернопіль : Книга, 2008. $206 \mathrm{c}$.

3. Карпенко О.Г. Роль педагогічних можливостей у процесі громадянського становлення студентів. Науковий часопис Національного педагогічного університету імені МП Драгоманова. Серія 11: Соціальна робота. Соиіальна педагогіка.-2018. Вип. 24 (2). С. 224-231. URI : http://nbuv. gov. ua/UJRN/Nchnpu_011_2018_24\% 282\% $29 \_33$

4. Карпенко О.Г. Теоретико-методологічні підходи до підготовки майбутніх соціальних працівників у вищих навчальних закладах. Науковий часопис Національного педагогічного університету імені М. П. Драгоманова. Серія 11 : Сойіальна робота. Соціальна педагогіка : зб. наук. праць. Київ : Вид-во НПУ імені М. П. Драгоманова, 2018. Вип. 25. С. 73-79.

5. Карпенчук С. Г. Самовиховання особистост і: навч. посіб. Київ: IЗМН,1998. 216 с. 
6. Лозовий В О., Сідак Л. В. Саморозвиток особистості у філософській рефлексії та соціальній практиці: монографія. Харків : Право, 2006. 256 с.

7. Мельничук I. Теорія і практика професійної підготовки майбутніх соціальних працівників засобами інтерактивних технологій : монографія. Тернопіль : Економічна думка, 2010. 326 с.

8. Петько Л. В. Виклики XXI століття для освітнього простору України. Наукові праці [Чорноморського державного університету імені Петра Могили комплексу "КиєвоМогилянська академія"]. Серія : Педагогіка : наук. журн. / Чорном. держ. ун-т імені Петра Могили; ред. кол. : О. П. Мещанінов (голова) [та ін.]. Миколаїв : Вид-во ЧНУ імені Петра Могили, 2017. Т. 303. Вип. 291. С. 10-14.

9. Тимошенко Н. Є. Вступ до спеціальності : соціальна робота. Модуль 2 : навч. посіб. Київ : Київ. ун-т імені Бориса Грінченка, 2014. 264 с.

10. Ткач М. В., Степанова О.Г. Про сутність професійного самопізнання. URI :http://www.rusnauka.com.

11 Троценко Н. С. Професійне самовдосконалення соціальних працівників у ресурсних центрах: дис... канд. пед наук : 13.00.05. Луганськ, 2011. 243 с.

12. Karpenko O. G. The formation of professionalism in future social workers in the conditions of higher school // Geopolitical processes in the world today: Collection of scientific articles. - «East West» Association for Advanced Studies and Higher Education. Vienna (Austria). 2016. P. 301-304.

13. Pet'ko Lyudmila. Developing students' creativity in conditions of university // Research: tendencies and prospects: Collection of scientific articles. - Editorial Arane, S.A. de C.V., Mexico City, Mexico, 2017. P. 272-276. 


\title{
Studying Gardens of the World with Students of Higher Education Establishments
}

\author{
Turchynova Ganna \\ Candidate of Pedagogic Sciences, Associate Professor \\ Dragomanov National Pedagogical University \\ Pet'ko Lyudmila \\ Candidate of Pedagogic Sciences, Associate Professor \\ Dragomanov National Pedagogical University \\ Holovko Tamila \\ Student of Faculty of Science Education and Ecology \\ Dragomanov National Pedagogical University (Ukraine, Kyiv) \\ We all have within us a need to create beauty. \\ And we all can in a garden, however small. \\ It is this need which has written the history of gardens. \\ Audrey Hepburn
}

\begin{abstract}
The image of one of the greatest actresses, Audrey Hepburn, is presented in different ways: actress, model, dancer, the Goodwill Ambassador for UNICEF. Audrey Hepburn, who loved nature and gardens, saw a rare opportunity to bring forth their beauty in poetic and meaningful ways in Gardens of the World. Her unique vision of the series included fusing the historical and aesthetic aspects with the arts of literature, music and painting.

Gardens of the World was filmed on location around the world, including:- Claude Monet s garden at Giverny; George Washington s Estate at Mount Vernon; the ancient moss temple garden Saiho-ji in Kyoto Japan; gardens at Mottisfont Abbey, Tintinhull House, Chilcombe Garden, Hidcote Bartram Village and Hidcote Manor in England; the Keukenhof Garden and the Tulip Fields of Lisse in the Netherlands, Villa Pancha in the Dominican Republic; Giardini di Ninfa and Villa Gamberaia in Italy; La-Roseraie de L Haÿ-les-Roses, Chateau de Courances, Jardin du Luxembourg, and Jardin du Luxembourg in France. The 8 episodes explore: Roses \& Rose Gardens, Formal Gardens, Tulips and Spring Bulbs, Country Gardens Japanese Gardens Flower Gardens, Tropical Gardens, Public Gardens and Trees. Each episode presents a different garden theme as well as broader concepts of aesthetic, botanical, cultural or environmental significance.
\end{abstract}

Key words: gardens, Audrey Hepburn, students, uniuversities, foreign language.

Introduction. Actress and humanitarian Audrey Hepburn, star of "Roman Holiday" (1953, Fig. 1), "Sabrina" (1954), "The Nun's Story", "Love In The Afternoon", "The Children's Hour", "My Fair Lady" (1964), "Two For The Road", "Charade" (1963), "How to Steal a Million", "Breakfast at Tiffany's" (1961), "Wait 
Until Dark" (1967) and other, remains one of Hollywood's greatest style icons (Fig. 2) and one of the world's most successful actresses. Gardens of the World with Audrey Hepburn is her final filmed project (Fig. 3).

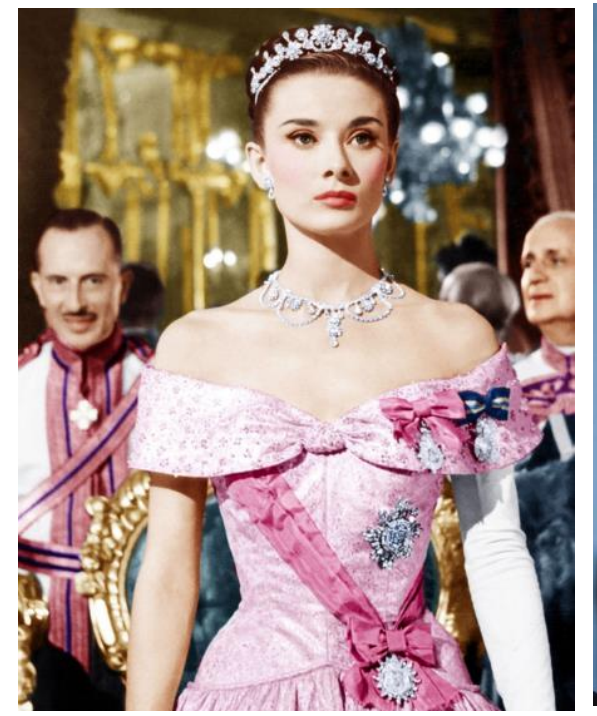

Fig. 1. Roman Holiday (1953).
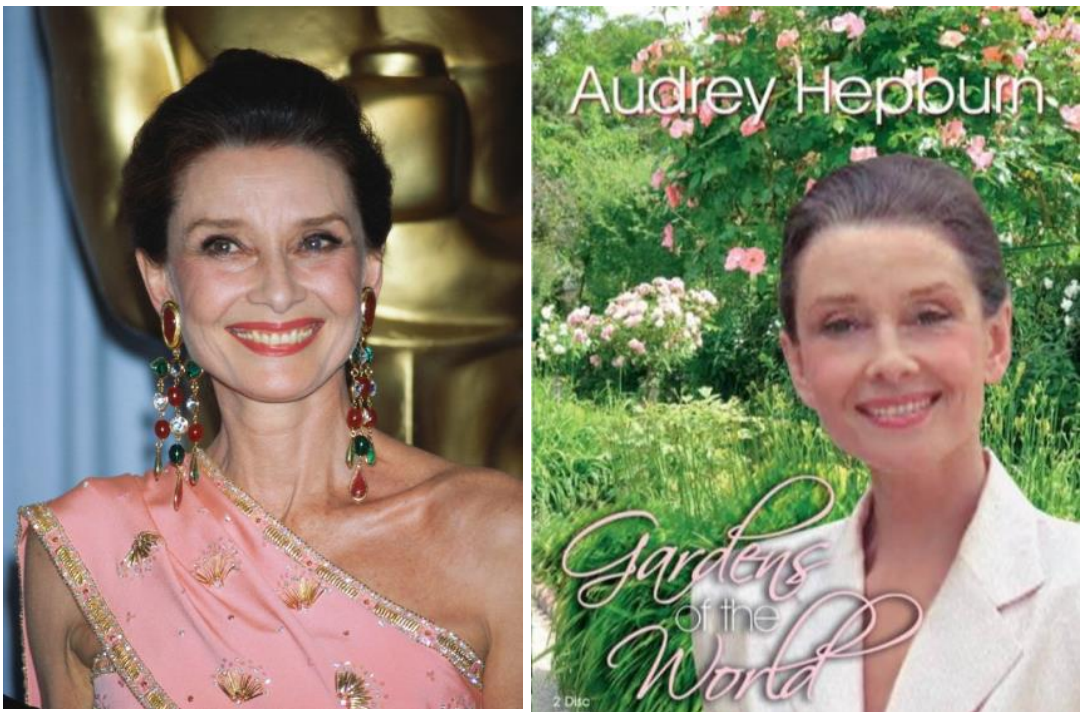

In the context of our research the formation of professional readiness of future Biology teachers has studied V. Bobrytska, A. Derkach, L. Horiana, N. Andreeva, L. Barna; some problems of the formation and development of personality in the process of preparation for professional activity and directly in its process are highlighted in the researches of L. Vygotskyi, O. Leontiev and others; using of the latest technologies and methods in teaching foreign languages for professional needs (O. Tarnopolski, S. Nikolaeva, G. Turchynova, L. Petko, V. Bezliudna, Z. Korneva).

The students at Biology department of universities can visit online many of the more famous gardens of the world with Audrey Hepburn and learn of their secrets [9; 13]. This documentary series is beautifully narrated by the elegant presence of garden lover, Audrey Hepburn. Visually lush, richly informative, refreshing, beautiful, Gardens of the World with Audrey Hepburn serves up a veritable treatise on our most illustrious cultivated environs. Each episode sets forth a different garden theme informed by broader concepts of aesthetic, historical or environmental importance, from masterful archetypes of the Italian Renaissance and 17th Century France, in Formal Gardens, to the world's first great story of urban renewal, "The Greening of Paris," in Public Gardens and Trees. All 8 episodes are wonderful and the interview 
with Audrey is a great bonus that shows us again what a special and great woman she was.

The aim of publishing papers is to present the importance of the highlyacclaimed documentary series Gardens of the World with Audrey Hepburn for the professional training of future Science teachers in the conditions of university.

The materials and the results of the research. Gardens of the World with Audrey Hepburn is a beautiful collector's series filmed on location, featuring some of the most beautiful gardens from around the world. Audrey Hepburn is as elegant as ever as she guides you on this magical journey and walks you through each of these magnificent landscapes, quoting some of her favorite authors and poets, and sharing her love and knowledge of gardens. Audrey Hepburn won an Emmy® Award for "outstanding individual achievement" in the making of this program.

Audrey Hepburn's final filmed project before her death, this gardening show is just about perfect. Magnificent gardens, fascinating historical information, Michael York's smooth and lilting narration and beautiful classical music mixed with the organic sounds of nature make this thoroughly enjoyable. But it is the moments when Ms Hepburn is on screen that are truly magical. As she gracefully walks through the landscapes and shares her love of all things horticultural with the audience.

The scene where she reads from Anne Frank's diary is just stunning (Anne Frank's diary has been translated into more than 70 languages). The chestnut tree that's been described by Anne has fallen this year, after a long struggle for survival. Audrey reads this part with so much insight, so much light, that in a way, she revives Anne's passion for life, and the tree that inspired her to write such wisdom at such a young age [8].

Audrey and Anne were two dark-haired Dutch girls who had been born in other countries. Both of these ladies were born in 1929 and have inspired countless people with their bravery; one in the written word, and the other through her emotionallycharged performances. They were less than six weeks apart in age Audrey born May 41929 (Fig. 4). and Anne, June 121929 (Fig. 6). And Anne had even known of and commented upon executions in Goirle when she wrote from the Franks' hidden 
rooms: "Prominent citizens - innocent people - are thrown into prison to await their fate. If the saboteur can't be traced, the Gestapo simply put about five hostages against the wall. Announcements of their deaths appear in the papers frequently [21]". Anne Frank wrote in her diary for two years while her family was in hiding in Amsterdam.
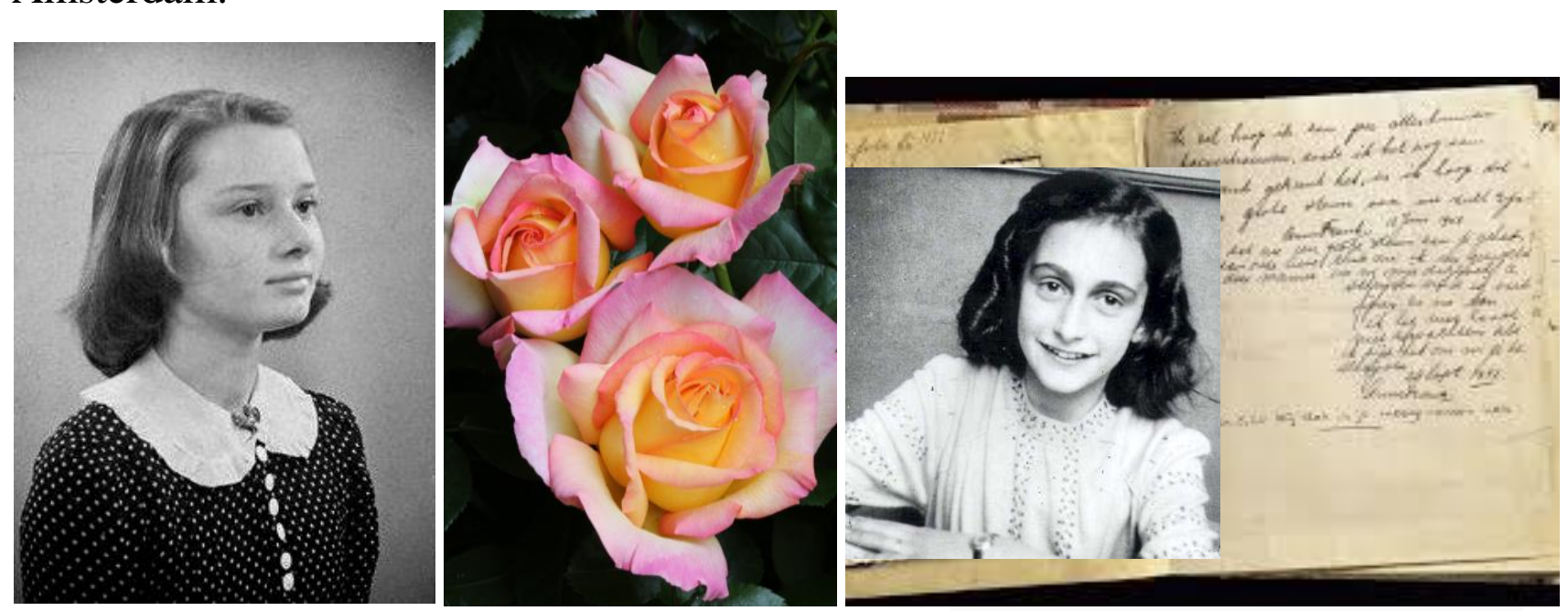

Fig. 4. Audrey Hepburn in Fig. 5. The Rose Peace (1945). Fig. 6. Anne Frank's diary1942-1944. occupied Holland (1943). Amsterdam.

Anne Frank was an ordinary teenage girl. Although she was originally from Germany, she was living in Holland when II World War broke out in 1939, as her parents had decided to leave their home country for safety reasons in 1933. In July 1942, they had to go into hiding on the top floor of a building in Amsterdam, where they lived for two years, because things were getting really difficult for Jewish families. In the summer of 1944, not long before the British, the Americans and their allies finally won the war and drove the German army away, her diary suddenly stopped. The Nazis killed Anne Frank, but luckily for everybody, they couldn't kill her memory [4], see movie [11].

Nature and flowers had special meaning for Audrey Hepburn due to the hope they brought after the World War II, assuring food was coming and reminding her to appreciate nature's beauty.

Audrey Hepburn became a fashion and cultural icon, and continues to be so today. She was also a magnificent humanitarian [6]. The memories of World War II horrors shaped her desire to help children and she became a goodwill ambassador for 
UNICEF in the late 1980s. Traveling the world, Hepburn tried to raise awareness about children in need. She understood too well what it was like to go hungry from her days in the Netherlands during the German Occupation. Making more than 50 trips, Hepburn visited UNICEF projects in Asia, Africa and Central and South America. She won a special Academy Award for her humanitarian work in 1993.

Marking the 70th anniversary of the United Nations' Universal Declaration of Human Rights, experience music that celebrates the triumph of the human spirit. Hear Grammy Award-winning mezzo-soprano Isabel Leonard narrate Michael Tilson Thomas' spellbinding musical setting From the Diary of Anne Frank, a piece written for Audrey Hepburn and UNICEF in 1990 [7]. Performance of "Elegy for Anne Frank" by Lukas Foss at The Oslo Concert [15], arranged in 1990 by Eli Wiesel Nobel Peace Prize Lauriate 1986. Audrey Hepburn's reciting from "The Diary of Anne Frank" starts at 5.12 [7].

Hepburn's first field mission for UNICEF was to Ethiopia in 1988 (Fig. 7, 9). She visited an orphanage in Mek'ele that housed 500 starving children and had UNICEF send food [5].

The United States President George Bush presented Hepburn with the Presidential Medal of Freedom (see video [10]) (Fig. 8) in recognition of her work with UNICEF, and the Academy of Motion Picture Arts and Sciences posthumously awarded her the Jean Hersholt Humanitarian Award for her contribution to humanity. Unfortunately, due to severe illness, Audrey Hepburn was unable to attend the medal ceremony.

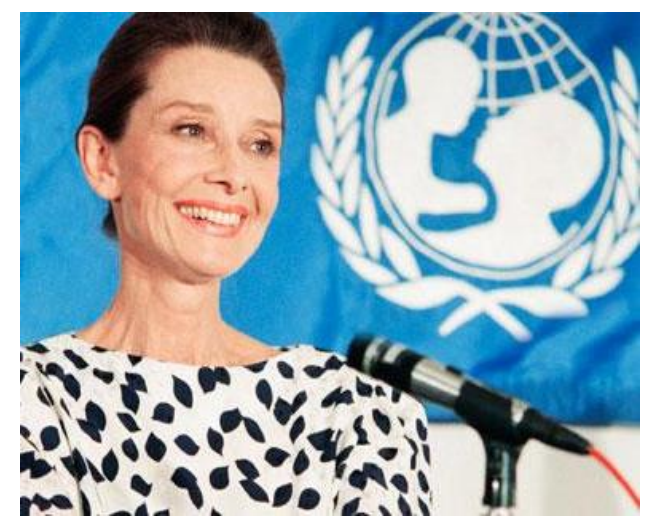

Fig. 7. Ambassador of UNICEF

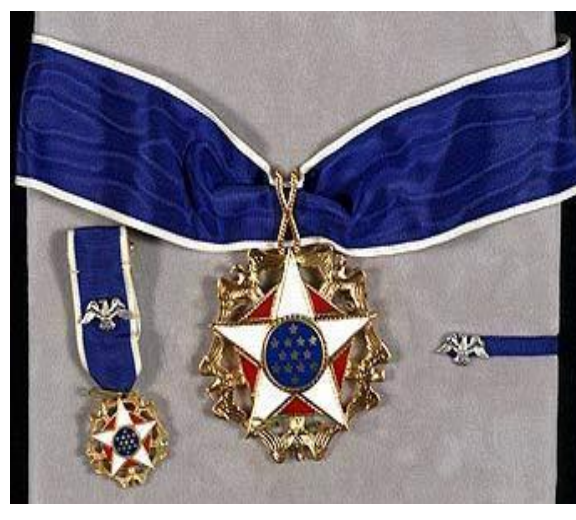

Fig. 8. Presidential Medal of Freedom.

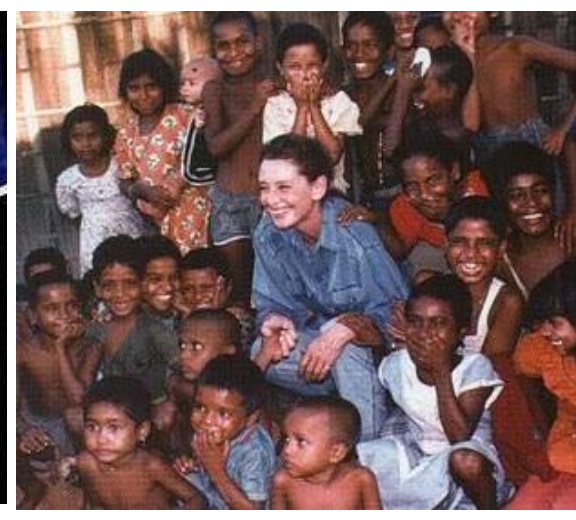

Fig. 9. Audrey Hepburn in Ethiopia. 
By the way Gardens of the World with Audrey Hepburn is an acclaimed documentary television series that debuted in the United States on PBS on January 21, 1993, filmed on location in seven countries in the spring and summer of 1990. Hepburn was awarded an Emmy for Outstanding Individual Achievement posthumously. The series features Hepburn visiting exemplary and elegant gardens both private and public; each episode sets forth a different garden theme, as well as aesthetic, environmental, historical or horticultural concepts. Interspersed with Hepburn's on-camera performances are expository and historical background segments narrated both by Audrey Hepburn and Michael York [12].

These are: Episode 1. "Roses and Rose Gardens": An adventure with the flower of legend, romance and beauty (see video [9]). Episode 2. "Formal Gardens": A journey through the evolution of formal garden design. Episode 3. "Country Gardens": An exploration of the earthly country garden. Episode 4. "Public Gardens and Trees": The stories of Mt. Vernon and the greening of Paris, concluding with Hepburn's tribute to trees and nature. Episode 5. "Flower Gardens": An exploration of Monet's gardens at Giverny and classic English perennial border styles. Episode 6. "Tropical Gardens": A wide ranging affirmation of nature's floral diversity. Episode 7. "Japanese Gardens": A journey reflecting centuries of Japanese cultural reverence for nature. Episode 8. "Tulips and Spring Bulbs": A focus on spring blossoms and their inspiration as art and in the garden. Some of the gardens featured in the show include: Claude Monet's gardens at Giverny, George Washington's estate at Mount Vernon, and Jardin du Luxembourg in Paris [12].

Back to studying gardens of the world. Episode 1. "Roses and Rose Gardens" [9].

A rose garden or rosarium is a garden or park, often open to the public, used to present and grow various types of garden roses or rose species. Designs vary tremendously and roses may be displayed alongside other plants or grouped by individual variety, colour or class in rose beds [35].

A rose is a woody perennial flowering plant of the genus Rosa, in the family Rosaceae, or the flower it bears. There are over three hundred species and tens of tens thousands of cultivars. They form a group of plants that can be erect shrubs, climbing, 
or trailing, with stems that are often armed with sharp prickles. The name rose comes from French, itself from Latin rosa [34].

Episode 1 (Fig. 12) Miss Audrey Hepburn's opening:

Dear rose, thy joy's undimmed,

Thy cup is ruby-rimmed,

Thy cup's heart nectar-brimmed [9].

It's poem "Women and Roses" by Robert Browning (1812-1889), Fig. 10, 11. He was an eminent British poet of the Victorian period. He is also classified among outstanding Romantics, such as, Wordsworth, Shelley, Keats and so on [33].

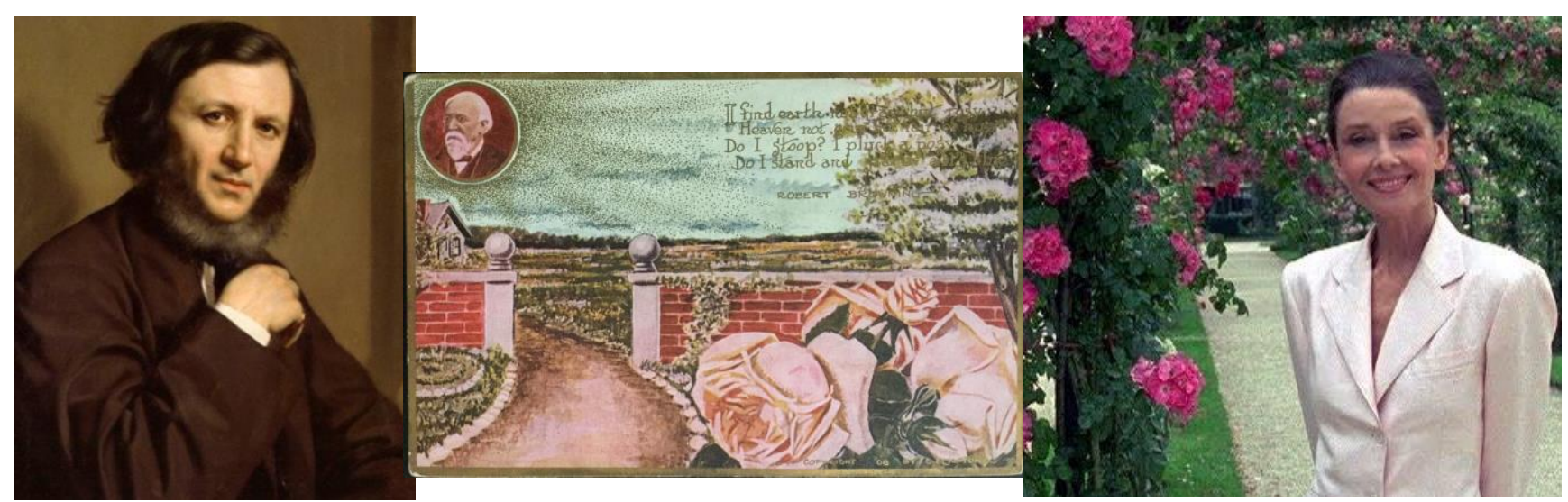

Fig. 10. Robert Browning. Fig. 11. Poem "Women and Roses".

Fig. 12. Episod 1 [14].

Audrey Hepburn leads an eloquent adventure in pursuit of the breadth and beauty of the rose: old roses, modern roses, wild roses; floribundas, climbers, and ramblers; Bourbons, Damasks, Gallicas [22] and Hybrid Teas. From the French ideal of a rose garden south of Paris at La Roseraie de l'Hays les Roses (La Roseraie du Val-de-Marne, see video [49], Fig. 13, 14) to the unsurpassed collection and allure of

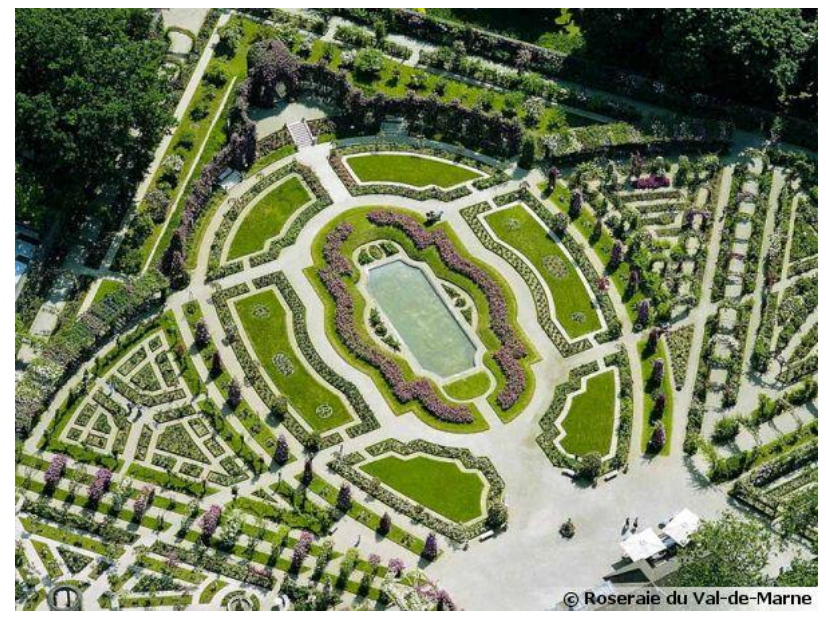

Fig. 13. Roseraie du Val de Marne, Paris.

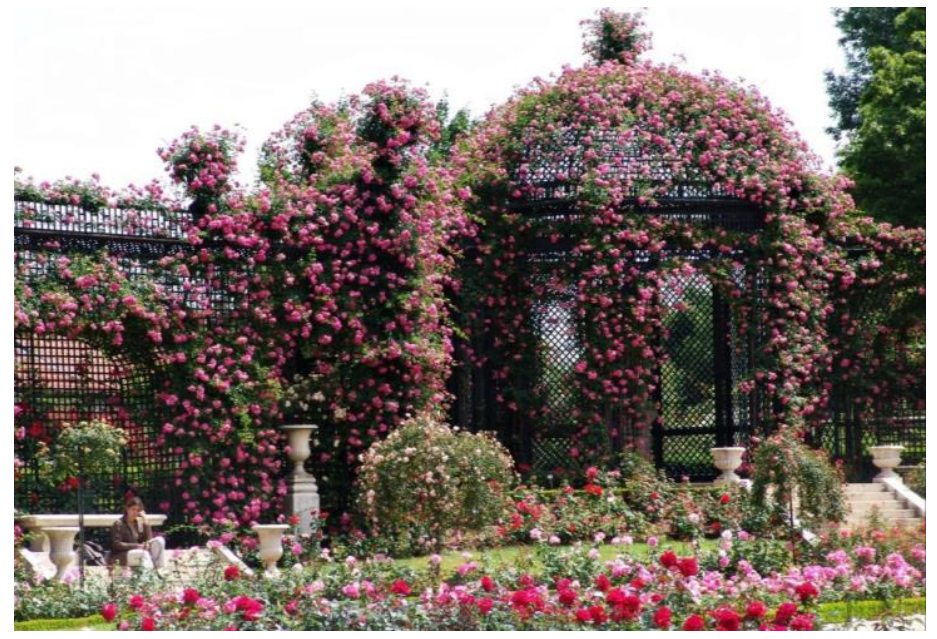

Fig. 14. Roseraie du Val de Marne. Dome.

old roses duringhigh rose tide at Mottisfont Abbey in Hampshire, England (Fig. 15, 19, 20), the rose affirms its rightful place as the ultimate flower of legend, romance 
and beauty. Appearing with Audrey Hepburn: Sir Graham Stuart Thomas (Fig. 16), one of the 20th century's greatest rosarians and author of world renown [36].
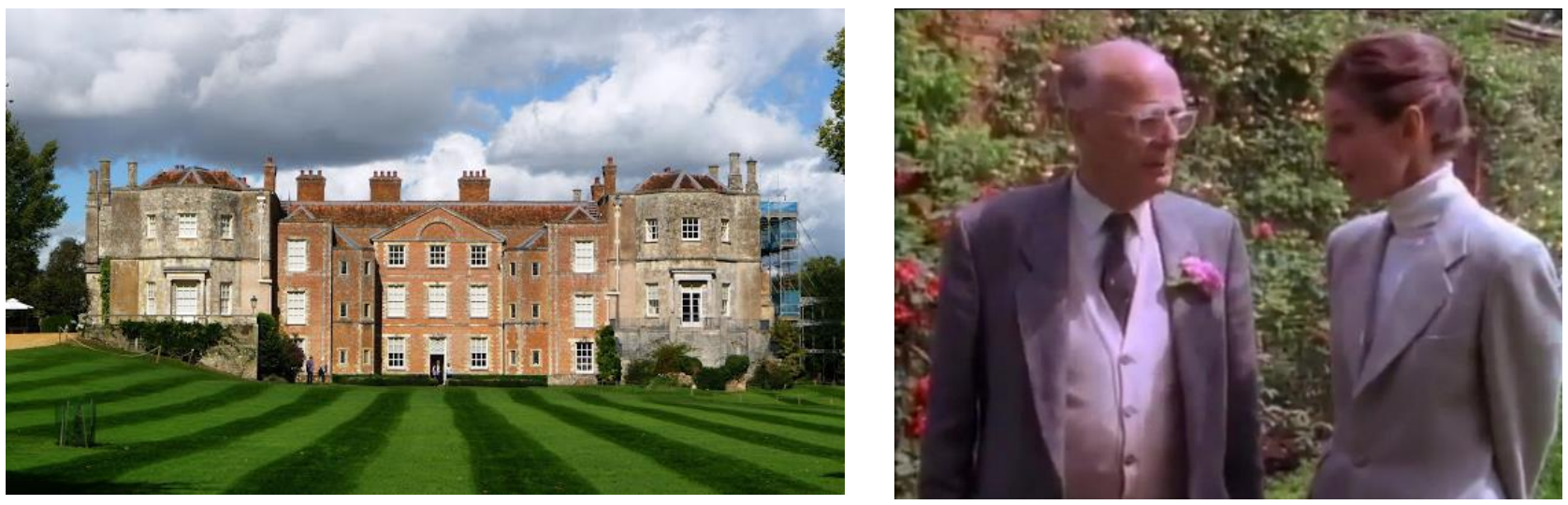

Fig. 15. Mottisfont Abbey in Hampshire, England. Fig. 16. With Sir Graham Stuart Thomas.

Mottisfont Abbey's walled garden has been home to the National Collection of old-fashioned roses since the 1970's when world-famous rosarian Graham Stuart Thomas (who has a yellow David Austin rose named after him, Fig. 18), re-designed the former kitchen garden at this former Augustinian abbey for the National Trust.

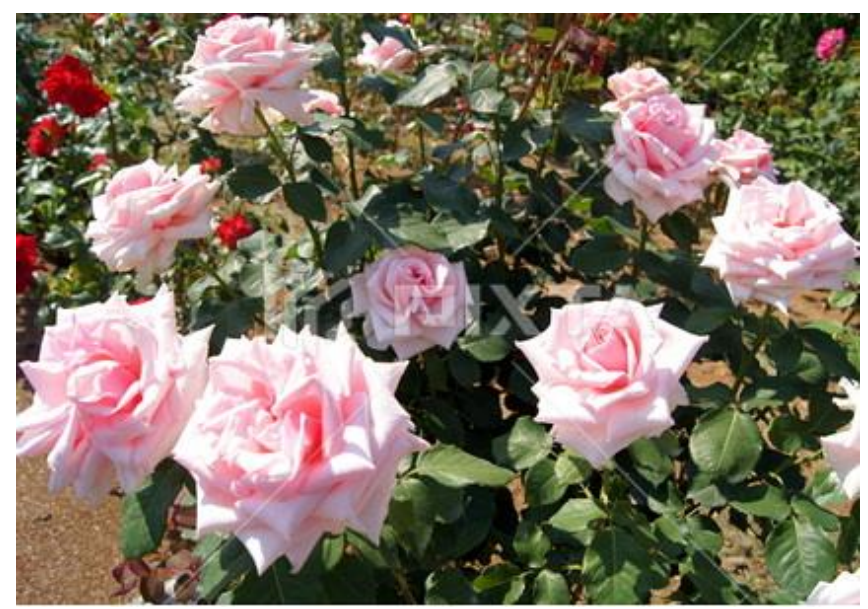

Fig. 17. Audrey Hepburn roses by breeder Jerry Twomey.

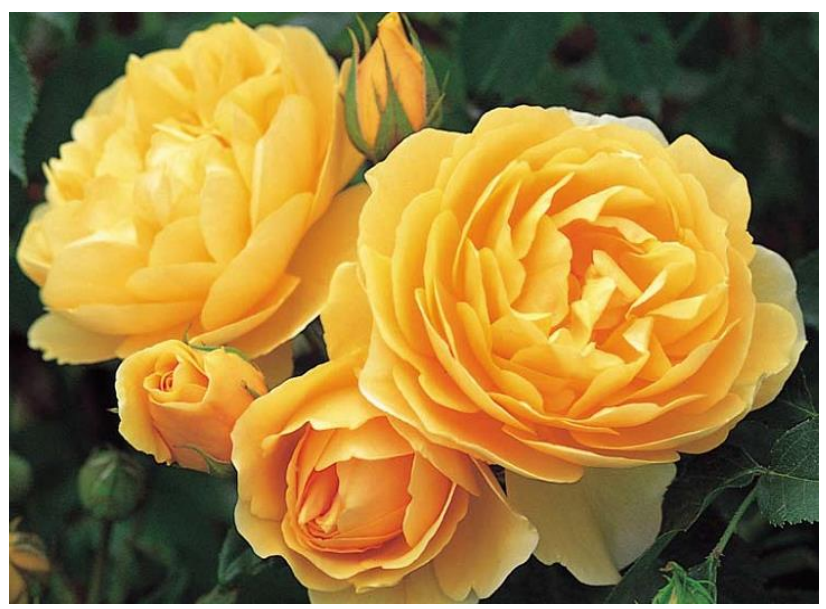

Fig. 18. Rosa Graham Thomas.

Four decades later, the rose garden is one of the most famous in the world and draws visitors from far and wide to marvel at the wonderfully scented garden.

The collection of roses is quite breathtaking.

The Abbey, which dates in part to the 13th century provides a striking backdrop to a 21-acre garden -designed in part by Sir Geoffrey Jellicoe. [37].

Set by the banks of the crystal River Test, cutting through the chalk downland, sits Mottisfont Priory, dating to the 13th Century and with a colourful history right up to the 20th Century with Maud and Gilbert Russell bringing life again to the old 
house and the National Trust subsequently taking the House and Gardens into its care - and particularly honouring its rose heritage [20].

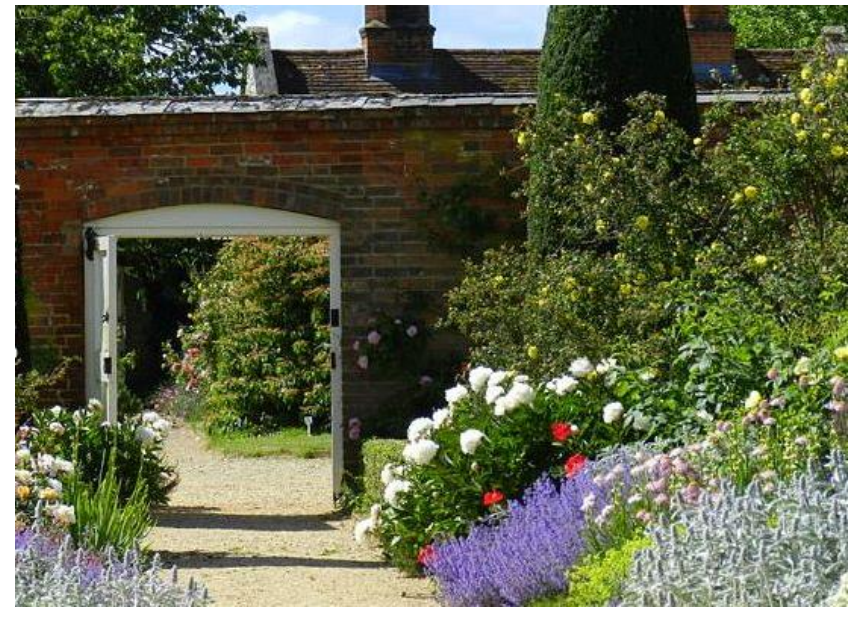

Fig. 19. Entrance to the walled garden.

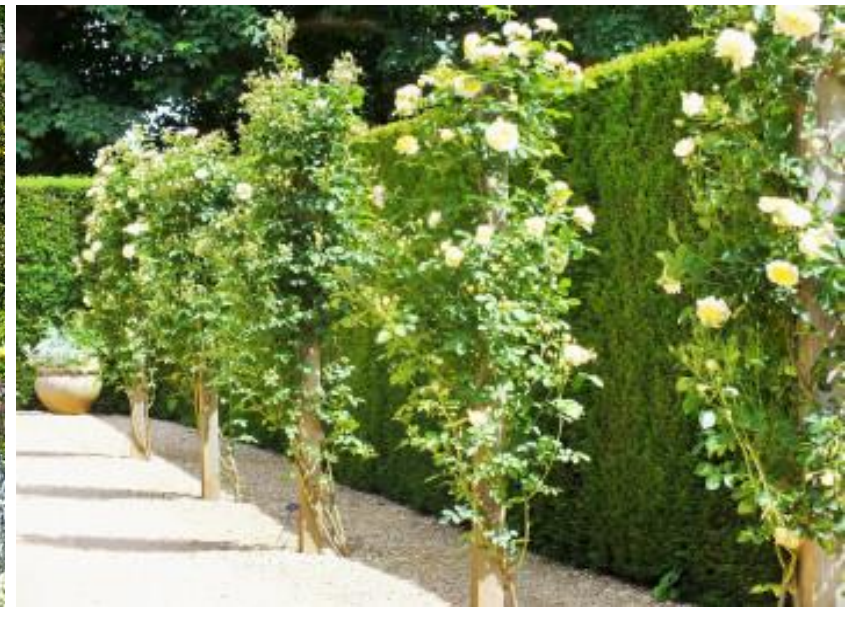

Fig. 20. The Pilgrim.

Audrey Hepburn ends "Roses and Rose Gardens" with words from song "A Red, Red Rose" (1794) in Scots by Robert Burns (video at 20.06 min [9]:

O my Luve's like a red, red rose

That's newly sprung in june;

O my Luve's like the melodie

That's sweetly play'd in tune... [1].

Our students can sing and listen to an old romantic ballad written by Scotland's National Poet, Robert Burns (1759-1796, Fig. 21, 22), sung and played by Josienne Clarke and Ben Walker [38].

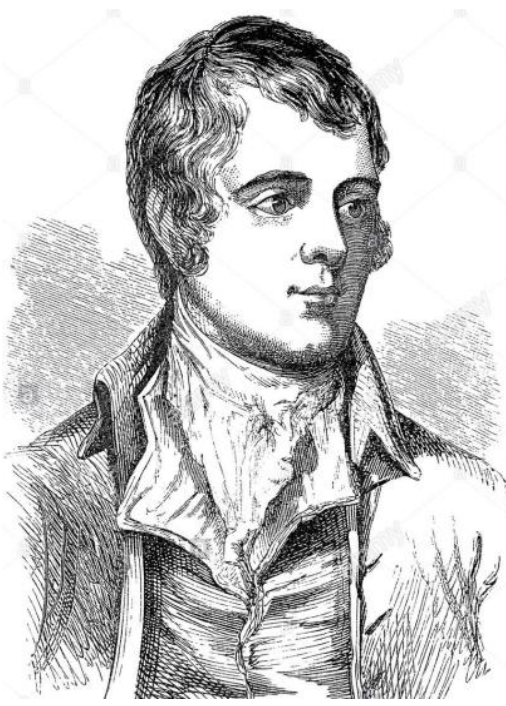

Fig. 21 Robert Burns.
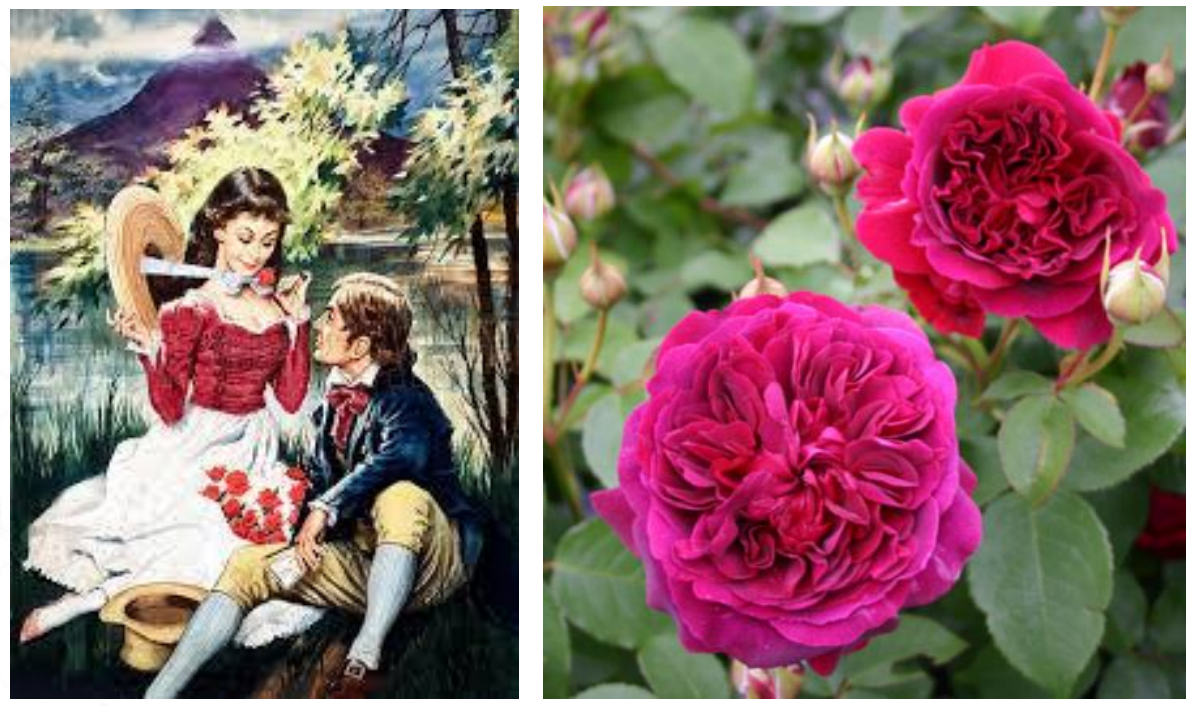

Fig. 22. A Red, Red Rose illustration, 1962. Fig. 23. William Shakespeare 2000. 
Getting to the point for the students of our Faculty Faculty of Science Education and Ecology the film "Roses and Rose Gardens" [9] is valuable because the students of scientific problem group have been studyng for 3 years the famous rosaries of the world and the selection work of their headbreeders (D. Austin, F. Meilland, G. Thomas, J. Twomey). The results were published at conferences as scientific and practical publications by students with supervisors, e.g., "The English "William and Catherine" Rose and Wedding of The Century" [19], "The image of British actress Audrey Hepburn in a rose named after "most beautiful woman of all time" [23], " The rose "Leonardo da Vinci" by Alain Mayland" [16], "Rosa "Sir Walter Scott Rose" by David Austin" [30], "Great Rosarian of the World' - British hybridizer of English Garden roses David Austin" [14], "The Wild Prairie Rose: official State Flower of North Dakota and Iowa" [31], "Rose: America's National Flower" [29], "The William Shakespeare Rose and the Rose in Shakespeare's works" [32], "William Shakespeare rose named after 'British Man of the Millennium' [40], "The rose Sweet Juliet is a tribute to young love" [41], "Wuthering Heights and rose Emily Brontë named after celebrating the bicentenary of the birth of the novelist" [18], "David Austin English Shrub Rose "Kew Gardens" [22], "Charles Darwin. English Shrub Rose bred by David Austin" [39].

R. J. Sternberg notes that creativity of personality, which can lead to new scientific discoveries, involves intellectual abilities, knowledge, and motivation, as does problem solving. But, he posits that creativity also requires the disposition or preference for engaging in novel ways of thinking [43; 44]. He characterizes these dispositions as "thinking styles" [42]. Thinking styles describes individual differences not in abilities, but in preferences for the use of our abilities. He claims that matching learners' thinking styles to their learning environment can enhance creative thinking and problem solving.

Americans scientists Eric M. Anderman and Gale M. Sinatra dwell on scientific problems of import require non-routine problem solving. That is, most problems worth solving are ill-structured and required "thinking outside the box" for an effective solution strategy. In general, successful problem solving requires 
domainspecific knowledge and skills (Chi \& Glaser, 1985) and the procedural and conditional knowledge to know when and how to apply those skills (Paris, Lipson, \& Wixson, 1983). Non-routine problem solving requires the ability to metacognitively monitor and selfregulate relevant skills and strategies. In addition, effective problem solvers also need the "will" (the motivational goals, attitudes, and interests) to attend to the problem and persist in the face of difficulties [3, p. 11].

Conclusion. We would to tell that Audrey Hepburn was a wonderful woman, mother, actress, presenter, ambassador of UNICEF. She did not consider herself ideal, but she was considered an icon of style. Her elegance and style will always be remembered in film history as evidenced by her being named in Empire magazine's «The Top 100 Movie Stars of All Time».

The last work by Audrey Hepburn in kinoindustry "Gardens of the World with Audrey Hepburn" is important for the training of Science students in the conditions of university.

Most important, we are at a critical point in terms of encouraging students to consider careers in Science. Many Ukrainian jobs are being shipped overseas to highly qualified individuals who are well trained in science. Many Ukrainian students turn away from science-related disciplines because they have had bad experiences in science classes during high school.

Much research in recent years has indicated that science classrooms can be created in ways that enhance the cognitive abilities of students. Lecturers can have profound effects on students' cognition and motivation as they attend to daily, routine issues. The specific decisions that future Science teachers make can affect a number of important educational outcomes.

\section{References}

1. A Red, Red Rose. URI : https://en.wikipedia.org/wiki/A_Red,_Red_Rose

2. A Red, Red Rose by Robert Burns (read by Tom O'Bedlam). URI : https://www.youtube.com/watch?v=xhl-KHkzPfY

3. Anderman Eric M., Sinatra Gale M., The Challenges of Teaching and Learning about Science in the 21st Century: Exploring the Abilities and Constraints of Adolescent Learners / Paper Commissioned by the National Academy of Education. $50 \mathrm{p}$.

URI : https://sites.nationalacademies.org/cs/groups/dbassesite/documents/webpage/dbasse_07 2608.pdf 
4. Anne Frank. URI : https://sites.google.com/site/darksides4eso/anne-frank

5. Audrey Hepburn URI: https://www.britannica.com/biography/Audrey-Hepburn

6. Audrey Hepburn. Biography. URI : https://www.biography.com/actor/audrey-hepburn

7. Audrey Hepburn et al in "Elegy for Anne Frank" (Lukas Foss) - 1990. URI : https://www.youtube.com/watch?v=JbmkSAODShQ

8. Audrey Hepburn journal Anne Erank. https://www.youtube.com/watch?v=OJj5RoLAhzw

9. Audrey Hepburn - Gardens of The World: Roses and Rose Gardens. URI : https://www.youtube.com/watch?v=bkGx6Ur3ToI

10. Audrey Hepburn Receiving the Medal URI: https://www.cspan.org/video/?c4533162/user-clip-audrey-hepburn-receiving-medal

11. Diary of Anne Frank (Das Tagebuch der Anne Frank), 2016 Germany, Dir. Hans Steinbichler. URI: http://baskino.me/films/dramy/14687-dnevnik-anny-frank.html

12. Gardens of the World with Audrey Hepburn. URI : https://en.wikipedia.org/wiki/Gardens_of_the_World_with_Audrey_Hepburn

13. Gardens of the World with Audrey Hepburn. Trailer. URI : https://eatlovesavor.com/gardens-of-the-world-with-audrey-hepburn/

14. Haladiy B. 'Great Rosarian of the World' - British hybridizer of English Garden roses David Austin / B. Haladiy, L. Pet'ko // Topical aspects of modern science and practice : I International Scientific and Practical Conference (Frankfurt am Main, 21-24 September 2020). Germany, 2020. Pp. 45-50.

15. Hatets anatomi. - Konsert (Oslo, 28.08.1990). Oslo Filharmoniske Orkester. Andre Audrey Hepburn, Gregory Peck, Frederica von Stade, James Galway, Elie Wiesel, Vaclav Havel og Chai Ling. Fra Oslo Konserthus. URI : https://tv.nrk.no/program/FNYH70004790

16. Holovko T., Pet'ko L., Turchynova G. The rose "Leonardo da Vinci" by Alain Mayland // About the problems of science and practice, tasks and ways to solve them : abstracts of VI International scientific-practical conference (Milan, 26-28 October 2020). - Milan, Italy : International Science Group, 2020. Pp. 51-59.

17. Jules Gravereaux. URI : https://en.wikipedia.org/wiki/Jules_Gravereaux

18. Kotliarova O., Pet'ko L. 'Wuthering Heights' and rose 'Emily Brontë' named after celebrating the bicentenary of the birth of the novelist // Current issues of science: materials of the first international scientific practice. Internet conferences (Berdyansk, April 30, 2020). Berdyansk: BSPU, 2020. Pp. 8-17. (in Ukrainian)

19. Klymenko N., Pet'ko L. The image of British actress Audrey Hepburn in a rose named after "most beautiful woman of all time". Topical Issues of Science and Practice : abstracts of VII Sientific and Practical Conference (London, 02-06 November 2020). Great Britain, London : International Science Group, 2020. 781 p. Pp. 42-51.

20. Mottisfont Abbey - a look back at the rose gardens in June 2014 (It's raining again in 2016). URI : https://teddingtongardener.com/2016/07/12/mottisfont-abbey-a-look-back-at-therose-gardens-in-june-2014-its-raining-again-in-2016/

21. Mudie Keir. The reason why Hollywood star Audrey Hepburn was haunted by Anne Frank's story. Mirror. 1 Nov. 2020. URI : https://www.mirror.co.uk/3am/celebritynews/reason-hollywood-star-audrey-hepburn-22940631 
22. Oleshchenko M., Pet'ko L. David Austin English bush rose "Kew Gardens" //Basic and applied research: current issues, achievements and innovations: materials of the I international scientific-practical Internet conference (Berdyansk, March 27, 2020). Berdyansk. 2020. Pp. 13-19. (in Ukrainian)

23. Ostapchuk A., Pet'ko L., Turchynova G. The English "William and Catherine" Rose and Wedding of The Century. Topical Issues of Science and Practice : abstracts of VII Sientific and Practical Conference (London, 02-06 November 2020). Great Britain, London : International Science Group, 2020.781 p. Pp. 52-63.

24. Pet'ko Lyudmila. Developing students' creativity in conditions of university // Research: tendencies and prospects: Collection of scientific articles. - Editorial Arane, S.A. de C.V., Mexico City, Mexico, 2017. Pp. 272-276.

25. Pet'ko L. V. Development of students' cognitive activity in foreign language teaching by using analogy method // Actual problems of globalization: Collection of scientific articles. - Midas S.A., Thessaloniki, Greece, 2016. Pp. 232-237.

26. Pet'ko L. The development of student youth aesthetic culture on professional direction // Topical issues of contemporary science: Collection of scientific articles. - C.E.I.M., Valencia, Venezuela, 2017.

27. Pet'ko L. Multicultural upbringing of students and the formation of professionally oriented foreign language teaching environment // Perspectives of research and development : Collection of scientific articles. SAUL Publishing Ltd, Dublin, Ireland, 2017. Pp. 164-170.

28. Pet'ko L. V. Teaching methods and the formation of professionally oriented foreign language learning environment in conditions of university. Intellectual Archive. 2016. Vol. 5. No. 4 (July/August). Toronto : Shiny Word Corp., Canada. Pp. 73-87.

29. Pet'ko L., Faut M. Rose: America's National Flower // Current Trends in the Development of Science and Practice: papers of the XXI ${ }^{\text {th }}$ International scientific and practical conference (15-16 June, 2020). Haifa, Israel. Publisher: International Science Groupe. 2020. Pp. 48-54.

30. Pet'ko L., Turchynova G., Bova K. Rosa "Sir Walter Scott Rose" by David Austin // Integration of scientific bases into practice: abstracts of IV International Scientific and Practical Conference (Stockholm, 12-16 October 2020 p.), Stockholm, Sweden : International Science Group, 2020. 523 p. Pp. 33-41.

31. Pet'ko L., Turchynova G., Faut M. The Wild Prairie Rose : official State Flower of North Dakota and Iowa. // Theoretical Foundations for the Implementation And Adaptation of Scientific Achievements in Practice : papers of the XXIInd International scientific and practical conference (22-23 June, 2020). Helsinki, Finland. Publisher : International Science Groupe, 2020.Pp. 106-114.

32. Pet'ko L., Turchynova G., Sokolov T. The William Shakespeare Rose and the Rose in Shakespeare's works // Impact of modernity on science and practice: Abstracts of XVIII International Scientific and Practical Conference. Boston, USA 2020. Pp. 116-125.

33. Robert Browning's 200th Birth Anniversary. URI : https://kochiread.blogspot.com/2012/09/robert-brownings-200th-birth.html

34. Rose. URI : https://en.wikipedia.org/wiki/Rose

35. Rose Garden. URI : https://en.wikipedia.org/wiki/Rose_garden

36. Roses \& Rose Gardens. Episode One. URI : https://www.artfilms.com.au/item/rosesand-rose-gardens-episode-one 
37. See some of the best roses in Britain at Mottisfont Abbey. URI : http://thegallopinggardener.blogspot.com/2011/05/make-date-with-mottisfont-rose-garden.html

38. Scottish Music - My Love Is Like A Red Red Rose. URI : https://www.youtube.com/watch?v=QK9WK0QhejA

39. Sharpilo D. Charles Darwin. English Shrub Rose bred by David Austin / D. Sharpilo, L. Pet'ko // Basic and applied research: current issues, achievements and innovations: materials of the first international scientific-practical Internet conference (Berdyansk, March 27, 2020). Berdyansk: BSPU, 2020. Pp. 30-36.

40. Shevchenko V., Pet'ko L. William Shakespeare rose named after 'British Man of the Millennium' // Fundamental and applied scientific research: current issues, achievements and innovations: materials of the first international scientific-practical Internet conference (sity Berdyansk, March 27, 2020). Berdyansk. 2020. 150 c. Pp. 37-44. (in Ukrainian)

41. Stepanchenko D., Pet'ko L. The rose Sweet Juliet is a tribute to young love // Current issues of science: materials and international scientific practice. Internet conference (Berdyansk, April 30, 2020). Berdyansk: BSPU, 2020. 202 p. Pp. 36-46. URI: http://enpuir.npu.edu.ua/handle/123456789/28862 (in Ukrainian)

42. Sternberg R. J. Thinking Styles. New York, NY: Cambridge University Press. 1997.

43. Sternberg R. J. Handbook of Creativity. New York, NY: Cambridge University Press. 1999.

44. Sternberg, R. J. The nature of creativity. Creativity Research Journal, 2006. 18(1), pp. $87-98$.

45. Turchynova Ganna. Training Teachers of Natural Sciences in the Context of the New Ukrainian School // Education, Law, Business: Collection of scientific articles. - Cartero Publishing House, Madrid, Spain, 2019. - 200 p. P. 175-178.

46. Turchinova G.V Preparation of future teachers of natural sciences for research activities in the process of learning a foreign language in the specialty / G.V. Turchynova // Actual problems of education: Collective monograph. Pegasus Publishing, Lisbon, Portugal, 2018. Pp. 70-84. (in Ukrainian)

URI http://enpuir.npu.edu.ua/handle/123456789/21238

47. Turchynova GV Foreign language training of future teachers of natural sciences in the world of the concept of the New Ukrainian school // Current issues of pedagogy: Collective monograph. - Edizioni Magi, Roma, Italy. 2019. Pp. 4-30. URI: http://enpuir.npu.edu.ua/handle/123456789/26904 (in Ukrainian)

48. Turchynova G., Alieksieienko T., Karaman S., Kushniruk S., Hladun T. Simulation of a Cloud Oriented Learning Environment at an Educational Establishment. The 36th IBIMA Conference (Granada, Spain, 4-5 November, 2020).

49. Val-de-Marne Rose Garden. URI : https://www.youtube.com/watch?v=R_uz22wdUjA

50. Webb Ali. The story behind the Audrey Hepburn tulip. URI :

https://www.crfashionbook.com/celebrity/a20065493/audrey-hepburn-namesake-tulip-storynetherlands/\#: :text=According\%20to\%20the\%20Netherlands\%20Flowerbulb,extensive $\% 20$ charita ble\%20work\%20for\%20UNICEF.

51. Zapruder Alexandra. A choir of voices: Holocaust diaries by Anne Frank and other young writers. URI : https://www.annefrank.org/en/anne-frank/go-in-depth/holocaust-diaries-annefrank-and-other-young-writer/ 


\title{
The Main Aspects of the Activities of Charitable Organizations in the Legacy of Mary Ellen Richmond
}

\author{
Petrukhan-Scherbakova Liudmyla \\ Lecturer at the Department of Theory and History of Pedagogy \\ Borys Grinchenko Kyiv University
}

Chernukha Nadiia

Doctor of Pedagogical Sciences, Professor

Taras Shevchenko National University (Kyiv, Ukraine)

\begin{abstract}
The article is devoted to the analysis of the scientific heritage of Mery Elen Richmond. A cornerstone of building the social work profession, Mary Richmond was known for her ability to organize communities, her development of casework practice, as well as her ability to teach and speak intelligently on a wide array of subjects.

The subject of the article is the provisions on the activities of charitable organizations in the United States during the life and work of the researcher. The article describes the main problems in the activities of charitable organizations of the late 19th - early 20th centuries During this time Richmond was connected to the COS, she demonstrated her qualities as a leader, teacher, and practical theorist; ; revealed the functions of charitable organizations in the theory and practice of M. E. Richmond; described possible provisions for improving the activities of charitable organizations in accordance with the legacy of Mary Ellen Richmond, who is considered a principle founder of the profession of social work and the importance of professional education.

Her first principle was that care had to focus on the person within their situation. Building on extensive research, she developed what she labelled 'social diagnosis'. Her famous circle diagram visualized the correspondence of client and environment. Richmond identified six sources of power that are available to clients and their social workers: sources within the household, in the person of the client, in the neighborhood and wider social network, in civil agencies, in private and public agencies. This is a precursor of the system theory that was so popular in 1970's social work.
\end{abstract}

Key words: charitable activities, charitable organization, social work, Mary Ellen Richmond.

Актуальність дослідження. Україна знаходиться в дуже стресовому історичному періоді. Коли з одного боку в усьому світі йде переформатування державної політики в умовах пандемії й майбутньої фінансової кризи, з іншого - наявність суто українських питань: бойові дії на території України та окупований Крим; процеси децентралізації. Як результат, перед соціальною політикою України постали нові виклики. Серед яких наступні питання: ресоціалізація осіб, що мають статус вимушених переселенців; психологічна допомога та ресоціалізація учасників бойових дій та їх родин; допомога родинам, які потрапили в кризові ситуації (і кількість таких родин щомісяця збільшується). В таких умовах недержавні об'єднання активно беруть на себе гуманітарну місію і допомагають населенню. Найбільш активними в такій кризовій 
ситуації виступають благодійні організації. На наш погляд, в таких умовах корисними $є$ наукові надбання зарубіжних науковців, чиї доробки можуть бути актуалізовані i адаптовані до сучасних українських реалій. Тому особливо цікавим виступає наукова та емпірична спадщина Мері Елен Річмонд, засновниці social case work (соціальна робота в ситуації або ведення випадку) та авторки наукових доробків, що розкривають специфіку роботи благодійних організацій та соціальної роботи в Америці.

Відповідно до означеного мета статті полягає у дослідженні спадщини Мері Елен Річмонд для формування основних компонентів діяльності благодійних організацій з подальшою метою актуалізації в сучасних українських реаліях. Для реалізації мети були сформовані наступні задачі статті: розглянути основні праці М. Е. Річмонд; сформувати основні позиції по діяльності благодійних організацій; описати можливі шляхи реалізації ідей в сучасній Україні.

Виклад основного матеріалу. Відповідно до українського законодавства благодійна організація визначається як «юридична особа приватного права, установчі документи якої визначають благодійну діяльність в одній або декількох сферах, визначених законом, як основну мету ії діяльності» [4]. На 1 жовтня 2020 р. в Україні зареєстровано 19625 благодійних організацій різного типу [1], що майже на тисячу організацій більше порівнюючи із минулим роком.

Вивченням діяльності та станом справ благодійних організацій в Україні займаються Л. Бідний, Д. Горєлов, В. Згурська, Г. Загорій, А. Зінченко, Н. Пеліванова, Т. Полонець, В. Родченко, М. Саприкіна В. Сичова та ін. Можливість впровадження зарубіжного досвіду в українську практику розглядають О. Безпалько, В. Давилюк, I. Завидняк, І. Звєрєва, О. Пилипенко, М. Строгаль, Н. Чернуха та ін. Ці дослідження та наукові доробки акцентують увагу більше на питаннях правового регулювання та фінансової діяльності благодійних організацій. Певного комплексного аналізу досвіду і теорій персоналій та пропозицій в процесі підготовки статті нами не було виявлено. В процесі аналізу робіт «What is social case work? An introductory description», «Social Diagnosis», «The Good Neighbor», «Friendly visiting among the poor. A Handbook for Charity Workers», «. A study of nine hundred and eighty-five widows», «The long view. Papers and addresses. by Mary E. Richmond» нами було окреслено наступні позиції [6; 7; 8; 9; 10; 11]. 
По-перше. В проаналізованих роботах сформовано опис функцій виконувані благодійними організаціями: 1) надання соціального працівника у супровід для вирішення складної ситуації клієнта; 2) надання матеріальної допомоги; 3) проведення дослідження та експертизи і формування звітів стосовно стану тієї чи іншої категорії населення; 4) включення в робочі групи 3 корекції законодавства, розробки та провадження реформ; 5) організація навчання фахівців соціальної сфери; 6) публікаціця корисних матеріалів та результатів проведених досліджень;7) посередництво між державними структурами та клієнтом; 8) консультація промислових підприємств різних масштабів щодо роботи із співробітниками; 9) долучення до практичного регулювання соціальних стосунків.

По-друге. Проведені Мері Елен Річмонд дослідження, дозволили виокремити групу проблемних питань, пов'язаних із діяльністю благодійних організацій. Ці проблеми були класифіковані за наступними категоріями:

А). Проблеми, що стосуються кадрового складу благодійних організацій: 1) наявний різний рівень кваліфікації соціальних працівників і працівників фондів; 2) наявність у складі соціальних працівників неоднорідностей (із різним рівнем досвіду, теоретичною та практичною підготовкою; фінансовим достатком родини; мала кількість жінок в управліннях благодійних структур та чоловіків в полі тощо); 3) обіймання керівних посад в благодійних організаціях осіб, які не займаються системно планом їх роботи або не розуміють куди має рухатися організація; 4) наявність серед соціальних працівників новачків, які вважають, що можливо всі проблеми вирішувати швидко із залученням спеціалізованих закладів виправного характеру, замість системної роботи із мисленням клієнта, яка є довготривалою.

Б). Проблеми, що стосуються внутрішньо організаційного розвитку та діяльності благодійних організацій: 1) фінансування благодійних об’єднань. Під цим, у своєму виступі «Criticism and reform in charity» Мері Річмонд [11, с. 46-50] наголошувала на помірне фінансування благодійних фондів їх засновниками. Адже забагате фінансування вбивало креативний підхід і винахідливість соціальних працівників, а замале змушувало соціальних працівниць шукати нові місця роботи, що спричиняло плин кадрів. Дуже добре, коли благодійна організація мала фінансування для оплати працівників, адже це дозволяло зберігати кадри; 2) наявність / відсутність інших типів 
ресурсів в організації; 3) наявність / відстуність плану розвитку організацій; 4) не системна робота з волонтерами та соціальними працівниками благодійних фондів.

В). Проблеми, що стосуються надання послуг / допомоги клієнтам: 1) надання благодійними структурами допомоги на рівних, не враховуючи специфіку клієнтів (комусь треба більше, а комусь у меншій кількості ніж дає організація); 2) акцент на матеріальній допомозі нужденним; 3) настороженість та недовіра клієнта при проведенні соціальним працівником оцінки кризової ситуації; 4) помилкове визначення в оцінці кризової ситуації при неповному аналізі і розкритті всіх сфер.

Г). Проблеми зовнішнього характеру (пов’язані із суспільством та державою): 1) відсутність сприйняття клієнта та його родини як єдине ціле кількома фахівцями різних форм благодійної діяльності, які одночасно допомагають (наприклад, викладач недільної школи, менеджер ясел, агент милосердя, окружна медсестра, акушерська медсестра, церковний працівник сфери соціального обслуговування, міської місіонер, допоміжний агент, голова зустрічей матерів, викладач гільдії й інші, - всі вони торкнуться сім'ї в певний момент, але ніколи не подбає про зображення сімейного життя в цілому» [7, с. 45]. Це призвело до того, що при засіданнях, де вирішувалися питання чоловіка і дружини інтереси дітей не були враховані і навпаки, при обговоренні справ дитини як учня забувалось про його участь в домашньому господарстві; 2) наявність в містах благодійних організацій, що не задовольняють жодної реальної потреби в громаді; 3) проблема гласності і допомоги (коли одна частина суспільства вважала, що якщо надавати гласність кризовій ситуації певної особи, то це пришвидшить фінансові вливання для її вирішення). Натомість більшість осіб, що знаходяться в кризовій ситуації хочуть навпаки знаходитися в тіні і все залишити приватним; 4) проблема законодавчого регулювання діяльності організацій.

Питання ефективності соціальної роботи та діяльності благодійних організацій у спадщині Мері Елен Річмонд розкрито нами в статті «Теоретичні підходи до поняття «ефективність соціальної роботи» в спадщині Мері Елен Річмонд [2], тому ми не зупинятимемося на цьому детально.

По-третє. Науковий аналіз робіт М. Е. Річмонд дозволив виокремити перелік рекомендацій щодо покращення роботи благодійних організацій, що призвело для розвитку соціальної сфери в Америці. Одним із ключових положень теорії соціальної 
роботи американки Мері Елен Річмонд стосовно діяльності благодійних організацій є важливість наявності зв'язку та обміну інформацією між благодійними [6, с. 27-28, 45]. Такий зв'язок має формуватися на етичних принципах соціальної роботи, таких як довіра, відповідальність, анонімність.

Зауваження і побажання щодо роботи працівників благодійних організацій, висловлені Мері Елен Річмонд: 1) урахування ким є соціальний працівник, адже особа 3 бідної сфери, яка розуміє ситуацію клієнта, але, нажаль, має недостатню кількість фахових знань, інколи це навпаки шкодить, адже соціальний працівник занадто співпереживає і жаліє; 2) має бути налагоджена робота із особами, що мають хороший фінансовий стан, а благодійність це їх покликання душі; 3) співробітники мають володіти фаховими знаннями і мати відповідну освіту; 4) врахування в роботі наявності у складі соціальних працівників з різним рівнем підготовки; 5) нагадувати працівнику, про має пам'ятати про свою кінцеву мету роботи.

Наступним положенням теорії М. Е. Річмонд є важливість врахування в роботі таких етичних принципів: 1) допомогу потрібно надавати індивідуально і конфіденційно; 2) голова сім'ї має бути активно включений і стати активним учасником на всіх рівнях і у всіх питаннях щодо вирішення проблемної ситуації та надання допомоги; 3) для вирішення ситуації клієнта соціальний працівник і працівник благодійної організації має активізувати оточуюче клієнта середовище; 4) при прийнятті рішення давати або відмовляти в допомозі, соціальні працівники мають керуватися його ймовірним впливом на майбутнє претендента. Увага звертається на форму допомоги і план іiі використання, адже будь яка допомога може без плану реалізації нашкодити; 5) замість того, щоб намагатися надати допомогу по трохи багатьом нужденним, благодійні організації повинні допомогти максимально тим, хто цього потребує найбільше; 6) форма допомоги може бути різною (знання, матеріальна, контакти, увага та ін.); 7) форма допомоги повинна змінюватися відповідно до індивідуальних обставин і потреб клієнта. Соціальні працівники мають знайти ту форму допомоги яка буде найкращим методом у вирішенні кризової ситуації та закритті специфічної потреби; 8) працівники благодійних організацій так само як і соціальні працівники з часом мають зменшувати рівень включеності соціального працівника в життя клієнта. Цей принцип виведений нами на основі робіт Мері Елен Річмонд, показує, що основною метою 
соціального працівника в роботі 3 клієнтом навчити останнього самостійності i відповідальності за власне життя, що дозволить не тільки вийти із даної кризової ситуації, а не потрапити до неї знову.

Отже, зазначені вище пункти як були актуальні в період життя і роботи Мері Елен Річмонд, лишаються і сьогодні, хоча принципи і були впроваджені в кодексі соціального працівника і використовуються в усьому світі.

Висновки. Зважаючи на викладене, можна дійти висновку про те, що основи соціальної роботи та діяльності благодійних організацій, які описала в своїх роботах Мері Елен Річмонд $є$ актуальними і по сьогодні. Дослідження проблем сучасних благодійних організацій потребує додаткового аналізу і має бути висвітлено в окремій статті. При цьому із впевненістю зазначаємо, що діяльність фахівців сучасних благодійних організацій можливо покращити за умови використання рекомендацій сформованих нами на основі аналізу робіт Мері Елен Річмонд.

\section{References}

1. Kilkist yurydychnykh osib za orhanizatsiyno-pravovymy formamy hospodaryuvannya. Sait Derzhstatystyky Ukrayiny [Number of legal entities by organizational and legal forms of management. Website of the State Statistics of Ukraine].

URI : http://www.ukrstat.gov.ua/edrpoy/ukr/EDRPU_2020/ks_opfg/ks_opfg_1020.htm

2. Petrukhan-Shcherbakova L. Teoretychni pidkhody do ponyattya «efektyvnist sotsialnoyi roboty" v spadshchyni Mery Elen Richmond [Theoretical approaches to the concept of "efficiency of social work" in the legacy of Mary Ellen Richmond]. Neperervna profesiyna osvita: Teoriya i praktyka. 2018. № 1-2.Pp. 108-113. DOI: https://doi.org/10.28925/16098595.2018(1-2)108113

3. Petko L.V. Vykhovnyi potentsial metodu sytuatsiinoho analizu ("Case study» method) $u$ formuvanni profesiino oriientovanoho inshomovnoho navchalnoho seredovyshcha $v$ umovakh universytetu [Educational potential of the «Case study» method for the forming of the professionally oriented foreign language teaching environment in the conditions of university]. Naukovyi chasopys NPU imeni M.D.Drahomanova. Seriia 17. Teoriia i praktyka navchannia ta vykhovannia: zb. nauk. pr. ; za red. akademika V.I.Bondaria. Kyiv: Vyd-vo NPU imeni M.P.Drahomanova, 2015. Issue 27. P. 133-140.

4. Pro blahodiynu diyal'nist' ta blahodiyni orhanizatsiyi: Zakon Ukrayiny [On charitable activities and charitable organizations: Law of Ukraine]. URI : https://zakon.rada.gov.ua/laws/show/5073-17\#Text

5. Chernukha N.M., Aslanov G. Sotsialni komunikatsii v interkulturnomu prostori: vidpovid na vyklyky sohodennia [Social communications in the intercultural space: a response to the challenges of today] // Innovative processes in education: Collective monograph. AMEET Sp. z o.o., Lodz, Poland, 2017. P. 230-237. 
6. Richmond Mary E. A study of nine hundred and eighty five widows. Known to certain charity organization societies in 1910. New York City: Charity Organization Dept of the Russell Sage Foundation. 1913. 83 p.

7. Richmond Mary E. Friendly Visiting among the Poor. A Handbook for Charity Workers. - New York The MacMillan Company London: MacMillan \& Co., Ltd. 1907/ All rights reserved/ Copyright, 1899, by The MacMillan Company. Set up and electrotyped January, 1899. Reprinted November, 1899; February, 1903; February, 1906; November, 1907. 219 p. Press Stable

URL: https://archive.org/details/friendlyvisiting00richrich/page/n1/mode/2up

8. Richmond, Mary E. Social Diagnosis. - New York: Russell Sage Foundation, 1917. No 1.487 p.

9. Richmond, Mary E. The good neighbor in the modern city.1908. 152 p.

10. Richmond, Mary E. Social work series. What is social case work? An introductory description. New York : RUSSELL SAGE FOUNDATION, 1915, 1922.

11. The long view. Papers and addresses. by Mary E. Richmond. selected and edited with biographical notes by Joanna C. Colcord, Director of the charity organization department, Russell sage foundation; and Ruth Z. S. Mann. - New York, Russell Sage Foundation. 1930. 165 p.

Translation of the Title, Abstract and References to the Author's Language

\section{УДК 378:37:37:013.42}

Петрухан-Щербакова Людмила, Чернуха Надія. Основні аспекти діяльності благодійних організацій у спадщині Мері Елен Річмонд.

Статтю присвячено аналізу наукової і практичної спадщини Мер Елен Річмонд. Предметом дослідження статті стали положення, присвячені діяльності благодійних організацій у Сполучених Штатах Америки в період життя та роботи американської дослідниці. Описано основні проблеми в діяльності благодійних організацій кіния XIXпочатку XX століття; розкрито функиії діяльності благодійних організацій періоду життя М. Е. Річмонд; охарактеризовано можливі напрямки для покращення діяльності благодійних організацій відповідно до спадщини Мері Елен Річмонд. Стаття буде иікава викладачам, які займаються підготовкою сочіальних працівників та сочіальних педагогів.

Ключові слова: благодійна діяльність, благодійна організація, соціальна робота, Мері Елен Річмонд.

\section{Література}

1. Кількість юридичних осіб за організаційно-правовими формами господарювання. Сайт Держстатистики України. URL : http://www.ukrstat.gov.ua/edrpoy/ukr/EDRPU_2020/ks_opfg/ks_opfg_1020.htm

2. Петрухан-Щербакова Л. Теоретичні підходи до поняття «ефективність соціальної роботи» в спадщині Мері Елен Річмонд. Неперервна професійна освіта: 
Теорія $і$ практика. 2018. № 1-2. C. 108-113. DOI : https://doi.org/10.28925/1609$8595.2018(1-2) 108113$

3. Петько Л. В. Виховний потенціал методу ситуаційного аналізу («Case study» method) у формуванні професійно орієнтованого іншомовного навчального середовища в умовах університету. Науковий часопис НПУ імені М.Д.Драгоманова. Серія 17. Теорія і практика навчання та виховання : зб. наук. пр. ; за ред. академіка В.І.Бондаря. Київ : Вид-во НПУ імені М.П.Драгоманова, 2015. Вип. 27. С. 133-140.

4. Про благодійну діяльність та благодійні організації: Закон України. URI : https://zakon.rada.gov.ua/laws/show/5073-17\#Text

5. Чернуха Н.М. Соціальні комунікації в інтеркультурному просторі: відповідь на виклики сьогодення / Н.М.Чернуха, Г.Асланов // Innovative processes in education: Collective monograph. - AMEET Sp. z o.o., Lodz, Poland, 2017. - P. 230-237.

6. Richmond, Mary E. A study of nine hundred and eighty five widows. Known to certain charity organization societies in 1910. New York City: Charity Organization Dept of the Russell Sage Foundation. 1913. 83 p.

7. Richmond, Mary E. Friendly Visiting among the Poor. A Handbook for Charity Workers. New York The MacMillan Company London: MacMillan \& Co., Ltd. 1907/ All rights reserved/ Copyright, 1899, by The MacMillan Company. Set up and electrotyped January, 1899. Reprinted November, 1899; February, 1903; February, 1906; November, 1907. 219 p. Press Stable URL : https://archive.org/details/friendlyvisiting00richrich/page/n1/mode/2up $487 \mathrm{p}$.

8. Richmond, Mary E. Social Diagnosis. New York : Russell Sage Foundation. 1917. No 1.

9. Richmond, Mary E. The good neighbor in the modern city 1908. $152 \mathrm{p}$.

10. Richmond, Mary E. Social work series. What is social case work? An introductory description. - New York : Russell Sage Foundation. 1915, 1922.

11. The long view. Papers and addresses. by Mary E. Richmond. selected and edited with biographical notes by Joanna C. Colcord, Director of the charity organization department, Russell sage foundation; and Ruth Z. S. Mann. New York : Russell Sage Foundation. 1930. $165 \mathrm{p}$. 


\title{
System of Exercises for Anglophone Strategic Competence Formation in Future Interpreters
}

\author{
Natalia Sabat \\ Ivan Franko National University of Lviv
}

\begin{abstract}
The article presents the substantiation of the process of development of exercise system aimed at building the Anglophone strategic competence in future interpreters. The system comprises three blocks of exercises according to the three stages of educational program (activation of language material, strategic training and speech simulations) according to the author's methods created specifically to develop the mentioned above competence. The author defines the types of exercises to be used in the exercise system on the basis of generally accepted criteria, but with respect to the specificity of the strategic competence formation in future interpreters. The key position in the system is occupied by the second block comprising four groups of exercises within the scope of the training session.
\end{abstract}

Keywords: future interpreters, strategic competence, strategies, system of exercises.

Навчальний процес, спрямований на формування в майбутніх перекладачів англомовної стратегічної компетентності, проходить у три етапи (активізація мовного матеріалу, стратегічне навчання і мовленнєві симуляції, що передбачають вирішення реальних професійних завдань із застосуванням сформованої стратегічної компетентності).

Фактично на першому етапі (активізація мовного матеріалу) студентська діяльність характеризується як частково самостійна, до певної міри рутинна. Студентам пропонується виконання вправ загального лінгвістичного змісту (оперування відповідним мовним матеріалом англійської мови загального вжитку), а також виконання блоку лексичних завдань на активізацію термінологічної компетентності (у нашому випадку у сфері медицини, економіки чи технологій). На другому етапі (власне стратегічне навчання) відбувається виконання програми комплексу авторських тренінгів. На третьому етапі (застосування) студенти не лише застосовують сформовану стратегічну компетентність (відповідні перекладацькі та комунікативні стратегіï), але й аналізують їх цінність для власної навчально-пізнавальної діяльності, свідомо і самостійно планують алгоритм використання тих чи інших стратегій, самостійно контролюють успішність реалізації цього алгоритму. Усе це відбувається за допомогою мовленнєвих симуляцій. 
Для характеристики розробленої нами підсистеми вправ і завдань зупинимося спершу на розумінні цих ключових понять: вправа і завдання.

Вправою вважають багаторазове виконання однотипних операцій і дій з мовним матеріалом, яка опирається на усвідомленості і супроводжується контролем чи самоконтролем [7, с. 91]; «спеціально організоване в навчальних умовах багаторазове виконання окремих операцій, дій або діяльності 3 метою оволодіння ними або їх вдосконалення» [1, с. 64]. Отже, під завданням розуміємо навчальне завдання, сформульоване в реальному навчальному мовленнєвому контексті, вирішення якого потребує використання відповідних умінь i стратегій (як комунікативних, перекладацьких, так і навчальних); тобто завдання спрямоване на формування і розвиток стратегічної компетентності, а вправа спрямована на формування окремих складових цієї компетентності (мовних навичок, окремих умінь тощо).

У навчальному завданні виділяють певну структуру:

- інструкція (постановка навчальної мети);

- частина виконання, в якій демонструються можливі способи вирішення комунікативного завдання (опори, орієнтири, мовленнєві зразки);

- контрольна частина, яка забезпечує (при потребі) рефлексію, (само)контроль чи (само)корекцію (наприклад, вказівку на теоретичний матеріал, знання якого закладені в алгоритм виконання завдання тощо) [6].

Для вирішення завдань нашого дослідження - розробки методики формування стратегічної компетентності майбутніх перекладачів, необхідно сформувати методичну систему, ключовим елементом якої повинна стати система вправ і завдань, яку розуміємо як систему нижчого порядку (чи підсистему) і складову системи вищого порядку [3], як обгрунтовану й цілеспрямовано впорядковану сукупність необхідних груп, типів і видів вправ i комунікативних завдань, які виконуються студентами у відповідній послідовності, спрямовані на вирішення поставленої дидактичної мети на кожному етапі(відповідно до структури, сутності і специфіки досліджуваного явища (у нашому випадку - англомовної стратегічної компетентності майбутніх перекладачів).

У методиці традиційно визначені основні вимоги до розробки системи вправ $\mathrm{i}$ завдань: 
1) вправи і завдання у системі (підсистемі, комплексі) повинні бути адекватні меті, змісту й умовам навчання загалом;

2) вправи і завдання повинні бути доцільними (до змісту складністю, місцем у системі);

3) завдання і вправи повинні бути організовані у чіткій послідовності у системі: кожна наступна вправа й завданням повинні виконуватися на основі навичок, вмінь i стратегій, сформованих у попередніх вправа і завданнях;

4) зміст вправ, завдань повинен узгоджуватися із етапами формування навичок, умінь і стратегій;

5) вправи і завдання повинні містити можливість для студента здійснення самоконтролю [2, с. 89].

Слідом за Н.К. Скляренко (за цитуванням С. Ю. Ніколаєвої [4] ) та О. Р. Світличною [5, с. 50], ми вважаємо, що основними критеріями типології вправ і завдань у нашій системі повинні бути обрані такі: вмотивованість, ступінь комунікативності, спрямованість навчальної діяльності на прийом або подачу інформації, ступінь керування, спосіб організації та необхідність забезпечення опорами. Враховуючи ці критерії, до розробленої нами підсистеми вправ і завдань увійшли такі типи:

1. Відповідно до критерію вмотивованості: вмотивовані. Майбутній перекладач повинен свідомо розуміти мету виконання вправи і їі розвивальний вплив на формування його професійної перекладацької компетентності.

2. За критерієм спрямованості: рецептивні, рецептивно-репродуктивні та рецептивно-продуктивні вправи і завдання. Рецептивні вправи у нашій підсистемі здебільшого готують майбутнього перекладача до знайдення «зайвого» терміну, пошуку правильної дефініції до терміну. До рецептивно-репродуктивних відносяться вправи на тренування різних видів пам'яті (мнемотехніка, безасоціативне та асоціативне запам'ятовування), розшифрування абревіатур, синонімічний переклад тощо. Продуктивні вправи сприяють розвитку умінь і стратегій прогнозування та розвиток перекладацької здогадки, формування й розвитку стратегії компресії та декомпресії тощо. 
3. Врахування критерію професійної спрямованості зумовило те, що усі вправи $і$ завдання у нашій системі $\epsilon$ професійно спрямованими, тобто мають на меті формування і розвиток професійної компетентності перекладача.

4. Відповідно до критерію наявності/відсутності опор: вправи і завдання 3 використанням вербальних опор, візуальних опор, звукових опор, аудіо-візуальних опор чи без опор.

5. Критерій комунікативності визначив необхідність і доцільність таких вправ у нашій системі (підсистемі): некомунікативні (повтор, імітація, тренування пам'яті), умовно-комунікативні (виконання завдань $\mathrm{i}$ вправ для формування окремих перекладацьких стратегій), комунікативні (виконання комунікативних симуляцій).

6. Відповідно до критерію специфіки контролювальних процедур: вправи i завдання, контрольовані з боку викладача, взаємоконтрольовані, з використанням самоконтролю або самоперевірки з використанням технічних засобів.

7. Враховуючи критерій характеру виконання, до системи увійшли усні і письмові вправи (зумовлені обставинами і специфікою типових комунікативних ситуацій у професійній діяльності перекладачів).

8. За критерієм режиму виконання у системі містяться вправи для виконання в парах, у групах та індивідуальні.

Таким чином, підсистема вправ i завдань для формування стратегічної компетентності майбутніх перекладачів складається із трьох блоків вправ і завдань, що узгоджуються із трьома етапами навчального процесу за розробленою нами методикою, спрямованого на формування англомовної стратегічної компетентності майбутніх перекладачів. На рисунку 1 подано схематично структуру авторської підсистеми вправ $\mathrm{i}$ завдань.

\section{References}

1. Bihych, O. B., Haponova, S. V., Hryniuk, H. A. ta in. Metodyka vykladannia inozemnykh mov u serednikh navchalnykh zakladakh: pidruchn. dlia studentiv vyshchykh navch. zakl. / Avtor. kol. pid ker. S. Yu. Nikolaievoi]. Kyiv: Lenvit, 2002.

2. Maksymenko, L. O. Navchannia profesiino spriamovanoho anhlomovnoho dialohu maibutnikh menedzheriv nevyrobnychoi sfery : dys. kand. ped. nauk : 13.00.02. Kyiv: Kyivskyi nats. linhv. un-t, 2012. 
3. Nikolaieva, S. Yu. «Tsili navchannia inozemnykh mov v aspekti kompetentnisnoho pidkhodu.» Inozemni movy, № 2 (2010): 11-17.

4. Nikolaieva, S. Yu. Osnovy suchasnoi metodyky vykladannia inozemnykh mov (skhemy i tablytsi) : Navchalnyi posibnyk. Kyiv: Lenvit, 2008.

5. Svietlichnaya, E. R. «Sistiema uprazhnieniy dlia obuchieniya ustnomu posliedovatielnomu dvustoronniemu profiessionalno orientirovannomu pierievodu.» Sbornik nauchnyih trudov SWorld. Matierialy miezhdunarodnoy nauchnopraktichieskoi konferentsii «Sovriemiennyie probliemy i puti ikh riesheniya v naukie, transporite, proizvodstvie i obrazovanii'2012» (KUPRIENKO) 25, \# 4 (2012): 45-54.

6. Skliarenko, N. K. «Suchasni vymohy do vprav dlia formuvannia inshomovnykh movlennievykh navychok i vmin.» Inozemni movy, № 3 (1999): 3-7.

7. Sysa, E. A. Obuchienie inoyazyichnomu chtieniyu s ispolzovaniem stratiegij na osnovie samostoyatielnoi uchiebno-poznavatielnoi dieyatielnosti (tiehnichieskij vuz, niemietskij yazyk) : dis. ... kand. pied. nauk : 13.00.02. Tomsk: Tomskiy nats. politeh. u-t, 2016. 


\section{Підсистема вправ і завдань для формування стратегічної компетентності майбутніх перекладачів}

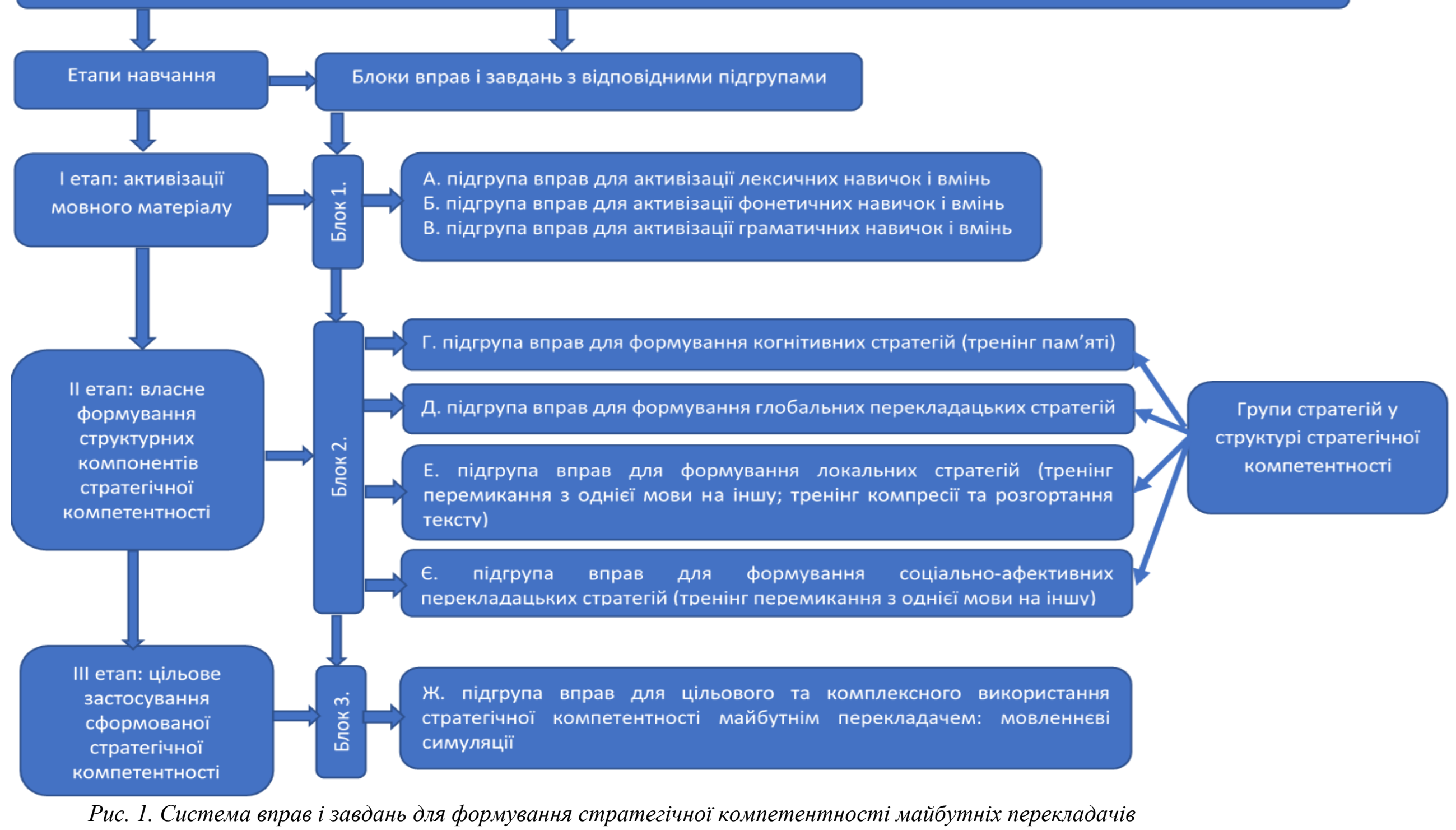




\title{
Theoretical and Methodological Aspects of Using Dialogue for the Purpose of Organizing Productive Interaction of Subjects of the Educational Process
}

\author{
Vanda Vyshkivska \\ Ph.D., Associate Professor \\ Dragomanov National Pedagogical University (Ukraine Kyiv) \\ Oleksandra Shykyrynska \\ Ph.D., Associate Professor \\ Vinnytsia Mykhailo Kotsiubynskyi State Pedagogical University (Ukraine \\ Vinnytsia) \\ Olena Malinka \\ Ph.D., Senior Lecturer \\ Vinnytsia Mykhailo Kotsiubynskyi State Pedagogical University (Ukraine \\ Vinnytsia) \\ Inna Lobachuk \\ Ph.D., Senior Lecturer \\ Vinnytsia Mykhailo Kotsiubynskyi State Pedagogical University (Ukraine \\ Vinnytsia)
}

\begin{abstract}
The article in the historical and philosophical, psychological and pedagogical aspects considers the current problem of improving pedagogical education - the use of dialogue in the implementation of effective interaction of the subjects of the educational process. It is emphasized that the modern pedagogical system is faced with objective processes of democratization in society, with the requirements of cultural development in terms of the scientific and technological progress, and is characterized by changing disciplinary and compulsory regulatory dominant of education to the dominant of cultural activity and creativity. Dialogue is analyzed as a form and method of organizing of the educational process that is based on the values of content and values of goal which are manifested in the problematic character, perception and mutual understanding at the interpersonal level. It is noted that the joint participation of the subjects of dialogue reveals its humanistic essence and gives multicolor, emotionality, spirituality to the relationship, gives the joy of their discovery of each other.

Emphasis is placed on the psychological and pedagogical essence of discussion (a kind of dialogue that takes place in a mode of competent equality and involves the clash of the participants' opinions in the course of strictly regulated negotiation of the problem) as the most cognitively effective form of dialogue.

Key words: dialogue, educational dialogue, pedagogical interaction, participants in the educational process, subjects of the educational process, discussion
\end{abstract}


Актуальність дослідження і постановка проблеми. Сучасний період розвитку освіти характеризується докорінним перетворенням самої піi парадигми - від авторитарної до гуманістичної, яка ставить у центр уваги особистість учня, активно включеного в процес вибору змісту, форми і методів свого навчання.

Згідно принципів гуманістичної психології (А. Маслоу, К. Роджерс та ін.) такий новий підхід до навчання передбачає, що: - сучасна освіта виходить із загальнолюдських цінностей та 3 їх узгодження 3 конкретними цінностями різних етнокультурних спільнот; - метою освіти визначено процес самореалізації особистості, для якої характерною $є$ гуманістична спрямованість іiі цінностей; - розвиток особистості відбувається цілісно, в єдності розуму і почуттів, душі і тіла; - усі права людини, в тому числі і її право на вільний вибір змісту, форм освіти, захищені; - освіта здійснюється за допомогою власної діяльності учня;

- групова робота в школі поєднується з індивідуальною роботою, причому особлива увага приділяється розвитку індивідуального стилю діяльності особистості;

- освіта як діяльність особистості грунтується на внутрішній мотивації учня, а також на повноцінному спілкуванні вчителя і учнів, причому участь школярів у рівноправному діалозі поважається і заохочується;

- найуспішніше навчання здійснюється в обстановці турботи, уваги, співпраці, а не формального керівництва [7].

Відтак, важливим завданням викладача $\epsilon$ включення учня в якості активного учасника в групову взаємодію на основі творчого діалогу в системі "вчитель - учень", "учні - учні". По суті, мова йде про проблемно-діалогічний підхід до навчання.

Мета статті - проаналізувати феномен діалогу, його внутрішню сутність і розмаїття зовнішніх проявів як одну з умов реалізації проблемно-методологічної стратегії діяльності учня (студента) за умови його активної участі у процесі навчання, як форму і метод організації ефективної взаємодії суб'єктів освітнього процесу.

Виклад основного матеріалу. У тлумачних словниках кінця XX ст. термін "діалог" визначався досить просто. Так, в Енциклопедичному словнику (1985 р.) діалог характеризувався як одна 3 форм усного мовлення (поряд 3 монологом), тобто як розмова двох або кількох осіб. Малися на увазі життєвий і діловий діалог, а також його відображення в художній літературі, а іноді - у філософській (наприклад, діалоги 
Платона). У психологічному словнику 1985 р. (під ред. А. В. Петровського та М. Г. Ярошевського) діалог визначався як почерговий обмін репліками двох і більше людей (в широкому сенсі реплікою вважається не тільки мовне висловлювання, але i відповідь у вигляді жесту і навіть мовчання).

Однак останнім часом поняття діалогу стало набувати все більш широких концептуальних меж. Дослідження, проведені в галузі філософії, культурології, психології, педагогіки та інших наук (М. М. Бахтін, В. С. Біблер, М. Бубер, М. С. Каган, І.А.Колеснікова та ін.), призвели до розуміння того, що діалогічність $\epsilon$ центральною характеристикою гуманітарно-орієнтованої взаємодії між людьми (індивідами, групами, спільнотами), вона - універсальний спосіб існування культури і людини в культурі, внутрішній механізм розвитку людського мислення. Зокрема, у концепції В.С. Біблера діалог проникає в саме серце сучасної шкільної освіти, яка визначається як «школа діалогу культур» [2].

Предметом грунтовного наукового аналізу діалог став зовсім нещодавно, що можна обгрунтувати усвідомленням того факту, що подолання глобальної кризи людства в навчанні, економіці, політиці і т.ін. можливе не шляхом конфронтації, а шляхом діалогу, зусиллями взаємного розуміння і довіри між викладачем і студентом, людьми, народами, країнами, конфесіями, партіями.

На Міжнародній конференції в 1992 році відомий фізик Д. Бом розкрив значення діалогу в наш час. Він стверджує, що подолання розбіжностей можливо тільки в разі «поділу сенсу», що сприяє створенню такої культури, яка могла б стати планетарною. Для цього необхідно створити умови для початку діалогу. Люди різних субкультур могли б зібратися і почати пошук спільних смислів, можливо, навіть нових, які все могли б прийняти. При цьому діалог слід почати з тими, хто є достатньо відкритим, - не можна говорити 3 тими, хто цього не хоче. А також науковець наголосив, що нам потрібен діалог у прямому значенні цього слова, згідно з яким “сенс тече крізь і серед людей на відміну від обміну, де кожен намагається виграти, утвердивши свій погляд”. А отже, діалог означає створення чогось нового, коли виграють усі [3].

В освіті ж інтерес до діалогічної взаємодії став помітно зростати в міру переходу школи від колишньої авторитарної парадигми до парадигми гуманістичної, в 
рамках якої міжсуб'єктний діалог створює найбільш сприятливі умови для вільного самовираження учнів.

Розглянемо це питання більш детально. Як відомо, формування діалогічної природи мислення і мовлення потребує реалізації двох взаємопов'язаних процесів. Дитина опановує своїми першими уявленнями спочатку в зовнішньому розгорнутому спілкуванні з дорослими, яке поступово переходить у спілкування внутрішнє, в розмову людини з самою собою. Це процес інтеріоризації, в результаті якого діалог стає опорою мислення у внутрішньому плані. Мислення, з певної точки зору, і $є$ не що інше, як внутрішній діалог.

Необхідність звернення до психологічного аспекту діалогу обумовлена й тим, що в сфері педагогічної праці процес міжособистісного спілкування $є$ основним засобом, за допомогою якого реалізуються завдання навчання.

К.А. Альбуханова-Славська, розглядаючи діалог як особливий спосіб мислення, вважає, що він розкриває суть діалектичного мислення: за припущенням слідує заперечення, припущення включає безліч альтернатив, кожна з яких зважується, обдумується i перевіряється. А також учена зазначає, що діалог становить вирішальний інтелектуальний центр саморегуляції особистості, саме в діалозі людина відображає ставлення до подій [1].

А.А. Бодальов і Г.А. Ковальов також акцентують увагу на факті діалогічності змісту психічної організації людини і обгрунтовують стратегію взаємодії, яка $\epsilon$ найбільш доцільною для реалізації інтерсуб'єктного підходу. Також зауважують, що психологічною умовою реалізації такої стратегії визначається діалог [8].

У цілому, психологи пропонують кілька площин інтерпретації цього поняття:

- первинна, родова форма людського спілкування, яка визначає здоровий психічний розвиток особистості;

- провідна детермінанта цього розвитку, що забезпечує функціонування механізму інтеріоризації;

- принцип і метод вивчення людини;

- вищий рівень організації відносин між людьми;

- творчий процес. 
Таким чином, з точки зору психології, діалог є складним, поліфункціональним, соціально-психофізіологічним феноменом, що пронизує весь життєвий простір людини як на рівні психофізичних, так і на рівні соціальних відносин.

Будь-який діалог спрямований на вирішення певної проблеми, причому проблеми досить складної, неоднозначної, багатогранної. Діалог - це первинна і найбільш фундаментальна форма в генезі міжособистісного спілкування, в процесі якого людина вступає в безпосередній контакт з іншими людьми, обмінюється 3 ними думками з того чи іншого питання, намагається з'ясувати те, що їй незрозуміло, підтверджує або спростовує наявні у неї точки зору.

I.А. Кузьмичова також зауважує, що діалог «спирається на особисту активність людини в комунікативних процесах, яка забезпечується тим, що вона включається в процес вирішення проблем, зміст яких для неї є справді глибоко особистісним» [8].

Природно, що основою діалогу є комунікація як умова обміну інформацією, яка пов'язана не стільки з наявністю питань, відповідей на питання, реплік, скільки 3 певним рівнем взаєморозуміння і цілеспрямованого бажання взаємодіяти. Саме діалогкомунікація - це вміння інформувати і отримувати інформацію, бажання розуміти i бути зрозумілим, прагнення бути відкритим і бути успішним. Кожен учасник діалогу представлений як самостійна, активна, вільна особистість, як партнер суб'єктсуб'єктної взаємодії. Діалог передбачає наявність несуміжних смислових позицій, відмінність точок зору. При цьому аргументація кожного з учасників грунтується на комунікативно-ціннісному аспекті взаємодії як основі вираження ставлення до подій.

I.I. Риданова вважає, що навчальний діалог в освітньому процесі грає специфічну роль і «є механізмом реалізації проблемного навчання, допомагає уникнути формального засвоєння знань» [9].

Специфічними є також форми і види навчального діалогу. У сучасній педагогічній науці розглядаються різні форми діалогу, однією з яких є лекція, де діалог лектора і слухачів - організоване і соціально орієнтоване спілкування для формування потрібних уявлень, думок, переконань 3 деяких питань, у той час як лекція в традиційному уявленні за своєю структурою і функціями близька до доповіді, звіту, повідомленням і т.ін. 
Широкого використовується також діалог у формі опитування. До нього належать: соціологічне опитування громадської думки, усне опитування студентів на семінарах, учнів на уроках і т.ін. Дана форма діалогу дає можливість отримати інформацію про об'єктивні чи суб'єктивні факти зі слів опитуваного.

У виразній формі діалогічність проявляється в бесіді, суперечці, дискусії, диспуті, дебатах, полеміці. У бесіді ऑiі учасники при однаковому погляді на обговорюваний предмет, обмінюючись думками в діалозі, розвивають і доповнюють своє розуміння цього предмета.

Найбільш поширеною і «сильною» в пізнавальному контексті є така форма діалогу, як дискусія.

Дискусія - це чітке зіставлення точок зору щодо актуальних питань 3 метою знаходження шляхів їх вирішення та встановлення загальної згоди.

М.М. Діаніна вважає, що відмінною рисою дискусії $є$ те, що вона «являє собою спільну пізнавальну діяльність, яка виникає за умови наявності об'єктивного предметно-логічного конфлікту, що характеризується розбіжністю поглядів учасників на предмет обговорення». При цьому під конфліктом автор розуміє «не конфлікт особистостей, що виражається в їхній конфліктній поведінці, а конфлікт ідей». Інакше кажучи, суттєвою ознакою дискусії є зіткнення в ній протилежних думок і полемічний характер рішення висунутої проблеми. Без зіткнення думок дискусія просто не виникає.

Культура дискусії передбачає дотримання кожним учасником певних норм і правил щодо яких має бути встановлено загальну згоду. Зокрема:

- вільний обмін думками: кожен індивід є рівноправним учасником спільного рішення проблеми; він має право на висловлювання власних думок про можливі варіанти вирішення; висування гіпотез та ідей; в процесі програвання варіантів вирішення кожному надається право на помилки, а на перших етапах пошуку зазвичай вводиться заборона на критику;

- повага до думки кожного учасника: думка, висловлена учасником, не може залишитися поза увагою; вона повинна бути "почута" і використана в ході обговорень (а в іншому випадку виникає "діалог глухих"); важливо зрозуміти його, знайти плюси і 
мінуси, прийняти хоча б в якості тимчасового припущення i "програти" можливі наслідки;

- терпимість до критики: кожен учасник групового рішення уникає спокуси вважати, що істинним є тільки його власне розуміння справи; важливо сприймати критичні висловлювання як більш точні варіанти вирішення; важливо заохочувати критику щодо своєї точки зору, а також відкрито визнавати вади у власній думці (природно, мова йде про критику по суті справи).

У нашому розумінні діалог виступає і одним із основних принципів викладання, який означає, що діалог поширюється на більшість конкретних навчальних дій і застосовується всіма учасниками навчання. Навчальні дії можуть бути спрямовані як на підготовку діалогу в аудиторії, так і проведення власне діалогу і використання його в різних вправах. У діяльність, спрямовану на підготовку діалогу в аудиторії, ми включаємо: діагностику студентів в групі; накопичення фактичних матеріалів; пошук протиріч в дійсності, думках, ідеях; формулювання думок, ідей, теорій; усвідомлення існування індивідуального досвіду учнів і вчителя; актуалізацію знань і використання знань і досвіду, отриманих 3 інших областей; активізацію позашкільних знань; мотивацію і підготовку до діалогу в різних формах (провокаційні питання або завдання, проблемні питання); вибір відповідних методів навчання, які дозволяють вступати в діалог і т. ін.

Висновки. Таким чином, використання діалогу з метою організації ефективної педагогічної взаємодії є досить продуктивним, оскільки він сприяє високому ступеню мотивації, максимальної індивідуалізації навчання та передбачає широкі можливості для творчості, самореалізації суб'єктів освітнього процесу.

Перспективи подальших досліджень пов’язані з вивченням особливостей застосування діалогу з учнями різних вікових груп та різних напрямів навчання.

\section{References}

1. Abulkhanova-Slavskaia K.A. Lychnostnbii aspekt problembl obshchenyia [The personal aspect of the communication problem]/ K.A. Abulkhano-va-Slavskaia // Problema obshchenyia $v$ psykholohyy [The problem of communication in psychology]/ ed. B.F. Lomova. M.: Nauka, 1981. 335 s. 
2. Bybler B.C. Dyaloh kultur (fylosofyia, psykholohyia, pedahohyka) [Dialogue of cultures (philosophy, psychology, pedagogy)] / B.C. Bybler // Pervoe sentiabria, 1998. S. 36.

3. Bom D. Nauka y dukhovnost, neobkhodymost yzmenenyia $v$ kulture [Science and spirituality, the need for change in culture]/ D. Bom // Chelovek. 1993. № 1. S. 7-17.

4. Buber M. Ya y ty [Me and you]/ M. Buber. M.: Vysshaia shkola, 1993. $198 \mathrm{~s}$.

5. Vyshkivska V.B. Subiektnist studentiv u navchalnomu protsesi-neobkhidna umova formuvannia profesiinoi kompetentnosti. [Subjectivity of students in the educational process is a necessary condition for the formation of professional competence] Naukovyi chasopys NPU imeni M.P.Drahomanova. [Scientific journal of NPU named after M.P.Dragomanov] 2008. Vyp.8 (18). C. 2-4.

6. Vyshkivska V., Shykyrynska O. Orhanizatsiia protsesu navchannia v novii ukrainskii shkoli: teoretyko-praktychnyi aspekt [Organization of the learning process in the new Ukrainian school: theoretical and practical aspect] // Molod i rynok, 2019. № 11 (178) . S. $115-119$

7. Kuliutkyn Yu.N., Bezdukhov V.P. Tsennostnble oryentyrbl y kohnytyvnble strukturbl $v$ deiatelnosty uchytelia. [Values and cognitive structures in the teacher's activity.] Samara: SamHPU, 2002. $400 \mathrm{~s}$.

8. Obshchenye $y$ dyaloh $v$ praktyke obuchenyia y vospytanyia y psykholohycheskoi konsultatsyy: [Communication and dialogue in the practice of teaching and education and psychological counseling:] sb. nauch. tr. M.: APN SSSR, 1987. $164 \mathrm{~s}$.

9. Rydanova Y.Y. Osnovy pedahohyky obshchenyia [Fundamentals of communication pedagogy] / Y.Y. Rydanova. Mynsk: Belarusskaia nauka, 1998. $320 \mathrm{~s}$.

10. O. V. Shykyrynska, V. B. Vyshkivska. Google-clasroom yak zasib formuvannia IKTkompetentnosti maibutnoho vchytelia pochatkovoi shkoly [Google-clasroom as a means of forming ICT competence of the future primary school teacher] // Naukovi zapysky Vinnytskoho derzhavnoho pedahohichnoho universytetu imeni Mykhaila Kotsiubynskoho. [Scientific notes of Vinnytsia State Pedagogical University named after Mykhailo Kotsyubynsky] Series: pedahohika i psykholohiia. 2020. Issue 61. s. 75-78.

Translation of the Title, Abstract and References to the Author's Language

УДК 37.013

\section{Вишківська В., Шикиринська О., Малінка О., Лобачук I. Теоретико- методологічні аспекти використання діалогу 3 метою організації продуктивної взаємодії суб'єктів освітнього процесу}

У статті в історико-філософському, психологічному та педагогічному аспектах розглядається актуальна проблема вдосконалення педагогічної освіти - 
використання діалогу в здійсненні ефективної взаємодї суб'єктів освітнього процесу. Наголошується, щзо сучасна педагогічна система стикається з об'єктивними прочесами демократизаиї в суспільстві, з вимогами розвитку культури в умовах науково-технічного прогресу $і$ характеризується зміною дисциплінарно-примусової нормативної домінанти освіти на домінанту культурної діяльності та творчості. Аналізується діалог як форма і метод організачії навчання, основу якого складають цุінності змісту та иџінності ичілі, які проявляються в проблемності, сприйнятті $i$ взаєморозумінні на міжособистісному рівні. Зауважено, щуо співучасть суб'єктів діалогу виявляе його гуманістичну сутність і надає багатобарвності, емоційності, духовності взаєминам, дарує радість відкриття людини людиною.

Акиентовано увагу на психолого-педагогічній сутності дискусії (різновид діалогу, який протікає в режимі компетентної рівності $i$ передбачає боротьбу думок учасників у ході суворо регламентованого обговорення проблеми) як найбільш ефективній у пізнавальному плані формі діалогу.

Ключові слова: діалог, навчальний діалог, педагогічна взаємодія, учасники освітнього процесу, суб’єкти навчання, дискусія

\section{Лimepamypa}

1. Абульханова-Славская К.А. Личностный аспект проблемы общения / К.А. Абульхано-ва-Славская // Проблема общения в психологии / под ред. Б.Ф. Ломова. М.: Наука, 1981. 335 с.

2. Библер В.С. Диалог культур (философия, психология, педагогика) / В.С. Библер // Первое сентября, 1998. С. 36.

3. Бом Д. Наука и духовность, необходимость изменения в культуре / Д. Бом // Человек. 1993. № 1. С. 7-17.

4. Бубер М. Я и ты / М. Бубер. М.: Высшая школа, 1993. 198 с.

5. Вишківська В.Б. Суб'єктність студентів у навчальному процесі-необхідна умова формування професійної компетентності. Науковий часопис НПУ імені М.П.Драгоманова. 2008. Вип.8 (18). С. 2-4.

6. Вишківська В., Шикиринська О. Організація процесу навчання в новій українській школі: теоретико-практичний аспект // Молодь і ринок, 2019. № 11 (178) . C. $115-119$ 
7. Кулюткин Ю.Н., Бездухов В.П. Ценностные ориентиры и когнитивные структуры в деятельности учителя. Самара: СамГПУ, 2002. 400 с.

8. Общение и диалог в практике обучения и воспитания и психологической консультации: сб. науч. тр. М.: АПН СССР, 1987. 164 с.

9. Рыданова И.И. Основы педагогики общения / И.И. Рыданова. Минск: Беларусская наука, 1998. 320 с.

10. О. В. Шикиринська, В. Б. Вишківська. Google-clasroom як засіб формування IКТ-компетентності майбутнього вчителя початкової школи // Наукові записки Вінницького державного педагогічного університету імені Михайла Коцюбинського. Серія: педагогіка і психологія. 2020. Випуск 61. с. 75-78. 


\title{
Plotless Ballets on the Stage of Ukrainian Theaters (1960-1970s)
}

\author{
Lukyanenko Ekaterina Arkadyevna, \\ graduate student, \\ Kiev National University of Culture and Arts, \\ Kiev, Ukraine
}

\begin{abstract}
The article examines the peculiarities of staging plot-free ballets on the stages of Ukrainian theaters in the 1960s and 1970s on the example of performances by A. Shekera, O. Segal and I. Chernyshov. The semantic essence of the concept of "plotless ballet" is specified and the process of formation of this type of ballet performances in historical retrospect is traced. The specifics of plotless ballets as a unique type of performance in the Ukrainian ballet theater of the 60-70s of the XX century are characterized. and the contribution of choreographers to the development of artistic and figurative forms of ballet art of Ukraine is determined. It is revealed that in the works of the leading Ukrainian choreographers of the mentioned period the author's comprehension of the plasticintonational content in the dialogue of music and choreography was embodied in many ways. The main choreographers of Ukrainian opera and ballet theaters, representing productions in which choreography is raised to the highest level of poetic generalization, helped to expand the horizons of Ukrainian choreography, to determine the main directions of national ballet in the second half of the twentieth century.
\end{abstract}

Key words: plotless ballet, Ukrainian ballet theater, choreographer, plastic-intonational content.

Постановка проблеми. Зміна вектору мислення провідних балетмейстерівпостановників українських театрів у 60-70-х рp. XX ст., зумовлена становленням та популяризацією балетів-симфоній посприяла розширенню обріїв творчого пошуку. Оригінальне виявлення інтегрування новаторських засобів виразності та специфічних форм отримало в безсюжетних балетах. Актуальність дослідження зумовлена необхідністю розширення теоретико-методологічних підходів до вивчення балетного театру в цілому та джерельної бази українського балетного мистецтва 1960-1970-х рр. тенденції розвитку якого суттєво вплинули на подальшу хореографічного мистецтва в Україні.

Аналіз останніх досліджень і публікацій. Неабиякий інтерес українських мистецтвознавців до проблеми розвитку балетного мистецтва другої половини XX ст. підтверджує значний масив наукових праць. Зокрема, вивченню особливостей стилістики та творчої манери провідних балетмейстерів, дослідженню специфіки створення найвизначніших балетних вистав означеного періоду присвячено наукові праці 
О. Кагадій, Є. Коваленко, А. Король, О. Мерлянової, О. Плахотнюк, О. Сайко, О. Шаповал та ін., проте специфіка постановки безсюжетних балетів лишається недостатньо висвітленою.

Мета статті - дослідити поняття «безсюжетний балет» в контексті творчих пошуків українських балетмейстерів-постановників 1960-1970-х рр. (А. Шекери, О. Сегаля, I. Чернишова) та виявити особливості постановки безсюжетних балетів на сценах українських театрів опери і балету.

Застосовано загальнонаукові методи, зокрема: метод історизму, що посприяв дослідженню процесу становлення безсюжетних балетів в історичній ретроспективі; проблемно-хронологічний метод - для виявлення основних тенденцій розвитку безсюжетного балету як самостійного виду балетного мистецтва в хронологічній послідовності; метод стильового підходу та метод мистецтвознавчого аналізу - для виявлення особливостей хореографічної структури проаналізованих балетних постановок та ін.

Виклад основного матеріалу. Дослідники акцентують, що зародження безсюжетного балету розпочалося за доби Відродження та бароко, коли балет, як правило, не мав сюжету, хоча і належав до синтаксично-сюжетних вистав [2, с. 9].

Протягом XVI-XVII ст. балетмейстери прагнули підняти форму танцю до рівня високого мистецтва, такого як драма. Д. Чазін-Беннахум та Д. Чепмен наголошують, що тогочасний танець повинен був пропонувати щось розуму, а не лише милувати око, в результаті чого концепція балетної дії XVIII ст. означила пік танцювального інтелектуалізму, створивши складні розповідні балети, що функціонували як «німі драми» або «безсловесні п’єси» [13, p. 375]. Теоретик балету, філософ-ієзуїт та балетмейстер XVII ст. К.-Ф. Менестрієр сформулював естетичні вимоги до балету як до художньої форми, що повинна «виражати дії, характери та пристрасті засобами гармонійних ритмів», втілених у людських рухах [16, p. 22].

Жанрове балетне дійство XVIII ст. було засноване на ретельно продуманому «синопсиси сюжету», інтегрованому з рухами та музикою. Е. Нуе наголошує, що балет Дж. Уівера «Любов Марса до Венери» (1717 р.) вважається попередником «драматичного танцю», оскільки історія була представлена через рухи та мову жестів [16, р. 45]. Ця концепція остаточно сформувалася у впливовій праці Ж.-Ж. Новера «Lettres sur la danse 
et sur les ballets» (1760р.), в якій балетмейстер пропагував інтегрування танцювальних форм «з мистецтвом гри» та описував стратегії вираження розповіді танцюристом через pyx [16, p. 86], а Аньоліні ввів термін «danza parlante» («танець має говорити»). С. Фостер акцентує, що відповідно цій тенденції балетмейстери прагнули стати переконливими драматургами, а артистизм танцюриста викликав найбільший захват у глядача лише коли репрезентація ними історій засобами хореографічної виразності була не менш складною за мистецтво театральних акторів [14, p. 70]. Протилежна тенденція - підкреслення естетичних властивостей руху, зміщуючи акцент з сюжету, простежується з кінця XVIII ст., коли після Французької революції 1789-1799 рр. відбулися трансформації в естетичних оцінках і глядачі почали надавати перевагу руху, замість змісту постановки. На думку Д. Чепмена, «нова плебейська французька аудиторія після Французької революції сприяла розвитку танцю як форми розваги - їх ентузіазм було пов'язано 3 атлетизмом та віртуозністю і не вимагав широких контекстуальних знань 3 інших дисциплін, зокрема літератури» [13, p. 372]. Дослідник наголошує, що пізніше впливові критики-романтики на чолі з Т. Готьє розглядали виражальний потенціал рухів лише як «вічний предмет балету», а розповідь історії лише як структурну властивість танцю. Не зважаючи на домінування наративних балетів, в оперних дивертисментах XVIII ст. популяризувалися ролі, що не залежали від сюжетної лінії - як інтермеції в межах розповіді ці короткі танцювальні сюїти. Неабияку роль в становленні безсюжетного балету в XX ст. відіграли симфонічні танцювальні картини балетів XIX ст., зокрема сцена тіней в «Баядерці», нереїд в «Сплячій красуні» та ін.

Дослідники наголошують, що тенденція популяризації безсюжетних балетів зокрема, новаторське концептуальне дослідження безсюжетних танцювальних ідіом, втілених у постановці М. Фокіна «Сильфіди» в 1909 р. (безсюжетний балет, що включав розповідні теми та поетичні метафори - кожна частина постановки виражала власний настрій та народжувала власні образи) - це продукт XX ст. Проте використання метафоричних образів лишалося найбільш поширеним методом для танцюристів. Не зважаючи на те, що ідея можливості виступів на сцені поза художнім образом на початку XX ст. популяризувалася в авангардному театрі в період 1907-1920-х рр. (наприклад, художники-дадаїсти хотіли розробити новий стиль театру, що містив процес «спонтанної дії, позбавленої будь-яких аспектів майстерності або техніки») [15, р. 61], а сміливі 
експерименти Ф. Лопухова (балетмейстер створив танцювальну симфонію «Велич світобудови», з метою посилення органічного зв’язку рухів та музики) та його учнів Л. Якобсона та I. Бельського посприяли становленню безсюжетного балету як нового жанру хореографічної вистави, в якому основним виражальним засобом хореографа є танець, класичний балет «поза персонажем» на балетній сцені вважався новаторством навіть в середині ХХ століття.

Поняття «безсюжетності» балетів розумілося як відсутність єдиної послідовності драматичних подій, конкретної інформації про персонажів (носіїв сюжетної лінії) та ситуації. На думку деяких тогочасних дослідників, абсолютизуючи проблеми музичності хореографічної вистави, окремі балетмейстери зверталися до готових музичних творів, створених «без розрахунку не лише на хореографічне, але й взагалі на театральне втілення» [1, с. 66], що позбавляло танець «власної первозданної самостійності образної сутності», перетворюючи на «пасивного коментатора образу музичного» [1, с. 66].

Варто зазначити, що в теорії хореографічного мистецтва XX ст. проблематика безсюжетних танцювальних постановок в цілому та балетів зокрема отримала досить широке висвітлення і різноманітні трактування поняття «безсюжетність». Наприклад, В. Ванслов та Ю. Слонімський визначали безсюжетні балети як «відтанцьовування» інструментальної та симфонічної музики [8]; А. Горський та І. Стравінський - як хореографічне інсценування [9]; С. Дулова - як сценічне трактування не балетної музики та художню інтерпретацію музичного тексту [4]; Н. Чернова як лінію нових контактів пластики та серйозної музики [12]; М. Тараканов - як хореографічну інтерпретацію музики, що заснована на симфонічному розвитку [10] та ін.

На думку дослідників, специфіка драматургії безсюжетної балетної вистави, відсутність сюжету в якій не означає беззмістовність постановки та відмову від відображення навколишнього світу, полягає в унікальній взаємодії музики та хореографії, оскільки саме хореографія не лише має зображувати усі тематичні, гармонійні та інтонаційні рухи музичного ряду, а й покликана виражати змістово-сенсову квінтесенцію музики [3, с. 127].

На сцені українського балетного театру 1960-1970-х рр. безсюжетні вистави отримали специфічне виявлення. Поява в середині 1950-х рр. танцювальної симфонії як новаторського напряму в радянському балетному театрі відкрила величезні можливості 
для втілення музичного і танцювального симфонізму та посприяла трансформаційним процесам в традиційній на той час структурі хореографічної вистави.

T. Павлюк наголошує, що на початку 60-х pp. XX ст. захоплені танцювальним аспектом балетної вистави постановники, свідомо чи несвідомо нівелюючи досвід минулого, репрезентували глядачу набір незрозумілих рухів - обтанцьовування симфонічної музики, відповідно складному та заплутаному лібрето: «велика хвиля таких балетів заполонила сцени театрів республіки. Твори П. Чайковського і С. Рахманінова, М. Римського-Корсакова і С. Прокоф’єва, М. Равеля і Д. Россіні, Д. Шостаковича і Д. Гершвіна одягали у літературно-хореографічне вбрання, роблячи їх одноактними балетами, у яких танець іноді ставав самоціллю і суперечив музиці» [7, с. 56]. Проте в окремих випадках така форма балетної вистави розкривала унікальні можливості, сприяючи новаторським пошукам українських балетмейстерів в напрямку розширення прийомів і методів відтворення засобами хореографії різноманітних тем та образів.

Наприклад, оригінальною інтерпретацією балетмейстера О. Сегаля вирізнялася симфонічна фантазія П. Чайковського «Буря», постановку якої було здійснено в 1965 р. [11, С. 187]. У процесі створення хореографічно-сценічного плану одноактної вистави та побудови ії драматургії, балетмейстер спирався в музиці на своєрідні музичні сенси, що трансформувалися на підтекст хореографічного тексту.

На думку М. Загайкевич яскравими зразками творів філософського, узагальненосимволічного змісту стали балети провідного балетмейстера А. Шекери «Досвітні вогні» Л. Дичко та «Каменярі» М. Скорика, постановку яких було здійснено на сценах Львівського театру опери і балету (1967 р.) та Київського театру опери і балету (1969 р.) відповідно [5, с. 235-236].

На сцені Одеського театру опери і балету одноактний балет «Варіації на тему Й. Гайдна» Й. Брамса було здійснено в 1974 р. І. Чернишовим - головним балетмейстером театру (1969-1975 рр.). Н. Іванова-Георгієвська визначає музику Й. Брамса як поєднання різних варіацій, поділених паузами та пов'язаних в єдине художньо-сенсове ціле однією темою-інваріантом і поступовим рухом цієї теми крізь розмаїття ритмічних, колористичних та мелодико-гармонічних форм [6].

Описуючи балет «Варіації на тему Й. Гайдна» в постановці І. Чернишова, Н. Іванова-Георгієвська стверджує, що балетмейстеру, на іiі думку, вдалося створити 
унікальний хореографічний ряд постановки завдяки майстерному використанню варіативності танцювальних засобів. Відповідно даний безсюжетний балет не має описаного сюжету та не розповідає про конкретні події, а побудовано відповідно законів драматургічного цілого, з метою вираження певної сенсової динаміки композиційної структури балетної вистави. Дослідниця наголошує, що I. Чернишов вдало уникнув постійних буквальних тематичних, ритмічних та інтонаційних збігів музичного i хореографічного рядів, в процесі досягнення чіткого узгодження та сходження виключно ключових композиційних моментів музики і танцю [6].

Варіаційна форма музики, що визначає циклічність сенсового розвитку та створює композицію усієї сценічної постановки, в якій виникають повтори деяких структурних елементів, була використана балетмейстером в процесі реалізації ритмічного мислення. Це проявилося в створенні хореографічної побудови, в якій структурно споріднені елементи не лише органічно пов'язали фрагменти танцю в зовнішньо єдину композицію, а почали виконувати сенсово-метафоричну функцію, вказуючи на змістовий зв'язок віддалено «римованих» елементів.

У безсюжетному балеті потенціал українських балетмейстерів постановників розкривається в новому напряму - експериментів з різноманітними можливостями людського тіла, виконавською технікою танцюристів та унікальними способами їх вираження в часопросторі; створенні специфічної атмосфери сценічного дійства, що надає можливість глядачу домислювали сюжетну лінію та отримувати естетичну насолоду від візуального та аудіального виконавства.

Висновки. Дослідження виявило, що на сцені українського балетного театру 1960-1970-х рр. безсюжетні вистави репрезентували оригінальний підхід балетмейстерів до виявлення нової естетики танцю, сповненої емоційним змістом за відсутності чітко окресленої сюжетної лінії.

Новаторські спроби осмислення пластично-інтонаційного змісту в діалозі музики і хореографії, що отримали багатогранне втілення у творчості А. Шекери, І. Чернишова, О. Сегаля та інших провідних балетмейстерів, репрезентувавши постановки в яких хореографія піднесена до найвищого рівня поетичного узагальнення, посприяли розширенню горизонтів української хореографії, визначенню основних напрямів розвитку національного балету в другій половині XX ст. 
Спираючись на музику, що не лише організувала метро-ритмічний простір хореографії, але й сприяла сенсовому розвитку балетної вистави, позбавивши іiі тлумачення як звичайної оповіді без слів, розширивши межі можливих асоціацій та ставши важелем асоціативного мислення, українські балетмейстери формували в безсюжетному балеті емоційно-змістову танцювальну драматургію, в складному процесі «перекладу» умовних узагальнених образів музики на мову пластики.

Перспективи подальших досліджень безсюжетних балетів на сцені українських театрів полягають в комплексному мистецтвознавчому аналізі специфіки їх постановки провідними балетмейстерами другої половини XX ст.

\section{References} composer.

1. Bogdanov-Berezovsky, V. M. (1962). Articles about ballet. Leningrad: Soviet

2. Brailovskaya, M. A. (2006). Russian ballet in the context of the tradition of the synthesis of arts (on the example of the first post-October emigration wave). Abstract of Ph.D. Yaroslavl : State educational institution of higher professional education "Yaroslavl State Pelagogical University named after KD Ushinsky".

3. Gutnik, I. M. (2018). Art as an object of aesthetic and art analysis. Current issues of history, theory and practice of art culture, Issue. 40, pp. 124-133.

4. Dulova, E. N. (2009). From text to text, or more about Sleeping Beauty. The hourpainting of the National Musical Academy of Ukraine named P.I. Tchaikovsky, no. 4, pp. 93107.

5. Zagaykevich, M. P. (1978). Ballet drama. Kyiv: Scientific opinion.

6. Ivanova-Georgievskaya, N. A. (2003). The dramatic and semantic specificity of the one-act ballet. Musical mystery and culture. Scientific newsletter of the Odessa State Musical Academy im. Nezhdanovo, Issue 4. URL: http://www.philosof.onu.edu.ua/elb/metodichki/ivanova/philcul_10.pdf.

7. Pavlyuk, T. S (2017). Ukrainian choreographic art (second half of the twentieth century). Kyiv: Ed. KNUKiM center.

8. Slonimsky, Y. (1962). Music in the ballet theater. Music of the Soviet ballet. Moscow. pp. 59-75.

9. Stravinsky, I. (1971). Dialogues: Memories. Reflections. Comments / ed. M. Druskin. Leningrad: Music.

10. Tarakanov, M. (1982). Musical drama in the Soviet ballet. Soviet Musical Theater. Genre problems. Moscow.

11. Todoryuk, Y. I. (2015). Creativity of Alexander Segal on the opera and ballet stage. Culture and art in the modern world, Issue. 16, pp. 185-189. 
12. Chernov, N. (1982). About ballets large and small. Soviet Musical Theater. Genre problems. Moscow. pp. 184-230.

13. Chapman, J. V. (1988). Silent Drama to Silent Dream: Parisian Ballet Criticism, 1800-1850. Dance Chronicle, Issue 11(3), pp. 365-380.

14. Foster, S. L. (1998) Choreography \& Narrative: Ballet's Staging of Story and Desire. Bloomington: Indiana University Press.

15. Meyer-Dinkgraefe, D. (2005). Approaches to Acting in The Twentieth Century. In Approaches to Acting: Past and Present, London, New York: Continuum International Publishing Group, pp. 38-94.

16. Nye, E. (2011). Mime, Music and Drama on the Eighteenth Century Stage: The Ballet d'action. Cambridge: Cambridge University Press.

\section{Translation of the References list to the original language}

\section{Сиисок використаних джерел}

1. Богданов-Березовский, В. М. (1962). Статьи о балете. Ленинград : Советский композитор.

2. Брайловская, М. А. (2006). Русский балет в контексте традиции синтеза искусств (на примере первой послеоктябрьской эмиграционной волны) : автореферат дис. канд. искусствоведения : 24.00.01 / Государственное образовательное учреждение высшего профессионального образования «Ярославский государственный пелагогический университет имени К. Д. Ушинского». Ярославль.

3. Гутник, I. М. (2018). Художня творчість як об'єкт естетико-мистецтвознавчого аналізу. Актуальні проблеми історії, теорії та практики художньої культури. Вип. 40. С. 124-133.

4. Дулова, Е. Н. (2009). От текста к тексту или еще раз о Спящей красавице. Часопис Національної музичної академії України імені П.І. Чайковського. № 4. С. 93-107.

5. Загайкевич, М. П. (1978). Драматургія балету. Київ : Наукова думка.

6. Иванова-Георгиевская, Н. А. (2003). Драматургически-смысловая специфика одноактного балета. Музичне мистецтво і культура. Науковий вісник Одеської державної музичної академії ім. Нежданової. Вип $4 . \quad$ URL : http://www.philosof.onu.edu.ua/elb/metodichki/ivanova/philcul_10.pdf.

7. Павлюк, Т. С. (2017). Українське балетмейстерське мистецтво (II половина XX ст.). Київ : Вид. центр КНУКіМ.

8. Слонимский, Ю. (1962). Музыка в балетном театре. Музыка советского балета. Москва. С. 59-75.

9. Стравинский, И. (1971). Диалоги: Воспоминания. Размышления. Комментарии / ред. М. Друскина. Ленинград : Музыка. 
10. Тараканов, М. (1982). Музыкальная драматургия в советском балете. Советский музыкальный театр. Проблемы жанров. Москва.

11. Тодорюк, Ю. І. (2015). Творчість Олександра Сегаля на оперно-балетній сцені. Культура і мистецтво у сучасному світі. Вип. 16. С. 185-189.

12. Чернова, Н. (1982). О балетах больших и малых. Советский музыкальный театр. Проблемы жанров. Москва. С. 184-230.

13. Chapman, J. V. (1988). Silent Drama to Silent Dream: Parisian Ballet Criticism, 1800-1850. Dance Chronicle. Issue 11(3). pp. 365-380.

14. Foster, S. L. (1998) Choreography \& Narrative: Ballet's Staging of Story and Desire. Bloomington: Indiana University Press.

15. Meyer-Dinkgraefe, D. (2005). Approaches to Acting in The Twentieth Century. In Approaches to Acting: Past and Present, London, New York: Continuum International Publishing Group, pp. 38-94.

16. Nye, E. (2011). Mime, Music and Drama on the Eighteenth Century Stage: The Ballet d'action. Cambridge: Cambridge University Press. 


\section{Manuscript Guidelines}

1. All submitted papers must contain the Title, Name of author(s), Affiliation (if any), Abstract and List of References (Literature) written in English. The Abstract must count not less than 100 and not more than 300 words and must be the good representation of your article. Optionally paper may also contain this information duplicated in another language.

2. Font faces. Arial, Times, Times New Roman, Courier New and Helvetica.

3. Language. You may use any language for your paper text, however English is MUCH preferable.

4. Title. Font size - 16, bold. Position - central alignment.

5. The author's name. Font size - 14, bold. Position - central alignment.

6. The affiliation (your University etc). Font size - 14, regular (not bold). Position - left alignment.

7. The word "Abstract". Font size - 12, bold-italics. Position - central alignment.

8. The text of the abstract. Font size - 10, regular (not bold).

9. The word "Keywords" (if any). Font size - 10, bold. Position - left alignment.

10. The text of keywords (if any). Font size - 10, regular (not bold). Position - left alignment.

11. Text of article. Font size - 14. Position - left alignment or fully justified. Line spacing - 1.5 lines.

12. The word "References" (if any). Font size - 12, bold-italics. Position - central alignment.

13. The text of References (if any). Font size - 12, regular (not bold).

In all other cases please use your own good judgment or contact our Editorial Board.

\section{Where to find us}

The "IntellectualArchive" is distributed to major libraries across Canada and the US, including

Library of Congress, USA (http://lccn.loc.gov/cn2013300046 ) ,

Library and Archives Canada

(http://collectionscanada.gc.ca/ourl/res.php?url_ver=Z39.88-2004\&url_tim=2012-09-

05T01\%3A46\%3A54Z\&url_ctx_fmt=info\%3Aofi\%2Ffmt\%3Akev\%3Amtx\%3Actx\&rft_dat=40904933\&r

fr_id=info\%3Asid\%2Fcollectionscanada.gc.ca\%3Aamicus\&lang=eng) and others.

The references to articles published in the "IntellectualArchive" are available in the

Google Scholar, (http://scholar.google.ca/scholar?q=\%22IntellectualArchive\%22 ),

Arxiv.org (http://search.arxiv.org:8081/?query=\%22Intellectual\%20Archive\%22\&in= ),

WorldCat.org (https://www.worldcat.org/search?q=n2\%3A1929-4700\&qt=advanced \&dblist=638 ) ,

Academia.edu

(http://www.academia.edu/15503799/Light_diffraction_experiments_that_confirm_the_STOE_model_and

_reject_all_other_models )

The National Research Council (Italy) (http://data.cnr.it/data/cnr/individuo/rivista/ID658222 )

Наукова бібліотека of the University named after Dragomanov, Ukraine

(http://enpuir.npu.edu.ua/handle/123456789/7974?mode=full )

Google.com (https://www.google.ca/\#q=site:IntellectualArchive.com ) thousands of links etc. 